UNIVERSIDADE DE SÃO PAULO

FFCLRP - DEPARTAMENTO DE BIOLOGIA

PROGRAMA DE PÓS-GRADUAÇÃO EM BIOLOGIA COMPARADA

"Colour polymorphism and its function in Hippolyte obliquimanus:

camouflage and resource use diversification"

“Polimorfismo de cor e sua função em Hippolyte obliquimanus:

camuflagem e diversificação no uso de recursos"

Rafael Campos Duarte

Tese apresentada à Faculdade de Filosofia, Ciências e Letras de Ribeirão Preto da USP, como parte das exigências para a obtenção do título de Doutor em Ciências, Área: Biologia Comparada.

RIBEIRÃO PRETO - SP 

UNIVERSIDADE DE SÃO PAULO

FFCLRP - DEPARTAMENTO DE BIOLOGIA

PROGRAMA DE PÓS-GRADUAÇÃO EM BIOLOGIA COMPARADA

"Colour polymorphism and its function in Hippolyte obliquimanus:

camouflage and resource use diversification"

“Polimorfismo de cor e sua função em Hippolyte obliquimanus:

camuflagem e diversificação no uso de recursos"

Rafael Campos Duarte

Orientador: Prof. Dr. Augusto Alberto Valero Flores

Tese apresentada à Faculdade de Filosofia, Ciências e Letras de Ribeirão Preto da USP, como parte das exigências para a obtenção do título de Doutor em Ciências, Área: Biologia Comparada.

RIBEIRÃO PRETO - SP 


\section{Ficha catalográfica}

\section{Duarte, Rafael Campos}

Colour polymorphism and its function in Hippolyte obliquimanus: camouflage and resource use diversification, 2017.

124 p. : il. ; $30 \mathrm{~cm}$

Tese apresentada à Faculdade de Filosofia, Ciências e Letras de Ribeirão Preto da USP, como parte das exigências para a obtenção do título de Doutor em Ciências, Área: Biologia Comparada.

Orientador: Flores, Augusto Alberto Valero

1. Colour change. 2. Camouflage. 3. Habitat use. 4. Visual models. 5. Stable isotopes. 6. Trophic niche. 
"I may not have gone where I intended to go, but I think I have ended up where I needed to be."

Douglas Adams 


\section{SUMMARY OF CONTENTS}

ACKNOWLEDGEMENTS

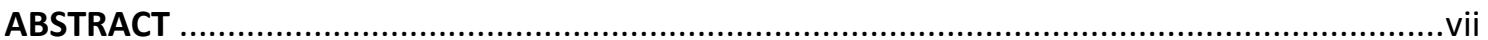

RESUMO

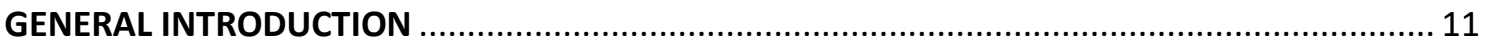

Colour polymorphism, camouflage and habitat use ......................................................... 11

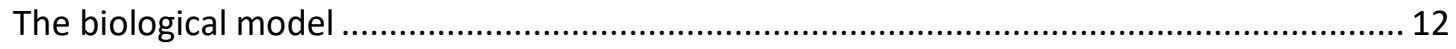

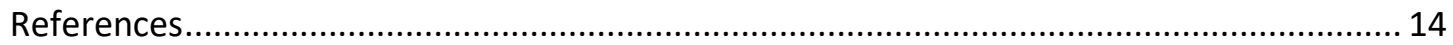

CHAPTER 1

Camouflage through colour change: mechanisms, adaptive value, and ecological

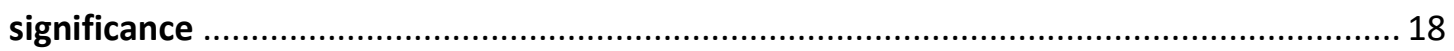

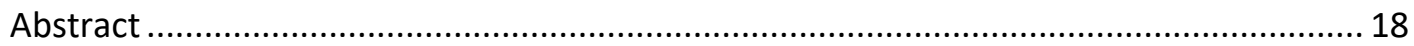

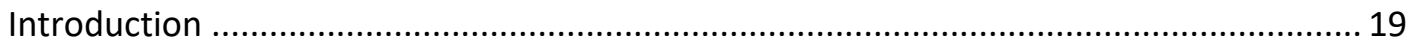

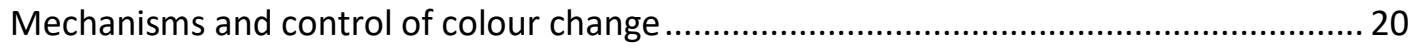

Causes, consequences, and ecological implications of colour change for concealment.... 26

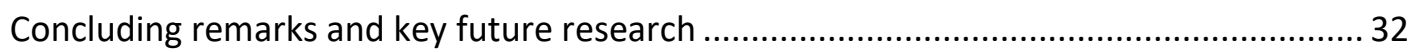

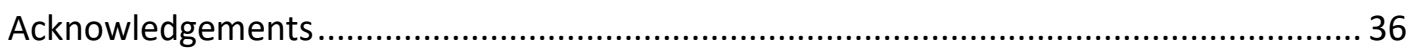

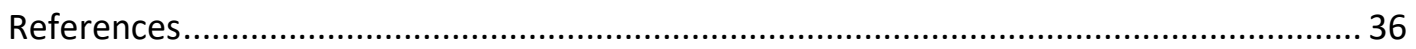

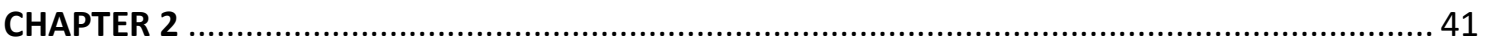

Shape, colour plasticity, and habitat use indicate morph-specific camouflage strategies in a

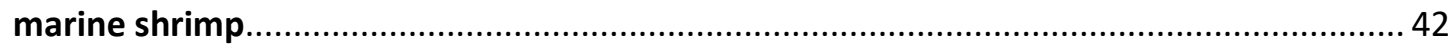

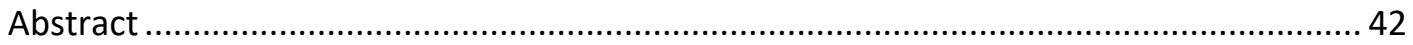

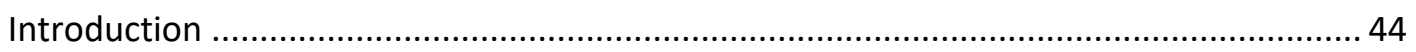

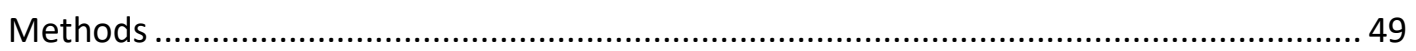

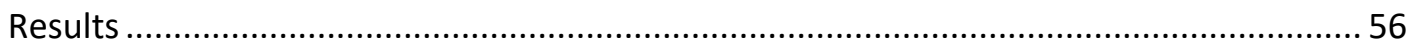

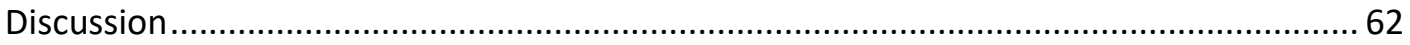

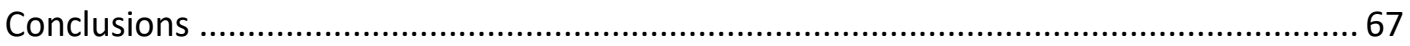




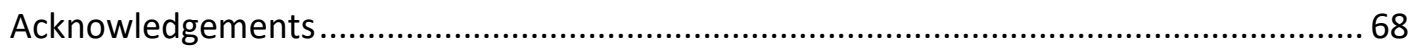

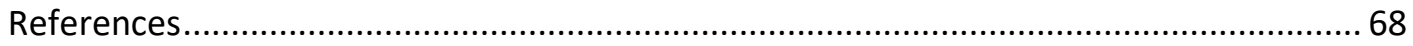

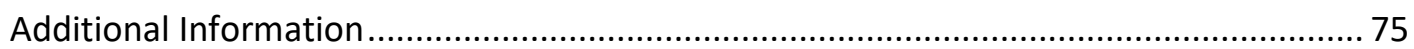

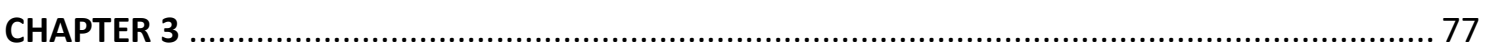

The adaptive value of camouflage and colour change in a polymorphic shrimp................ 78

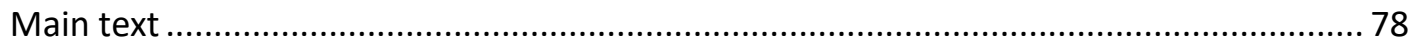

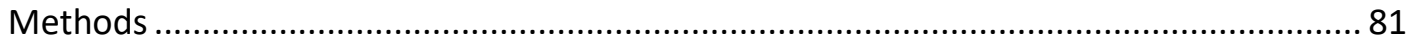

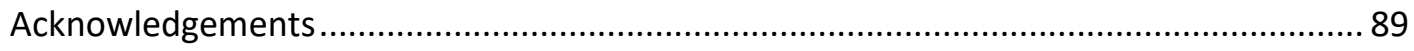

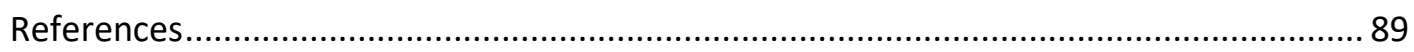

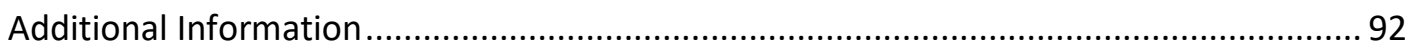

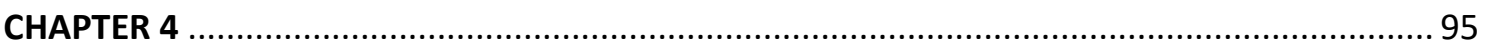

Habitat-dependent niche partitioning between colour morphs of the algal-dwelling shrimp

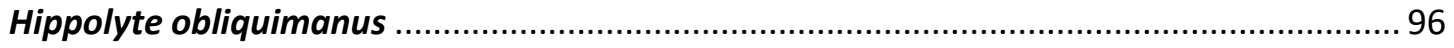

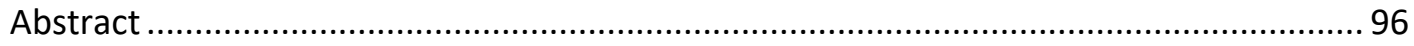

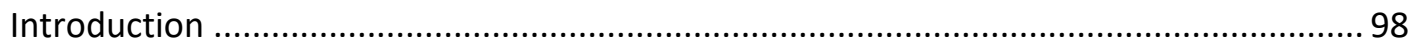

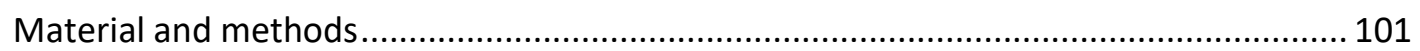

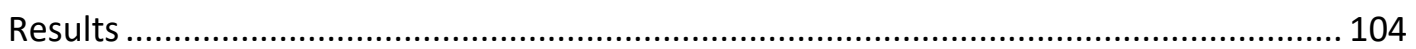

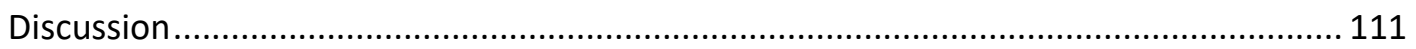

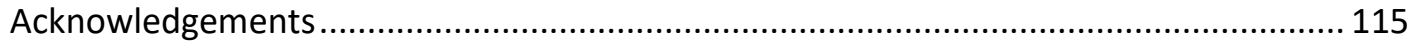

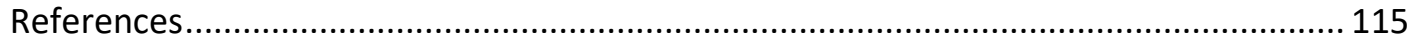

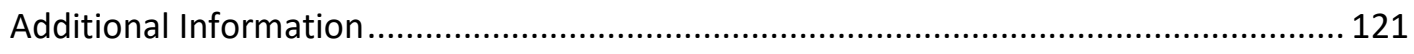

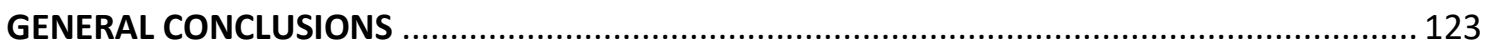




\section{ACKNOWLEDGEMENTS}

I am very thankful to...

My supervisor Augusto Flores for all his help and stimulus to transform me in a scientist who thinks and develops your questions before anything else. Thanks for your friendship, confidence and freedom that allowed me to develop new skills sometimes far from your research line. Your optimism and admiration for your work encourages me to persist in this crazy world of science!

To the post-graduation program in Comparative Biology (FFCLRP-USP) for receiving me as a PhD student and to the secretary Vera for helping me in all administrative issues even though the distance.

To Fundação de Amparo à Pesquisa do Estado de São Paulo (FAPESP) for the financial support provided by a regular PhD fellowship (\#2012/17003-0) and a BEPE grant to develop my research abroad (\#2015/ 04484-8).

To my collaborator and supervisor in the UK, Martin Stevens, for receiving me so good in Cornwall and open my mind to a new world about animal camouflage, image analysis and Cornish life-style. Thanks for all the meetings and discussions in different pubs when we forgot the time while we were talking about the fascinating world of the colourful prawns!

To Catarina Vinagre and Miguel Leal for their assistance with the stable isotopes work and for all the discussions regarding the Chapter 4 of this thesis.

To Álvaro Migotto for teaching me about photography and video recordings and for helping me to get the nicest and awarded shrimp images ever!

To all CEBIMar staff for providing the infra-structure and technical support along these five years of project. A special thanks to Seu Zé, for cooking and serving everyday a delicious lunch, which is extremely needed when your brain is burning all the time; and to the technicians Elso and Zeilto for helping me in the field samplings and to setup all the crazy experiments. 
To all CEBIMar friends (Sol, Serginho, Daniel, Damián, Amabile, Aurore, Phill, Fernando, Cielo, Seth, Paula, Pedro, Caju, Geada, Karniça, Camilla, Bis, Andreia, Karine, Vanessa, Jéssica, Inês and Rodrigo), for the good coffee times, scientific meetings and barbecues! Special thanks to the lab technicians Ludi, Mari and Felipe for helping me in the field and lab procedures (especially for shacking algae until the arm hurts!) and to my several housemates, in particular Sayão, Bodeia, Felipe, Bis and Caju for all the good moments that we spent together!

To the Sensory Ecology Lab of the University of Exeter for having received me as a visitor research, providing all necessary equipment and technical support. To my British friends Sara, Sam, Jenny, Emm, Lina, Guill, Vic, Jolyon, Sarah and Jared, and to my Mexican friend Luis for helping me during my adaptation in Cornwall.

To my family, especially my parents Paulo and Lúcia, for all the support along this long journey and for always trust and stimulate my career giving me unconditional love and affection! To my brothers Vini and João, and to all my relatives for all love and shared moments!

To my lovely Suely for sharing her life with me since the beginning (literally!) of this thesis! Thanks for all the patience, strength, support and love (so much love!) along all these years! Receiving your sweet smile everyday made me a much better person and helped me to focus and outline new and fantastic goals for our shared life! Love you honey!

Finally, thanks to all the people that directly or indirectly contributed to make this thesis possible! Without your support these pages could have never come out of my head! 


\section{ABSTRACT}

This thesis addresses the mechanisms regulating the evolution and maintenance of colour polymorphism in the shrimp Hippolyte obliquimanus. It includes four chapters that illustrate, in an integrative approach, the ecological and behavioural consequences of different camouflage and habitat use strategies selected in main colour morphs. In the first chapter entitled "Camouflage through colour change: mechanisms, adaptive value, and ecological significance", the physiological and structural mechanisms underpinning colour change, and hence camouflage, in different species were detailed within a general framework. Also in this section, both the adaptive value and the ecological and evolutionary implications of these processes were discussed. In the second chapter entitled "Shape, colour plasticity, and habitat use indicate morph-specific camouflage strategies in a marine shrimp" morph-specific colour change and habitat selection were investigated as potential mechanisms affecting camouflage efficiency and the natural distribution of $H$. obliquimanus colour morphs between macroalgal habitats formed by Sargassum furcatum and Galaxaura marginata. Moreover, morph-specific morphology and behavioural traits were also assessed. Shrimp showing a homogeneous coloration $(\mathrm{H})$ changed colour when placed in colour-mismatching backgrounds and also exhibited a more robust shape associated to high substrate fidelity and specialization. On the other hand, striped translucent shrimp (ST) were not capable of colour change and showed high mobility, consistent with a more streamlined shape and a generalised use of algal habitats. In the third chapter entitled "The adaptive value of camouflage and colour change in a polymorphic shrimp" visual models and predation trials were used to test the adaptive value of camouflage and colour change of $\mathrm{H}$. obliquimanus colour morphs against colour-contrasting macroalgae, which provide different levels of colour concealment. The low colour discrimination predicted by a visual model of a seahorse predator for pink shrimp against the red weed Galaxaura was directly translated to lower detection and consumption rates on this 
morph by captive seahorses in a laboratory experiment, demonstrating the high adaptive value of camouflage in this species. Finally, in the fourth chapter entitled "Habitat-dependent niche partitioning between colour morphs of the algal-dwelling shrimp Hippolyte obliquimanus" the trophic ecology of $\mathrm{H}$ and ST morphs when using Sargassum and Galaxaura habitats were assessed through stable isotope analysis. Morphs showed different isotopic signatures only in Galaxaura, where the supply of food resources are limiting, leading to a tropic niche diversification between $\mathrm{H}$ and ST shrimp and a probable relaxation of intra-specific competition. Conversely, in Sargassum, where resources are abundant, morphs coexistence is possible even without niche partitioning. Altogether, the results of this thesis contributed to a better understanding of the adaptive value and the underlying mechanisms controlling for the maintenance of colour polymorphism in $H$. obliquimanus. From both an ecological and evolutionary perspective, morph-specific strategies of camouflage and habitat use likely promote the stability of shrimp populations in a spatially heterogeneous and markedly seasonal habitat.

Keywords: colour change, camouflage, habitat use, visual models, stable isotopes, trophic niche 


\section{RESUMO}

Esta tese aborda os mecanismos que regulam a evolução e manutenção do polimorfismo de cor no camarão Hippolyte obliquimanus ao longo de quatro capítulos que ilustram de forma integrada as consequências ecológicas e comportamentais das distintas estratégias de camuflagem e de uso do habitat selecionadas nos principais morfótipos da espécie. No Capítulo 1, intitulado "Camouflage through colour change: mechanisms, adaptive value, and ecological significance", são detalhados de maneira geral os mecanismos fisiológicos e estruturais responsáveis pelo processo de mudança de cor e obtenção de camuflagem em diferentes espécies de animais. Nessa seção também é detalhado o valor adaptativo e as implicações ecológicas e evolutivas desses processos. No Capítulo 2, intitulado "Shape, colour plasticity, and habitat use indicate morph-specific camouflage strategies in a marine shrimp", são investigados os processos de mudança de cor e de seleção de habitat como possíveis mecanismos reguladores dos padrões de camuflagem e de distribuição dos morfótipos de cor de $H$. obliquimanus entre os bancos das algas Sargassum furcatum e Galaxaura marginata. Além disso, também são avaliadas diferenças morfológicas e comportamentais entre os morfótipos na utilização dos habitats vegetados. Camarões caracterizados por uma coloração homogênea $(H)$ mudam de cor quando em contato com substratos de coloração diferente à sua, exibindo também uma morfologia mais robusta e um comportamento de alta fidelidade e especialização aos substratos de macroalgas. Por outro lado, camarões transparentes listrados (TL) não mudam de cor e apresentam elevada mobilidade, consistente com uma morfologia mais hidrodinâmica e com uso mais generalizado dos habitats estudados. No Capítulo 3, intitulado "The adaptive value of camouflage and colour change in a polymorphic shrimp", são utilizados modelos visuais e experimentos de predação para testar o valor adaptativo da camuflagem e mudança de cor em diferentes morfótipos do camarão $H$. obliquimanus quando estes estão associados a macroalgas que fornecem diferentes graus de semelhança cromática. 
O baixo grau de discriminação cromática previsto para camarões rosa em associação à alga vermelha Galaxaura através da modelagem visual de um predador (cavalo-marinho) resultou em baixas taxas de detecção e predação desse morfótipo por cavalos-marinhos em um experimento de laboratório, demonstrando um alto valor adaptativo da camuflagem nessa espécie. Por fim, no Capítulo 4, intitulado "Habitat-dependent niche partitioning between colour morphs of the algal-dwelling shrimp Hippolyte obliquimanus", a ecologia trófica dos morfótipos de cor H e TL na utilização dos bancos de Sargassum e Galaxaura é avaliada através de análises de isótopos estáveis. Os morfótipos de cor mostraram diferenças nas razões isotópicas apenas em Galaxaura, onde a abundância de recursos alimentares é limitante, levando à diversificação de nicho trófico entre camarões H e TL e uma provável redução da competição intraespecífica. Por outro lado, em Sargassum, onde há abundância de recursos, a coexistência entre os morfótipos é possível mesmo sem partição de nicho ecológico. Em conjunto, os resultados obtidos nessa tese detalham tópicos centrais sobre os mecanismos reguladores e o valor adaptativo do polimorfismo cromático em $\mathrm{H}$. obliquimanus. Dentro de uma abordagem ecológica e evolutiva, as diferentes estratégias de camuflagem e de uso de habitat dos morfótipos de cor parecem ser essenciais para o equilíbrio populacional da espécie, uma vez que os bancos de macroalgas utilizados como habitat pelos indivíduos são bastante heterogêneos e sua disponibilidade varia sazonalmente.

Palavras-chave: mudança de cor, camuflagem, uso de habitat, modelos visuais, isótopos estáveis, nicho trófico 


\section{GENERAL INTRODUCTION}

\section{Colour polymorphism, camouflage and habitat use}

The study of animal coloration has fascinated evolutionary biologists for a long time. Names like Charles Darwin and Alfred Wallace spent considerable time describing animal colour types and using their discoveries to defend their ideas about adaptation and natural selection (Darwin 1859; Wallace 1867). Coloration may play an important role, for instance, as a visual signal used in mate choice, or as a warning signal used to prevent attacks of potential predators (Andersson 1994; Caro et al. 2016). For ectothermic animals, such as reptiles and insects, colour patterns may influence body temperature, affecting the gain of energy and locomotion (Stuart-Fox and Moussalli 2009). In other cases, maintaining a coloration that provides efficient background matching may lead to decreased predation pressure and increased individual fitness (Stevens and Merilaita 2009). For species living in heterogeneous backgrounds, where two or more habitat patches vary in spatial configuration and colour pattern, achieving an overall efficient camouflage pattern may be challenging (Merilaita et al. 1999). In such cases, the existence of more than one coloration type in a single species (i.e. colour polymorphism) can be the solution found by natural selection to maintain viable populations living in heterogeneous background habitats (Gray and McKinnon 2007).

Colour polymorphism is widely distributed in many animal taxa (Bond 2007) and has been used to test different theories and evolutionary hypotheses (Cott 1940; Forsman et al. 2008; Caro et al. 2016). Polymorphic species frequently exhibit some strategy to obtain camouflage in the habitat they live (Cain and Sheppard 1954; Kettlewell 1955; Palma and Steneck 2001; Todd et al. 2006, Stevens et al. 2014), which would be adaptive in reducing individual detection by predators. Intra-specific variation in colour appearance can be either attained through genetic polymorphism (Nachman et al. 2003), or through colour change and 
phenotypic plasticity (Stuart-Fox and Moussalli 2009; Stevens 2016). Camouflage can also result from behavioural preferences of individuals to rest on backgrounds that provide enhanced concealment (Lovell et al. 2013; Kang et al. 2015).

Besides its importance to enhance overall camouflage, colour polymorphism linked to other morph-specific behavioural traits may enable species to exploit a larger array of habitats (Galeotti and Rubolini 2004; Karpestam and Forsman 2011; Stevens et al. 2014) through the diversification of habitat use strategies. In such cases, resources may be gathered more efficiently and trophic niche range can be expanded, which ultimately reduce intra-specific competition (Bolnick et al. 2003; Ahnesjö and Forsman 2006; Lattanzio and Miles 2014; Kusche et al. 2015). Therefore, the evolution of animal coloration and camouflage cannot be fully understood by approaching single traits in species or morphs, but must be examined as part of a complex interaction involving different morphological and behavioural attributes (Forsman et al. 2008; Caro et al. 2016; Duarte et al. 2016). Such integration would be expected to be selected mostly on polymorphic species living in heterogeneous and variable habitats, in which individuals would diversify their strategies to maximize the use of the available resources.

\section{The biological model}

The caridean shrimp Hippolyte obliquimanus Dana, 1852 is a small gonochoric (Terossi et al. 2008) and colour polymorphic species (Duarte and Flores 2016) very abundant in macroalgal meadows composed mainly by the brown alga Sargassum furcatum and the red weed Galaxaura marginata at shallow rocky areas along the South-eastern Brazilian coast. Shrimp populations can be divided in two main colour morphs, all belonging to the same species (Terossi and Mantelatto 2010): homogeneous shrimp (H) of variable coloration, with the body totally covered by a brown or pink colour pattern; and striped translucent shrimp (ST), in which individuals are transparent but present longitudinal or transversal colour bands (Duarte and Flores 2016) (see the Figure 1 of Chapter 2 for more details). $\mathrm{H}$ shrimp visually conceal to both 
the brown alga S. furcatum (where they show a brown coloration) and the red-pink weed $G$. marginata (where individuals are pink), while ST shrimp, although found in both habitats, show no background-specific colour pattern.

The distribution of $H$. obliquimanus shrimp among algal habitats along the São Sebastião Channel (SP, Brazil) is clearly morph dependent. While H shrimp occupy colour-matching backgrounds, where they can attain very large densities, especially in S. furcatum, ST individuals are equally distributed between S. furcatum and G. marginata algae (Duarte and Flores 2016). Shrimp densities and morph frequencies are probable affected by seasonal variations in the cover and biomass of algal canopies, especially S. furcatum which show very high biomass during summer but a much reduced density in winter (Godoy and Coutinho 2002). Morph differences in habitat distribution may be related to specific behavioural traits possibly associated to contrasting patterns of habitat use (Merilaita and Jormalainen 1997; Ahnesjö and Forsman 2006). This can implicate in a differential use of the available resources and result in trophic niche divergence between individuals (Herder et al. 2008; Karpestam and Forsman 2011). In the case of $H$. obliquimanus colour morphs, it would be expected the selection of a cryptic behaviour for $\mathrm{H}$ shrimp, with individuals remaining on colour-matching backgrounds where they could obtain camouflage and reduce predation risk. Alternatively, a more general life-style would be favoured for transparent ST shrimp, in which individuals would be less restricted to a specific background and would move more frequently among different substrate types.

In this thesis, I investigated across four chapters the mechanisms behind the evolution and maintenance of colour polymorphism in the caridean shrimp Hippolyte obliquimanus, with a special focus on the ecological consequences of camouflage strategies, colour change and resource use diversification for a species living in a heterogeneous and variable habitat. In the first chapter entitled "Camouflage through colour change: mechanisms, adaptive value, and ecological significance" I reviewed the mechanisms underpinning animal coloration, colour 
change and developmental plasticity for camouflage and discussed on their adaptive value and evolutionary-ecological implications in a general framework. In the second chapter entitled "Shape, colour plasticity, and habitat use indicate morph-specific camouflage strategies in a marine shrimp" I investigated the camouflage strategies that exist in the shrimp $H$. obliquimanus and how they interact with colour change abilities and with morphological and behavioural diversification in the way individuals use the available habitats. In the third chapter entitled "The adaptive value of camouflage and colour change in a polymorphic shrimp" I used digital image analysis, visual modelling and predation experiments to test whether the level of camouflage achieved by different colour morphs of $\mathrm{H}$. obliquimanus shrimp against their main algal habitats is adaptive in reducing shrimp predation. In the fourth and last chapter entitled "Habitat-dependent niche partitioning between colour morphs of the algal-dwelling shrimp Hippolyte obliquimanus" I used stable isotope analysis to test the existence of diet and trophic niche segregation between $\mathrm{H}$. obliquimanus colour morphs living in different algal meadows.

\section{References}

Ahnesjö J, Forsman A (2006) Differential habitat selection by pygmy grasshopper color morphs; interactive effects of temperature and predator avoidance. Evol Ecol 20:235-257.

Andersson M (1994) Sexual selection. Princeton Universiy Press, Princeton

Bolnick DI, Svanbäck R, Fordyce JA, et al (2003) The ecology of individuals: incidence and implications of individual specialization. Am Nat 161:1-28.

Bond AB (2007) The evolution of color polymorphism: crypticity, searching images, and apostatic selection. Annu Rev Ecol Evol Syst 38:489-514.

Cain AJ, Sheppard PM (1954) Natural Selection in Cepaea. Genetics 39:89-116.

Caro T, Sherratt TN, Stevens M (2016) The ecology of multiple colour defences. Evol Ecol 30:797809.

Cott H (1940) Adaptive coloration in animals. Methuen, London 
Darwin C (1859) On the origin of species by means of natural selection, or the preservation of favoured races in the struggle for life. John Murray, London

Duarte RC, Flores AAV (2016) Morph-specific habitat and sex distribution in the caridean shrimp Hippolyte obliquimanus. J Mar Biol Assoc United Kingdom 1-8. doi: 10.1017/S0025315416000230

Duarte RC, Stevens M, Flores AA V. (2016) Shape, colour plasticity, and habitat use indicate morph-specific camouflage strategies in a marine shrimp. BMC Evol Biol 16:218.

Forsman A, Ahnesjö J, Caesar S, Karlsson M (2008) A model of ecological and evolutionary consequences of color polymorphism. Ecology 89:34-40.

Galeotti P, Rubolini D (2004) The niche variation hypothesis and the evolution of colour polymorphism in birds: a comparative study of owls, nightjars and raptors. Biol J Linn Soc 82:237-248.

Godoy EAS, Coutinho R (2002) Can artificial beds of plastic mimics compensate for seasonal absence of natural beds of Sargassum furcatum? ICES J Mar Sci 59:111-115.

Gray SM, McKinnon JS (2007) Linking color polymorphism maintenance and speciation. Trends Ecol Evol 22:71-9.

Herder F, Pfaender J, Schliewen UK (2008) Adaptive sympatric speciation of polychromatic "roundfin" sailfin silverside fish in Lake Matano (Sulawesi). Evolution (N Y) 62:2178-95.

Kang C, Stevens M, Moon J-Y, et al (2015) Camouflage through behavior in moths: the role of background matching and disruptive coloration. Behav Ecol 26:45-54.

Karpestam E, Forsman A (2011) Dietary differences among colour morphs of pygmy grasshoppers revealed by behavioural experiments and stable isotopes. Evol Ecol Res 13:461-477.

Kettlewell H (1955) Selection experiments on industrial melanism in the Lepidoptera. Heredity (Edinb) 9:323-342.

Kusche H, Elmer KR, Meyer A (2015) Sympatric ecological divergence associated with a color polymorphism. BMC Biol 13:82.

Lattanzio MS, Miles DB (2014) Ecological divergence among colour morphs mediated by changes in spatial network structure associated with disturbance. J Anim Ecol 83:1490-1500.

Lovell PG, Ruxton GD, Langridge K V, Spencer KA (2013) Egg-laying substrate selection for optimal camouflage by quail. Curr Biol 23:260-264.

Merilaita S, Jormalainen V (1997) Evolution of sex differences in microhabitat choice and colour polymorphism in Idotea baltica. Anim Behav 54:769-78. 
Merilaita S, Tuomi J, Jormalainen V (1999) Optimization of cryptic coloration in heterogeneous habitats. Biol J Linn Soc 67:151-161.

Nachman MW, Hoekstra HE, D’Agostino SL (2003) The genetic basis of adaptive melanism in pocket mice. Proc Natl Acad Sci U S A 100:5268-5273.

Palma AT, Steneck RS (2001) Does variable coloration in juvenile marine crabs reduce risk of visual predation? Ecology 82:2961-2967.

Stevens M (2016) Color change, phenotypic plasticity, and camouflage. Front Ecol Evol 4:1-10.

Stevens M, Lown AE, Wood LE (2014) Camouflage and individual variation in shore crabs (Carcinus maenas) from different habitats. PLoS One 9:1-31.

Stevens M, Merilaita S (2009) Animal camouflage: current issues and new perspectives. Philos Trans R Soc Ser B, Biol Sci 364:423-427.

Stuart-Fox D, Moussalli A (2009) Camouflage, communication and thermoregulation: lessons from colour changing organisms. Philos Trans R Soc Lond B Biol Sci 364:463-70.

Terossi M, López Greco LS, Mantelatto FL (2008) Hippolyte obliquimanus (Decapoda: Caridea: Hippolytidae): a gonochoric or hermaphroditic shrimp species? Mar Biol 154:127-135.

Terossi M, Mantelatto FL (2010) Sexual ratio, reproductive period and seasonal variation of the gonochoric shrimp Hippolyte obliquimanus (Caridea: Hippolytidae). Mar Biol Res 6:213-219.

Todd P, Briers R, Ladle R, Middleton F (2006) Phenotype-environment matching in the shore crab (Carcinus maenas). Mar Biol 148:1357-1367.

Wallace A (1867) Mimicry and other protective resemblances among animals. Westminster Rev (London Ed) 1 July:1-43. 


\section{CHAPTER 1}

Camouflage through colour change: mechanisms, adaptive value, and ecological significance

Manuscript accepted for publication in the journal "Philosophical Transactions of the Royal Society B: Biological Sciences" 


\title{
Camouflage through colour change: mechanisms, adaptive value, and ecological significance
}

\author{
Rafael C. Duarte ${ }^{1,2}$, Augusto A. V. Flores ${ }^{1}$, and Martin Stevens ${ }^{3}$ \\ 1 - Centro de Biologia Marinha, Universidade de São Paulo, São Sebastião, Brazil. \\ 2 - Programa de Pós-Graduação em Biologia Comparada, Faculdade de Filosofia, Ciências e Letras de Ribeirão Preto, \\ Universidade de São Paulo, Ribeirão Preto, Brazil. \\ 3 - Centre for Ecology and Conservation, College of Life and Environmental Sciences, University of Exeter, Penryn \\ Campus, Penryn, Cornwall, TR10 9FE. United Kingdom.
}

\section{Abstract}

Animals from a wide range of taxonomic groups are capable of colour change, of which camouflage is one of the main functions. A considerable amount of past work on this subject has investigated species capable of extremely rapid colour change (in seconds). However, relatively slow colour change (over hours, days, weeks, and months), as well as changes arising via developmental plasticity are probably more common than rapid changes, yet less studied. We discuss three key areas of colour change and camouflage. First, we review the mechanisms underpinning colour change and developmental plasticity for camouflage, including cellular processes, visual feedback, hormonal control, and dietary factors. Second, we discuss the adaptive value of colour change for camouflage, including the use of different camouflage types. Third, we discuss the evolutionary-ecological implications of colour change for concealment, including what it can tell us about intraspecific colour diversity, morph-specific strategies, and matching to different environments and microhabitats. Throughout, we discuss key unresolved questions and present directions for future work, and highlight how colour change facilitates camouflage among habitats, and arises when animals are faced with environmental changes occurring over a range of spatial and temporal scales.

Keywords: colour change, camouflage, behaviour, chromatophores, predator-prey interactions 


\section{Introduction}

Many pioneers of evolutionary biology, including Wallace and Poulton, spent considerable time discussing animal coloration and describing the types of camouflage that may exist (Wallace 1867; Poulton 1890), providing key examples of natural selection. Early experts were also aware that individuals of many species could change colour, and Poulton even conducted experiments into the mechanisms and function of this (e.g. Poulton 1903). Ever since, colour change has been a valuable system to study both the adaptive value of camouflage and the physiological processes shaping animal form and diversity (Stuart-Fox and Moussalli 2009). However, research into colour change for camouflage is limited, focussing on relatively few taxa, often lacking tests of its adaptive value, sometimes lacking evolutionary-ecological perspectives, and often failing to rigorously quantify camouflage.

Colour change is well known to occur over multiple timescales. Cephalopods like cuttlefish can change rapidly in seconds, many fish change in minutes, some crabs over a period of hours, caterpillars over days and weeks, and certain arctic animals over months (Caro et al. 2016; Stevens 2016). In many species, a fundamental reason for colour change is that it allows individuals to modify their appearance to provide camouflage tuned to the habitat where they live, and to cope with environmental changes occurring over a range of spatial and temporal scales. For example, rapid changes in appearance may enable animals to cope with fine-scale temporal and spatial heterogeneity, whereas slower changes are often associated with more predictable long-term environmental variation (Caro et al. 2016).

Spanning over 120 years, substantial research work has sought to understand the functions and mechanisms of colour change for camouflage. However, numerous key questions remain, including: what are the mechanisms of colour change across species?; what are its physiological costs?; what is the adaptive value provided?; and how does colour change relate to intraspecific diversity and various ecological processes? Here, we discuss the mechanisms and functions of colour change for camouflage and identify key questions for future work. Our 
synthesis differs from recent reviews on a similar theme that have either discussed the general ecological factors favouring flexible animal defences (from startle displays to camouflage), but not covered mechanisms (Caro et al. 2016), or focussed on colour change in one specific group (e.g. crabs) (Stevens 2016). Here, we provide an integrative synthesis of the mechanisms that underpin colour change for camouflage, its adaptive value, and the evolutionary-ecological factors and implications of colour change for concealment.

\section{Mechanisms and control of colour change}

\section{(a) Cellular basis}

The basis of colour change has been studied for a considerable time (e.g. Keeble and Gamble 1899), and the varied mechanisms involved have been reviewed in detail (Bagnara and Hadley 1973; Bagnara and Matsumoto 2006; Umbers et al. 2014; Ligon and McCartney 2016), primarily with regards to endocrine and cellular control. Colour change can involve a range of mechanisms (Umbers et al. 2014). However, it has been studied most with regards to changes in the state and abundance of pigment-containing chromatophore cells. These cells can respond directly to light (a primary response) or via visual system pathways (a secondary response), with the latter being more relevant to camouflage. Broadly, secondary responses can involve two processes and occur over a variety of timescales (Figure 1). Physiological colour change involves expansion and contraction of pigment granules within chromatophores over seconds, minutes, and hours (Bagnara and Hadley 1973; Bagnara and Matsumoto 2006; Umbers et al. 2014). This can include rapid changes brought about by neuromuscular action directly on the cells, such as in many cephalopods (Bagnara and Hadley 1973), or slower endocrine pathways, such as in arthropods (Umbers et al. 2014). Colour change can also involve morphological processes, including changes in the number and proportion of chromatophore types and pigment content (Bagnara and Hadley 1973; Bagnara and Matsumoto 2006). This includes moulting in many species (e.g. crabs and caterpillars - Noor et 


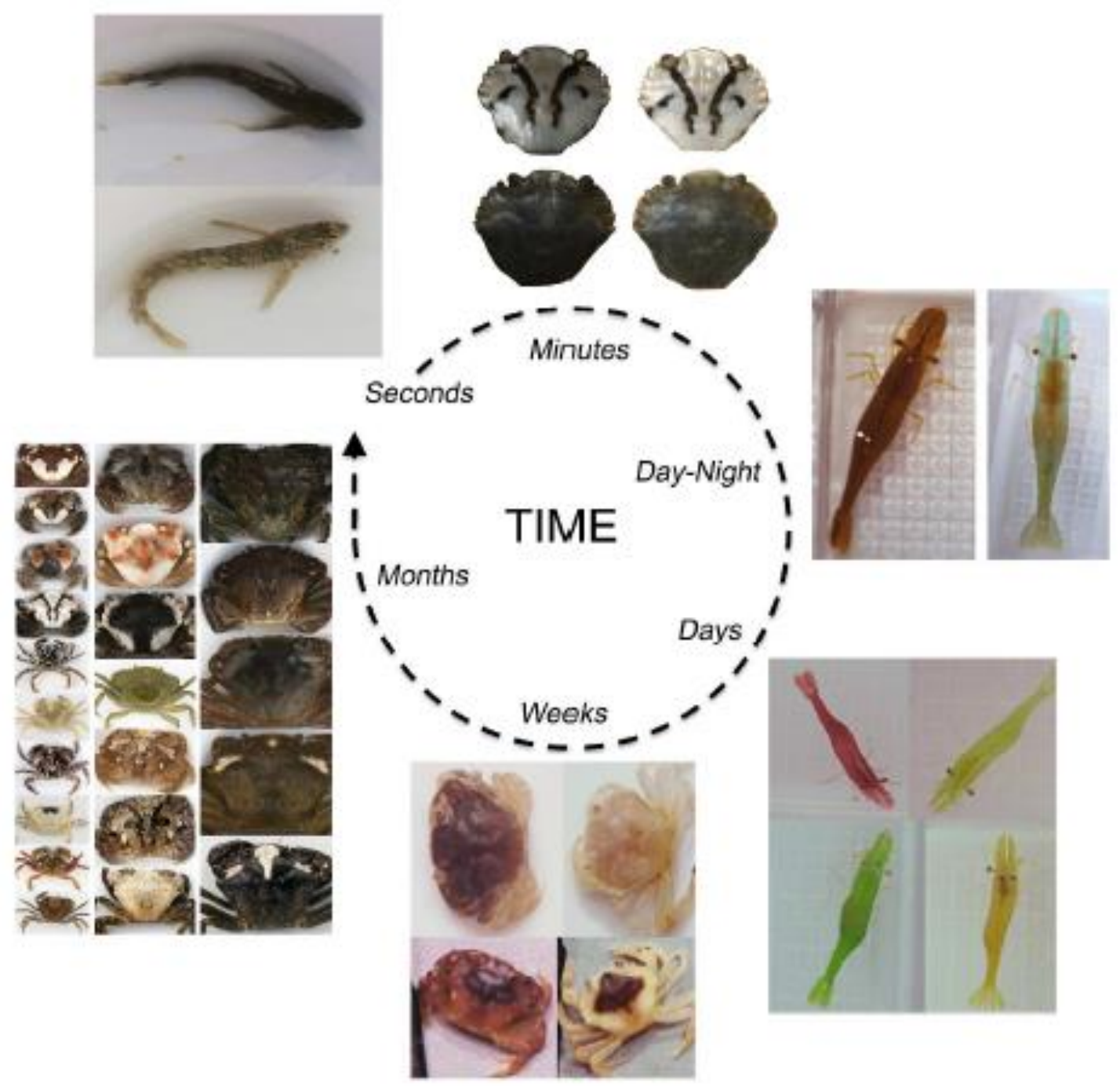

Figure 1. Animals can modify their appearance over varied timescales. Some fish, like rock gobies (Gobius paganellus), change brightness and colour in less than a minute. Shore crabs (Carcinus maenas) change brightness over two hours, becoming darker on black (left images) and lighter on white backgrounds (right images). Chameleon prawns (Hippolyte varians) undergo day-night changes from their diurnal type (here a brown morph) to blue-grey at night. Colour change often occurs over longer periods. Red chameleon prawns change to green when on green seaweed for 20 days (top), and begin to change from green to yellow-red when on red seaweed (bottom; though this direction of change is slower). Shore crabs substantially change appearance as they moult over weeks and months. Here, the top individual changes from dark to light post-moult after being kept on a white substrate. The bottom images show an individual changing colour and pattern with moult after having been kept on a light yellow substrate. Changes also occur with ontogeny, with juvenile crabs (left column) highly diverse in appearance, but variation declining from sub-adults (middle column) to adults (right column). 
A significant body of work, especially in crabs, fish, and amphibians, has investigated the nature and control of chromatophores, and described the types of cell that exist. These include melanophores (black/brown melanin pigment), erythrophores and xanthophores (red and yellow, respectively, with pteridine and carotenoid pigments), and leucophores or iridophores (involving purines producing especially white and blue colours mainly through light reflection) (Bagnara and Hadley 1973; Bagnara and Matsumoto 2006; Ligon and McCartney 2016). Much is known about these cells and their control. However, most past work on camouflage scored individual chromatophore states based on a pigment-dispersion index and few studies have related changes in chromatophore state and abundance to objective changes in the animal's appearance, let alone quantifying actual camouflage match (but see for example, Stuart-Fox et al. 2008; Chiao et al. 2011; Stevens et al. 2014a; Stevens et al. 2014b; Kang et al. 2016). The role of molecular pathways and genetic control is somewhat less known (but see Bagnara and Matsumoto 2006; Ligon and McCartney 2016).

Despite a widespread lack of camouflage quantification in studies focusing on chromatophore cells, numerous experiments demonstrate that many species change using these cells through assessing the pattern, colour, and brightness of the background. For example, many amphibians become darker on a black background due to melanosome dispersal and iridophore aggregation, with the opposite situation observed on a light background (Bagnara and Matsumoto 2006). Similar outcomes and processes occur in invertebrates (Powell 1962; Fingerman 1973; Stevens et al. 2013; Stevens et al. 2014b). Overall, the exact colour change responses are determined by the combined interacting effects of changes in the state, proportion, and abundance of chromatophore types occurring in different tissue layers (Bagnara and Matsumoto 2006). 


\section{(b) Metabolic and physiological costs and constraints}

Colour change is often assumed to involve physiological costs and energetic expenditure. However, to what extent this is true, and how much it actually impacts on other processes and animal energy budgets is little known. In cephalopods, controlling large numbers of chromatophore cells rapidly and in synchrony continuously over time likely carries a cost that impacts on the individual's energy budget. Pigments used in morphological colour change may also be important for non-camouflage functions, such as immune response and health, representing further constraints (especially if colour change involves a role of diet) (Stevens 2016). Therefore, metabolic costs and other constraints associated with changing colour and maintaining chromatophore state may be important, but as yet, these are almost untested. One study has at least demonstrated that when guppy fish (Poecilia reticulata) are induced to change colour by altering the background, individuals increase their food consumption levels (Rodgers et al. 2013). The implication is that increased food consumption occurs to offset the energetic costs of changing colour. However, while valuable, this finding comprises indirect evidence. Alternative explanations include, for instance, that surplus feeding is a stress response, or that fish need to obtain the pigments required for colour change from their food (i.e. a constraint but not a cost). Experiments taking metabolic respirometry measurements, while inducing individuals to change by presenting them with different visual backgrounds are needed to quantify energetic expenditure associated with changing colour.

\section{(c) Role of visual pathways}

Most work on how visual information drives change in appearance for camouflage has been undertaken in cephalopods, especially cuttlefish (reviewed by Hanlon et al. 2009). Such work has shown that cephalopods change their patterns in response to the size, contrast, and presence of visual edges and discrete objects, among other factors. Similar studies have also been undertaken in flatfish (e.g. Kelman et al. 2006), but manipulative tests of background 
appearance and camouflage change responses are more sparse in other taxa. In addition to changes in pattern, animals also change colour and brightness (e.g. Stuart-Fox et al. 2008; Stevens et al. 2014a). This potential should be enhanced by an increased ability to resolve greater colour, or via rules of thumb associated with scene brightness. In contrast, poor visual ability may constrain colour change and matching. Furthermore, responses to background brightness are thought to be mediated not by overall light levels, but by the ratio of incident light from around the animal to the light reflected from the substrate (Stevens 2016). Experiments have seldom tested these assumptions but one study on grasshoppers has shown that colour change to darker or lighter forms occurs when the substrate is comparatively light or dark, but not simply when individuals are put into dark containers or bright light (Burtt 1951).

In cephalopods and some fish, chromatophore state is under direct nerve control from the visual system, whereas in many other animals it is guided by hormones. A wide range of work on Uca crabs and other crustaceans shows a chromatophore response at least partly based on eyestalk (sinus gland) produced hormones (e.g. Fingerman and Yamamoto 1967). However, in Cancer crabs, evidence also suggests a role of the optic nerve controlling other non-eyestalk sources of pigment-dispersing hormones (Shibley 1968). In many vertebrates, especially amphibians, much is known regarding the hormones involved in colour change and how they act on the pigment cells (see Bagnara and Hadley 1973; Bagnara and Matsumoto 2006). Work on other taxa investigating these pathways and specifically into the role of vision would be valuable in understanding the control of colour change and associated constraints. Finally, there is growing evidence that colour change for camouflage may also be partly guided by light-detecting opsin proteins outside of the eye, and this is an important area for future work (see summary in Stevens 2016). 


\section{(d) Role of diet}

While visual feedback for colour change is undoubtedly important in many species, a role of diet also exists in some groups, and likely often interacts with vision. For example, diet is known to influence coloration in some spiders (Gillespie 1989). In Hippolyte prawns (Figure 1, 2), effective colour change from one morph to another seems to require the presence of the real seaweed, rather than colour matched artificial backgrounds (Duarte et al. 2016), although this does not discount a role of vision. In caterpillars, studies (some stemming back to Poulton 1890) have shown that, depending on the species, larval coloration and morphs can be induced by either diet, substrate reflectance, or a combination of these (Greene 1996; Noor et al. 2008), though the precise mechanisms are uncertain. Further manipulative experiments are needed, changing the visual appearance of the substrate through coloured filters, alongside diet, to tease apart the relative roles of diet and vision.

\section{(e) Circadian rhythms}

Many animals that change appearance also show clear circadian rhythms of colour change. For example, various crabs become lighter at night and darker during the day (perhaps to save energetic costs at night when predation risk is lower) (Darnell 2012), or darker at night and lighter during the day to improve camouflage (Stevens et al. 2013). These changes do not generally occur simply when individuals are put into the dark, and are in tune with natural daynight cycles, indicating endogenous control modified by long-term changes in light conditions and day length (e.g. Fingerman and Yamamoto 1967; Darnell 2012; Stevens et al. 2013). Other species, such as chameleon prawns (Hippolyte varians) also show pronounced changes at night (changing from a green, red, or brown diurnal colour to a blue-transparent nocturnal appearance (Gamble and Keeble 1900; Figure 1). However, these changes seem to involve responses to light conditions over a few hours (Kleinholz and Welsh 1937), suggesting a 
periodic release of hormones (Bagnara and Hadley 1973). Overall, the functional significance of circadian rhythms, and quantification of their impact on camouflage has received little study.

\section{(f) Behavioural adaptations}

Unlike species known to rapidly change appearance (e.g. certain cephalopods and fish), most animals cannot change immediately but likely over hours, days, and weeks (Umbers et al. 2014; Stevens 2016). This means that if coloration is to effectively provide camouflage in heterogeneous environments individuals should also behaviourally choose backgrounds that match their appearance. Recent evidence in some species (e.g. birds, Lovell et al. 2013) shows that individuals can choose backgrounds based on their individual appearance, though the mechanisms by which they do so are unknown. Species that change colour should not have fixed behavioural preferences, however, because they would then often chose inappropriate backgrounds after having changed colour. In contrast, preference should be flexible. For example, a crab newly found on a white background may both turn white and develop preferences for white substrates over time. As yet, we are aware of few tests of such ideas (but see Ryer et al. 2008; Hultgren and Stachowicz 2010). However, evidence from Hippolyte prawns and filefish (Monacanthus chinensis) shows some evidence of morph-specific substrate preferences (Chassard 1956; Gilby et al. 2015; Duarte et al. 2016).

\section{Causes, consequences, and ecological implications of colour change for concealment}

\section{(a) The survival benefit of colour change for camouflage}

It is widely assumed that predation pressure is the ultimate selective force promoting camouflage. However, direct experimental testing of any camouflage strategy in mitigating predation is surprisingly limited and available evidence is restricted to studies using model replicas of real animals (e.g. Vignieri et al. 2010). While these are valuable for testing camouflage effectiveness, the stimuli used are necessarily simplified and do not show the 
direct survival advantage afforded by camouflage in the real animals. Other studies, such as those of melanism in the peppered moth (Biston betularia), have analysed morph frequencies and recapture rates in different habitats (e.g. Kettlewell 1955). Most studies, however, typically lack direct quantification of how individual-level camouflage, to predator vision, equates to predation risk.

Tests of the survival value of camouflage in colour changing species are even less common, although some studies have used mathematical vision models to assess changes in background matching. For example, in cuttlefish, appearance changes may allow efficient concealment of individuals to both di- and trichromatic fish predators (Chiao et al. 2011). Likewise, colour change in chameleons conceals individuals to the vision of birds and snakes (Stuart-Fox and Moussalli 2008). Adjustments in background matching, assessed using models of predator vision, have also been undertaken in crabs and fish (Stevens et al. 2014a; b). Some studies, for example on colour-changing isopods (Hultgren and Mittelstaedt 2015), have used tethering experiments to show that survival (recapture) of morphs is higher against matching than nonmatching substrates. This approach is valuable because it is closer to testing the actual survival of individuals of differing camouflage in the wild. However, so far, studies of this nature have not analysed levels of concealment to predator vision. Overall, direct measurements of how colour change affects the survival of individuals in natural systems represent a major research avenue for the future. Such work should undertake predation experiments with real predators and prey, either under field conditions or controlled, but ecologically realistic, laboratory studies. Furthermore, because colour-changing animals exploit a variety of (micro)habitats, the transition from one habitat patch to another, coupled with the time for changes to occur once settled, are critical periods when predation rate is theoretically highest. Therefore, a better understanding of the adaptive value of colour change demands not only testing whether colour matching actually renders lower predation pressure, but also measuring predation rates under transitional non-matching conditions. 


\section{(b) Multiple camouflage strategies}

Colour change has a variety of functions, from thermoregulation to sexual signals, and the ability to change should allow animals flexibility in how these are used. Non-camouflage uses of colour change have been well covered elsewhere (e.g. Stuart-Fox and Moussalli 2009; Caro et al. 2016), and here we focus on changes in concealment strategies. Camouflage prevents detection or recognition by predators and can be achieved by a number of strategies (see Stevens and Merilaita 2011). Various studies have examined how animals employ distinct strategies and their adaptive value, but mostly focusing on species with fixed coloration and using artificial prey. Most past work on colour change considers background matching, whereby the animal resembles the general appearance of the background. In contrast, disruptive coloration breaks up animal outlines and creates false boundaries (Stevens and Merilaita 2011). Other camouflage strategies include masquerade (resembling objects in the environment to prevent recognition), and transparency. For colour changing animals, assessment of camouflage types individuals use and how they provide concealment to different backgrounds are rare, let alone quantifying the presence and effectiveness of strategies such as disruptive coloration. Exceptions include work on cephalopods, which can quickly change between a background matching strategy and one of potential disruptive coloration when individuals are exposed to backgrounds differing in levels of pattern contrast (Hanlon et al. 2009). In Sepia officinalis, individuals exhibit 'uniform' or 'mottled' coloration when placed against low contrast backgrounds, indicating background matching. On the other hand, when placed against strongly contrasting backgrounds, individuals produce a coarse contrasting pattern, composed of spots varying in colour, size, and shape, possibly affording a disruptive effect (Hanlon et al. 2009). Many cephalopods are also adept at masquerade. Beyond cephalopods, if and when animals use colour change to switch between types of camouflage, why they do this, and the relative benefits, are questions waiting to be tackled. Such work should consider manipulative experiments placing individuals against substrate 
types coupled with analysis of their resulting colour patterns. The latter could involve using models of animal spatial vision to calculate levels of disruption to body edges (e.g. Stevens and Cuthill 2006) and analysis of body shape and structure to assess similarity to other objects (masquerade). Furthermore, investigations of the colour pattern and body forms adopted by free-ranging individuals would help in understanding under what contexts different camouflage strategies are adopted.

Most animals are exposed to multiple predators, potentially differing in visual ability and strategies for prey detection. Colour change may thus be an important mechanism for individuals to adjust their camouflage when facing different predator threats. Dwarf chameleons, for example, change depending on the predators' visual capabilities, showing greater changes in background colour matching when presented with birds versus snakes. They appear, however, more camouflaged to the snake, since this trichromatic predator has poorer colour discrimination than tetrachromatic birds (Stuart-Fox and Moussalli 2008). Changes in predation risk with ontogeny in some crustaceans may also be an important selective force maintaining high colour polymorphism (see below, Palma and Steneck 2001; Todd et al. 2009; Stevens et al. 2014c). Further experiments testing if and how animals adjust their camouflage when facing different predator types would be welcome. This could include short-term changes in animals such as cuttlefish, which are known to show divergent responses to different types of predator (Langridge et al. 2007), and also how appearance is altered in animals that change colour over longer periods when exposed to different levels of predator risk.

\section{(c) Ontogenetic changes and polymorphism}

Many animals move from one habitat to another over their life in a predictable way. For example, some colour changing crabs shift from occupying intertidal habitats as juveniles to subtidal algal patches when larger/adult (Hultgren and Stachowicz 2010). In many species, 
larger crabs are subjectively less cryptically patterned than juveniles (Todd et al. 2009; Figure 1). Presumably, because these young stages have not yet reached a refuge size against most of their predators, crypsis is prevalent. In contrast, lower plasticity in adults may be a result of moving to more homogeneous background environments, or weaker predator selection for camouflage if individuals are more defended (Todd et al. 2009). Finally, physiological constraints may also limit chromatic variation among adults. For larger crustaceans, thicker exoskeletons are less transparent and can impair the potential for colour change.

There are many examples of high intraspecific variation and polymorphisms across a wide array of animal groups (Figure 2). These can arise under selection for various functions, but camouflage is one of the most common. In many decapod crustaceans, including crabs and lobsters (Anderson et al. 2013; Stevens et al. 2014c), juveniles exhibit higher colour variation than adults, and subjectively achieve camouflage in a wider variety of (micro)habitats (Figure 1, 2). This is paralleled in other groups (e.g. snakes, Wilson et al. 2006). There are a number of unresolved issues here regarding why polymorphism in juveniles is high and how it arises. First, to what extent early-stage phenotypic diversity is due to genetic variation versus plasticity is poorly understood - in some groups, the mechanisms may vary from one species to the next (Burtt 1951; Karlsson et al. 2009). Second, why juveniles are so variable is an unresolved question. Greater diversity may reflect habitat heterogeneity being high at small spatial scales - individual phenotypes may match different habitat patches. Juvenile shore crabs, for example, have greater variation in more diverse habitat types (Stevens et al. 2014c). It would be valuable to test whether individuals change their specific patterns to resemble particular background patches, or simply increase general pattern expression when occurring in more variable habitats. Another selective force promoting polymorphism may be that polymorphism interferes with predator search image formation, resulting in apostatic selection. There is some evidence that colour polymorphism may reduce predation rates on juvenile rock crabs (Cancer irroratus) inhabiting heterogeneous habitats, whereby predator exclusion led to a 
higher proportion of the adult-like (drab brown) morphs compared to control conditions (Palma and Steneck 2001). It is unclear, however, to what extent juvenile crabs changed colour in their microhabitats. Experiments similar to those of Bond \& Kamil (2006), but with real prey phenotypes rather than artificially generated 'moths', would be valuable to investigate whether polymorphisms interfere with predator search image formation.

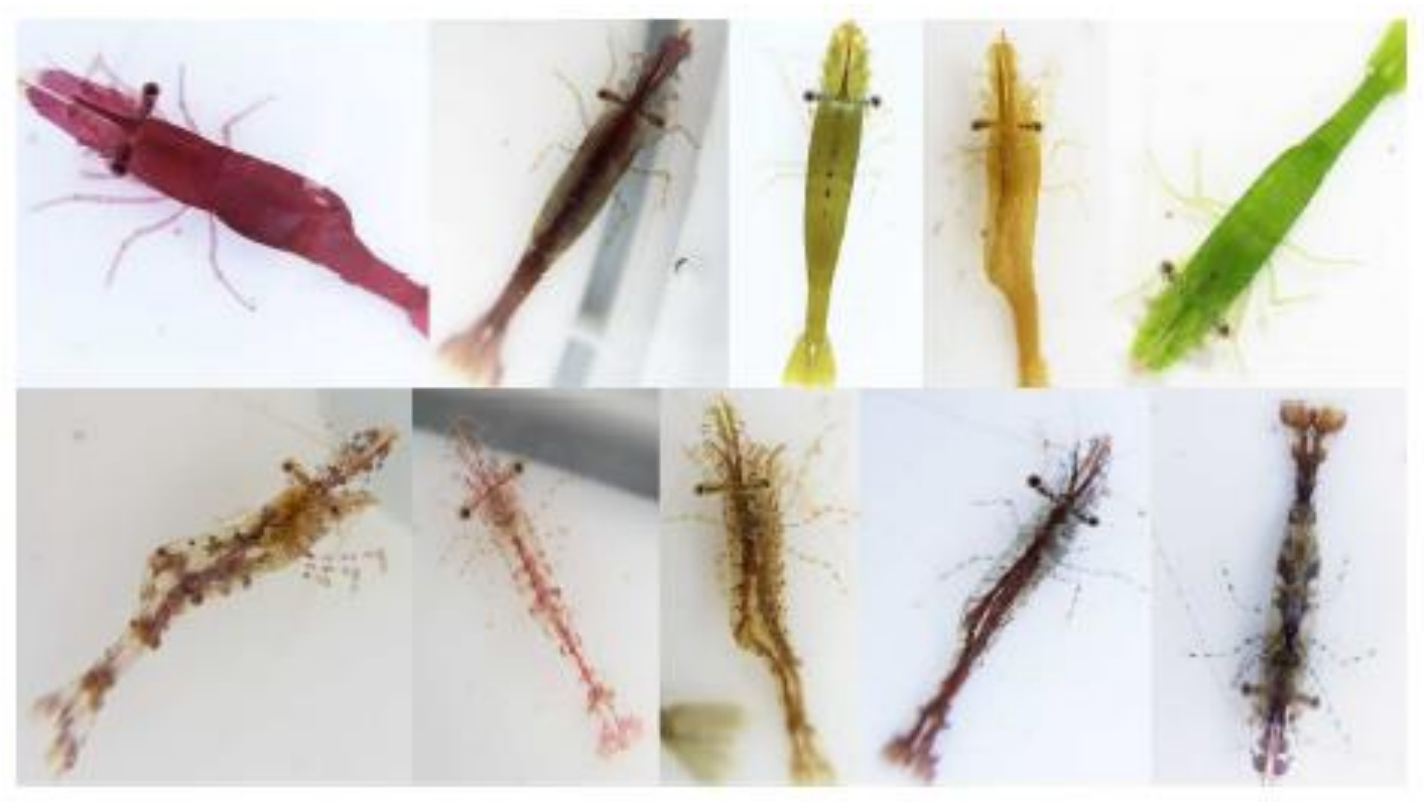

Figure 2. Intraspecific diversity and matching to different backgrounds. The chameleon prawn (Hippolyte varians) has considerable intraspecific variation, with multiple relatively homogenous and inter-changeable colour types ranging from red to green (top row), in addition to seemingly fixed transparent morphs (bottom row). These different morphs allow camouflage against different seaweed types.

\section{(d) Morph-specific strategies}

Not all individuals in a population may be equally capable of colour adjustments, with habitat and resource use differing across morphs. In Pacific tree frogs (Hyla regilla), individuals occur in either fixed green or brown morphs, or a separate morph capable of relatively slow colour change (Wente and Phillips 2003). These morphs seem to represent different camouflage strategies for dealing with seasonal changes in a heterogeneous habitat. 
Other species also show segregation into plastic and fixed morphs associated with habitat use and potentially camouflage types. In the algal-dwelling shrimp Hippolyte obliquimanus, individuals occur in either a homogeneous morph $(\mathrm{H})$, capable of colour change within a few days, or a striped translucent morph (ST), in which colour pattern seems relatively fixed (Duarte et al. 2016). In nature, $\mathrm{H}$ individuals occur in high densities against certain weed species, whereas ST individuals are more evenly distributed among various habitats (Duarte and Flores 2016). Habitat fidelity is higher and swimming activity lower in $\mathrm{H}$ shrimp compared to ST individuals, and, correspondingly, ST shrimp have a more pelagic streamlined shape. These morphs may reflect different camouflage strategies, with $\mathrm{H}$ individuals well concealed to specific background types at any given time, and ST individuals relying more on transparency to cope with their more mobile life-style (Duarte et al. 2016).

Similar morph-specific differences occur in other species. Many grasshoppers, for example, occur in fire-affected habitats, whereby melanic morphs camouflaged against burnt ground and lighter morphs against fresh vegetation arise through developmental plasticity based on background brightness (Burtt 1951). Coupled with dispersal, this can allow for movement into new patches. In some pygmy grasshoppers (Tetrix) there is also evidence for differences in dispersal ability and dietary niches between morphs (Karpestam and Forsman 2013). Such linked polymorphic states of coloration and behaviour may allow individuals to exploit different habitat types and reduce competition.

\section{Concluding remarks and key future research}

Below we outline 10 inter-connected areas of camouflage and colour change that we feel are most important for future work to address.

i. When do visual processes underlie colour change for camouflage and what are the specific pathways? Clearly, for many species, visual feedback is key to guiding colour change. Yet some animals also appear to rely on dietary factors. Generally, visual feedback 
should be important when colour change occurs in the short-term and when future background environments are unpredictable. For example, cuttlefish moving rapidly to new patches should require visual information to change appropriately, as should juvenile crabs that might settle in a wide range of habitats. In contrast, species that consume what they live on and change via diet (e.g. some caterpillars), or where changes in background colour are predictable (e.g. snow cover and hares) or indicated by other cues (e.g. odour) may not need visual feedback.

ii. What are the physiological costs of colour change? It is widely assumed that colour change carries energetic or metabolic costs. We would predict that costs would be dependent on the speed and type of change. Animals that change rapidly and continuously likely incur some costs, whereas in species that change slowly or with a dietary component the costs may be small. Quantification of metabolic rate over different timescales for individuals induced to change colour versus those that are not are needed.

iii. What are the adaptive functions of circadian rhythms of colour change? Rhythms are common in crustaceans, amphibians, reptiles and beyond, yet their functional significance (and mechanisms) are poorly understood. In some species, rhythms may facilitate thermoregulation and UV protection, or simply energy saving, whereas in others rhythms allow concealment over 24 hours.

iv. How do behavioural adaptations complement (or conflict with) colour change for camouflage and how are these behaviours controlled? The significance of behavioural choice is striking for animals that change colour because, in many cases, substrate preferences should no longer be fixed, but like appearance be flexible. We would expect animals with very rapid and effective colour change to lack strong behavioural preferences (e.g. cephalopods), whereas in slow changing species and those living in situations where the habitat patches are large compared to body size (e.g. caterpillars, grasshoppers, crustaceans), substrate preferences linked to coloration should exist. 
Experiments should compare if and how behavioural preferences change when individuals are induced to match different substrates.

v. To what extent does colour change improve camouflage and increase survival chances? Visual modelling or experiments using artificial prey remain the most common ways to test the value of camouflage. However, direct measurements of the survival benefits achieved by colour change, including risk during transitional phases, using real predators and prey in the field or laboratory are much needed.

vi. What camouflage strategies are used by colour changing animals? Studies subjectively describing the occurrence of distinct camouflage types, such as background matching or disruptive coloration, are common for species with fixed coloration. However, much less is known regarding the use and value of different strategies in colour-changing species. Experiments testing the response of animals when presented with different visual scenes, coupled with measurements of background matching, disruptive coloration, and masquerade would reveal when different types of camouflage are used. In general, species that have a high degree of plasticity and the potential for highly patterned appearance make ideal systems for testing this issue.

vii. Can colour change allow animals to resolve conflicting selection pressures? Many species are frequently exposed to multiple predators, differing in their sensory systems and modes of attack, and change with various ecological parameters and age. Colour change may be a valuable solution to deal with multiple pressures. Future work should explore the life history factors that predict changes from one defensive strategy to another. Insect larvae may be particularly useful systems, given that different instars frequently change between types of defence.

viii. How important are phylogenetic constraints in shaping patterns of colour change abilities across taxa? Many species across multiple phyla change colour over varied timescales. Controlled phylogenetic comparative analyses are greatly needed to identify the 
driving forces and constraints on colour change evolution and the patterns observed. Potentially valuable groups to explore these issues are crustaceans and fish because they show diversity in colour change abilities among species, and because colour change occurs over varied temporal scales that may be linked to differing life history factors.

ix. What factors underlie ontogenetic changes in appearance? In many species, individuals vary in appearance through ontogeny. Understanding this could help us comprehend the driving factors behind colour change, ranging from species life-history and ecology through to predator avoidance behaviour. Crustaceans and insect larvae are good candidates for such work, given the common ontogenetic changes that they display.

$x$. How common are discrete morphs in colour changing species and why do they exist? It is often assumed that all individuals of a colour changing species have this ability yet recent work shows the presence of alternative fixed morphs in some species. How widespread within-species alternative morphs are, how they differ in strategy and habitat use, and even in reproductive behaviour are issues of widespread importance. In some cases, morphs may represent alternative ways of exploiting varying resources, with knock-on effects for population densities, competition, and migration among habitats and patches.

Colour change involves multiple, often interconnected, mechanisms, including processes and pathways that we are yet to properly understand. In many species, a suite of mechanisms and selection pressures will be driving the ultimate appearance and adaptive value of colour forms. Despite substantial progress, there is much left to understand and this subject has much to reveal about key questions in ecology, physiology, and evolution. 


\section{Acknowledgements}

We thank Fundação de Amparo à Pesquisa do Estado de São Paulo (FAPESP) which granted a PhD fellowship to R.C.D. (\#2012/17003-0) and a visiting researcher grant to M.S. (\#2015/22258-5). We thank Russell Ligon, Tom Tregenza, two anonymous referees and the Editor for helpful comments on the manuscript. We thank the editors for the invitation to submit this paper to the special issue.

\section{References}

Anderson JR, Spadaro AJ, Baeza JA, Behringer DC (2013) Ontogenetic shifts in resource allocation: colour change and allometric growth of defensive and reproductive structures in the Caribbean spiny lobster Panulirus argus. Biol J Linn Soc 108:87-98.

Bagnara JT, Hadley ME (1973) Chromatophores and Color Change, Prentice-Hall Inc.

Bagnara JT, Matsumoto J (2006) Comparative anatomy and physiology of pigment cells in nonmammalian tissues. In The Pigmentary System: Physiology and Pathophysiology, Second Edition (eds. Nordlund J.J., Boissy R.E., Hearing V.J., King R.A., Oetting W.S., J-P. O.), Blackwell Publishing Ltd.

Bond AB, Kamil AC (2006) Spatial heterogeneity, predator cognition, and the evolution of color polymorphism in virtual prey. PNAS 103:3214-3219.

Burtt E (1951) The ability of adult grasshoppers to change colour on burnt ground. Proc R Entomol Soc Lond 26:45-49.

Caro T, Sherratt TN, Stevens M (2016) The ecology of multiple colour defences. Evol Ecol 30:797-809.

Chassard C (1956) Polymorphisme des populations d'Hippolyte varians Leach et comportement en function de leur adaptation chromatique presente. B Soc Zool Fr 81:413-418.

Chiao CC, Wickiser JK, Allen JJ, Genter B, Hanlon RT (2011) Hyperspectral imaging of cuttlefish camouflage indicates good color match in the eyes of fish predators. PNAS 108:9148-9153.

Darnell MZ (2012) Ecological physiology of the circadian pigmentation rhythm in the fiddler crab Uca panacea. J Exp Mar Biol Ecol 426-427:39-47.

Duarte RC, Flores AAV (2016) Morph-specific habitat and sex distribution in the caridean shrimp Hippolyte obliquimanus. J Mar Biol Assoc UK doi: 10.1017/S0025315416000230 (online). 
Duarte RC, Stevens M, Flores AAV (2016) Shape, colour plasticity, and habitat use indicate morphspecific camouflage strategies in a marine shrimp. BMC Evol Biol 16:218.

Fingerman M (1973) Behavior of chromatophores of the fiddler crab Uca pugilator and the dwarf crayfish Cambarellus shufeldti in response to synthetic Pandalus red pigment-concentrating hormone. Gen Comp Endocr 20:589-592.

Fingerman M, Yamamoto Y (1967) Daily rhythm of melanophoric pigment migration in eyestalkless fiddler crabs, Uca pugilator (Bosc). Crustaceana 12:303-319.

Gamble FW, Keeble FW (1900) Hippolyte varians: a study in colour-change. J Cell Sci 43:589-698.

Gilby BL, Mari RA, Bell EG, Crawford EW, Jun D, Lederer BI, Tibbetts IR, Burfeind DD (2015) Colour change in a filefish (Monacanthus chinensis) faced with the challenge of changing backgrounds. Environ Biol Fish 98:2021-2029.

Gillespie RG (1989) Diet-induced color change in the Hawaiian happy-face spider Theridion grallator (Araneae, Theridiidae). J Arachnol 17:171-177.

Greene E (1996) Effect of light quality and larval diet on morph induction in the polymorphic caterpillar Nemoria arizonaria (Lepidoptera: Geometridae). Biol J Linn Soc 58:277-285.

Hanlon RT, Chiao C-C, Mäthger LM, Barbosa A, Buresch KC, Chubb C (2009) Cephalopod dynamic camouflage: bridging the continuum between background matching and disruptive coloration. Phil Trans R Soc B 364:429-437.

Hultgren KM, Mittelstaedt $\mathrm{H}$ (2015) Color change in a marine isopod is adaptive in reducing predation. Curr Zool 61:739-748.

Hultgren KM, Stachowicz JJ (2010) Size-related habitat shifts facilitated by positive preference induction in a marine kelp crab. Behav Ecol 21:329-336.

Kang C, Kim YE, Jang Y (2016) Colour and pattern change against visually heterogeneous backgrounds in the tree frog Hyla japonica. Sci Rep 6:22601.

Karlsson M, Johansson J, Caesar S, Forsman A (2009) No evidence for developmental plasticity of color patterns in response to rearing substrate in pygmy grasshoppers. Can J Zoolog 87:1044-1051.

Karpestam E, Forsman A (2013) Stable isotopes reveal dietary divergence between dispersal phenotypes in Tetrix subulata pygmy grasshoppers (Orthoptera: Tetrigidae). Eur J Entomol 110:65-70.

Keeble FW, Gamble FW (1899) The colour-physiology of Hippolyte varians. Proc. R. Soc. B 65:461-468. 
Kelman E, Tiptus P, Osorio D (2006) Juvenile plaice (Pleuronectes platessa) produce camouflage by flexibly combining two separate patterns. J Exp Biol 209:3288-3292.

Kettlewell HBD (1955) Selection experiments on industrial melanism in the Lepidoptera. Heredity 9:323342.

Kleinholz LH, Welsh JH (1937) Colour changes in Hippolyte varians. Nature 140:851-852.

Langridge KV, Broom M, Osorio D (2007) Selective signalling by cuttlefish to predators. Curr Biol 17: 1044-1045.

Ligon RA, McCartney KL (2016) Biochemical regulation of pigment motility in vertebrate chromatophores: a review of physiological color change mechanisms. Curr Zool 62:237-252.

Lovell PG, Ruxton GD, Langridge KV, Spencer KA (2013) Individual quail select egg-laying substrate providing optimal camouflage for their egg phenotype. Curr Biol 23:260-264.

Noor MAF, Parnell RS, Grant BS (2008) A reversible color polyphenism in American peppered moth (Biston betularia cognataria) caterpillars. PLoS ONE 3:e3142.

Palma AT, Steneck RT (2001) Does variable coloration in juvenile marine crabs reduce risk of visual predation? Ecology 82:2961-2967.

Poulton EB (1890) The Colours of Animals: Their Meaning and Use. Especially Considered in the Case of Insects. Second Edition. London, Kegan Paul, Trench Trübner, \& Co. Ltd.

Poulton EB (1903) Experiments in 1893, 1894, and 1896 upon the colour-relation between lepidopterous larvae and their surroundings, and especially the effect of lichen-covered bark upon Odontopera bidentata, Gastropacha quercifolia, etc. Trans Entomol Soc Lond 1903:311-374.

Powell BL (1962) The responses of the chromatophores of Carcinus maenas (L. 1758) to light and temperature. Crustaceana 4:93-102.

Rodgers GM, Gladman NW, Corless HF, Morrell LJ (2013) Costs of colour change in fish: food intake and behavioural decisions. J Exp Biol 216:2760-2767.

Ryer CH, Lemke JL, Boersma K, Levas S (2008) Adaptive coloration, behavior and predation vulnerability in three juvenile north Pacific flatfishes. J Exp Mar Biol Ecol 359:62-66.

Shibley GA (1968) Eyestalk function in chromatophore control in a crab, Cancer magister. Physiol Zool 41:268-279.

Stevens M (2016) Color change, phenotypic plasticity, and camouflage. Front Ecol Evol 4:51. 
Stevens M, Cuthill IC (2006) Disruptive coloration, crypsis and edge detection in early visual processing. Proc R Soc B 273:2141-2147.

Stevens M, Lown AE, Denton AM (2014a) Rockpool gobies change colour for camouflage. PLoS ONE 9: e110325.

Stevens M, Lown AE, Wood LE (2014b) Colour change and camouflage in juvenile shore crabs Carcinus maenas. Front Ecol Evol 2:14.

Stevens M, Merilaita S (2011) Animal Camouflage: From Mechanisms to Function. Cambridge, Cambridge University Press.

Stevens M, Pei Rong C, Todd PA (2013) Colour change and camouflage in the horned ghost crab Ocypode ceratophthalmus. Biol J Linn Soc 109:257-270.

Stevens M, Wood LE, Lown AE (2014c) Camouflage and individual variation in shore crabs (Carcinus maenas) from different habitats. PLoS ONE 9:e115586.

Stuart-Fox D, Moussalli A (2009) Camouflage, communication and thermoregulation: lessons from colour changing organisms. Phil Trans R Soc B 364:463-470.

Stuart-Fox D, Moussalli A, Whiting MJ (2008) Predator-specific camouflage in chameleons. Biol Lett 4:326-329.

Todd PA, Qiu W, Chong KY (2009) Ontogenetic shifts in carapace patterning and/or colouration in intertidal and subtidal brachyuran crabs. Raffles B Zool 57:543-550.

Umbers KDL, Fabricant SA, Gawryszewski FM, Seago AE, Herberstein ME (2014) Reversible colour change in Arthropoda. Biol Rev 89:820-848.

Vignieri SN, Larson JG, Hoekstra HE (2010) The selective advantage of crypsis in mice. Evolution 64: 2153-2158.

Wallace AR (1867) Mimicry and other protective resemblances among animals. Westminster Review 1 July, 1-43.

Wente WH, Phillips JB (2003) Fixed green and brown color morphs and a novel color-changing morph of the Pacific tree frog Hyla regilla. Am Nat 162:461-473.

Wilson D, Heinsohn R, Legge S (2006) Age- and sex-related differences in the spatial ecology of a dichromatic tropical python (Morelia viridis). Austral Ecol 31:577-587. 


\section{CHAPTER 2}

Shape, colour plasticity, and habitat use indicate morph-specific camouflage strategies in a marine shrimp

Manuscript published in the journal "BMC Evolutionary Biology"

Duarte RC, Stevens M, Flores AAV (2016) Shape, colour plasticity, and habitat use indicate morph-specific camouflage strategies in a marine shrimp. BMC Evolutionary Biology 16:218.

DOI: 10.1186/s12862-016-0796-8. 


\title{
Shape, colour plasticity, and habitat use indicate morph-specific camouflage strategies in a marine shrimp
}

\author{
Rafael C. Duarte ${ }^{1,2}$, Martin Stevens ${ }^{3}$ and Augusto A. V. Flores ${ }^{1}$ \\ 1 - Centro de Biologia Marinha, Universidade de São Paulo, São Sebastião, Brazil. \\ 2 - Programa de Pós-Graduação em Biologia Comparada, Faculdade de Filosofia, Ciências e Letras de Ribeirão \\ Preto, Universidade de São Paulo, Ribeirão Preto, Brazil. \\ 3 - Centre for Ecology and Conservation, College of Life and Environmental Sciences, University of Exeter, Penryn \\ Campus, Penryn, Cornwall, TR10 9FE. United Kingdom.
}

\section{Abstract}

Colour and shape polymorphisms are important features of many species and may allow individuals to exploit a wider array of habitats, including through behavioural differences among morphs. In addition, differences among individuals in behaviour and morphology may reflect different strategies, for example utilising different approaches to camouflage. Hippolyte obliquimanus is a small shrimp species inhabiting different shallow-water vegetated habitats. Populations comprise two main morphs: homogeneous shrimp of variable colour $(\mathrm{H})$ and transparent individuals with coloured stripes (ST). These morphs follow different distribution patterns between their main algal habitats; the brown weed Sargassum furcatum and the pink-red weed Galaxaura marginata. In this study, we first investigated morph-specific colour change and habitat selection, as mechanisms underlying camouflage and spatial distribution patterns in nature. Then, we examined habitat fidelity, mobility, and morphological traits, further indicating patterns of habitat use. $\mathrm{H}$ shrimp are capable of changing colour in just a few days towards their algal background, achieving better concealment in the more marginal, and less preferred, red weed habitat. Furthermore, laboratory trials showed that habitat fidelity is higher for $\mathrm{H}$ shrimp, whereas swimming activity is higher for the ST morph, aligned to morphological evidence indicating these two morphs comprise a more benthic $(\mathrm{H})$ and a more 
pelagic (ST) life-style, respectively. Results suggest that $\mathrm{H}$ shrimp utilise a camouflage strategy specialised to a limited number of backgrounds at any one time, whereas ST individuals comprise a phenotype with more generalist camouflage (transparency) linked to a more generalist background utilisation. The coexistence within a population of distinct morphotypes with apparently alternative strategies of habitat use and camouflage may reflect differential responses to substantial seasonal changes in macroalgal cover. Our findings also demonstrate how colour change, behaviour, morphology, and background use all interact in achieving camouflage.

Keywords: camouflage strategy, caridean shrimp, polymorphism, geometric morphometrics, colour change, habitat use, life-styles 


\section{Introduction}

Polymorphism is a common trait in many animal taxa (Gray and McKinnon 2007; Mclean and Stuart-Fox 2014) and has been a subject of numerous empirical studies testing several evolutionary theories and hypotheses (e.g. Cain and Sheppard 1954; Kettlewell 1955a; Forsman et al. 2008). Aside from facilitating the exploitation of a wider array of habitats (Van Valen 1965; Hultgren and Stachowicz 2010; Stevens et al. 2014c; Duarte and Flores 2016), polymorphism may also involve a segregation of behavioural traits among morphs, such as related to differences in mating tactics (Sinervo and Lively 1996; Martin and Taborsky 1997) or habitat use (Bourke et al. 1997; Joron 2005). Morph-specific morphological and behavioural traits can allow individuals to more efficiently gather resources and exploit different niches through the diversification and specialisation of life-history strategies (Van Valen 1965; Bolnick et al. 2003; Kusche et al. 2015). Identifying the selective forces responsible for the origins and maintenance of morphs, and unravelling their relative advantages, are important tasks in order to predict population dynamics in varying environments and for understanding evolutionary and developmental strategies (Bond 2007; Magellan and Swartz 2013; Mclean and Stuart-Fox 2014).

One of the most longstanding areas where colour and shape polymorphisms have been studied in nature relates to camouflage (Kettlewell 1955a; Hacker and Madin 1991; Palma and Steneck 2001; Todd et al. 2006; Stevens et al. 2014c). Habitat-specific camouflage of colour morphs may be obtained via a number of mechanisms, whereby behavioural and morphological traits of individuals can interact with environmental characteristics to reduce their relative risk of predation (Forsman and Appelqvist 1998; Karpestam et al. 2012; Kang et al. 2015). For instance, individual appearance for camouflage can be either attained through genetic polymorphism (Nachman et al. 2003; Rosenblum 2006), or through colour change and phenotypic plasticity (Stuart-Fox and Moussalli 2009; Umbers et al. 2014; Stevens 2016). In addition to changes in appearance, camouflage can also be driven by the behavioural 
preferences of individuals to rest on backgrounds that provide enhanced camouflage (Lovell et al. 2013; Kang et al. 2015; Marshall et al. 2016). Evidence of morph-specific behavioural preferences for substrate types has been observed in a variety of taxa, including moths (Kettlewell 1955b), grasshoppers (Ahnesjö and Forsman 2006) and crabs (Hultgren and Stachowicz 2010), and we would expect this to be common if morphs have evolved under selection for camouflage against different substrates. Therefore, camouflage in polymorphic species should be driven by both colour change in line with the predominant visual background, and behavioural preferences for individuals to rest on backgrounds that they match.

The degree to which different morphs can exploit alternative (micro) habitats should depend on how effectively individuals can conceal themselves against the background. Therefore, for species living in heterogeneous substrates, different morphs may be effectively concealed in microhabitats with different background colour patterns within the same general environment (Houston et al. 2007; Karpestam et al. 2013; Magellan and Swartz 2013). In this case, predation by visual consumers may drive disruptive selection leading to individuals specializing in each of the available backgrounds (Merilaita et al. 1999; Bond and Kamil 2006), and/or the ability of some individuals to change colour depending on the patch type they live on (Stuart-Fox and Moussalli 2009; Stevens et al. 2014a; Stevens et al. 2014b). On the other hand, a more generalist fixed strategy may be favoured when optimal colouration is achieved by a compromise in the degree of crypsis obtained in different microhabitats while matching no background very closely (Merilaita et al. 2001; Houston et al. 2007), or through camouflage types that are less restricted to one background type alone (e.g. transparency).

Differential coloration and camouflage strategies may evolve together with both morphological and behavioural traits in polymorphic species (Forsman and Appelqvist 1998; Ahnesjö and Forsman 2006). For example, colour patterns in Midas cichlid fish are correlated to both body shape and life-style, with golden deeper bodied fish mostly associated to the 
benthic habitat, and dark slender individuals exhibiting a more limnetic life-style (Kusche et al. 2015). Also, Dalmatian wall lizards comprise three different colour morphs, with different body and relative head size, which relate to morph-specific trophic niches and cross-habitat distributions (Huyghe et al. 2007). Theory also predicts that morphs with a specialist camouflage strategy would concentrate in habitat patches where concealment is most efficient, increasing substrate fidelity and lowering predation risk (Théry and Casas 2002; Ahnesjö and Forsman 2006). Active preference for these patches may lead to exceptionally high population densities, only constrained by habitat carrying capacity (Diffendorfer 1998), favouring high intra-specific competition, with some individuals being displaced to marginal habitat patches (Pulliam 1988). Alternatively, for individuals with a generalist strategy, in which camouflage is less constrained to a limited number of backgrounds, selection may favour a more opportunistic life-style with individuals possessing differential morphology and behaviour (Herder et al. 2008; Magellan and Swartz 2013). A generalist life-style with lower habitat fidelity and increased mobility may allow individuals to reduce competitive interactions and facilitate more efficient resource exploitation and mate searching (Andersson 1994; Langellotto et al. 2000). Strong specialization, coupled to habitat fidelity, and high mobility associated to a more opportunistic use of resources, can be found in different morphs within populations, and their coexistence is apparently mediated by environmental conditions dictating relative fitness of individuals at different frequencies (Denno et al. 1991; Novotný 1994).

The shrimp Hippolyte obliquimanus is a small gonochoric and polymorphic species (Terossi et al. 2008), very abundant in algal meadows composed of Sargassum furcatum (hereafter Sargassum) and Galaxaura marginata (from now on Galaxaura), the dominant algal species of shallow rocky substrates in the northern coast of São Paulo State, Brazil (Duarte and Flores 2016). Shrimp populations comprise distinct morphs, all belonging to the same species (Terossi and Mantelatto 2010), which can be classified as (i) homogeneous individuals (H) with 
different coloration, most being greenish-brown $\left(\mathrm{H}_{\mathrm{GB}}\right)$ or pink $\left(\mathrm{H}_{\mathrm{P}}\right)$, and (ii) striped translucent shrimp (ST), with either longitudinal or transversal colour bands (Figure 1). Homogeneous shrimp are visually well concealed in both the brown alga Sargassum $\left(\mathrm{H}_{\mathrm{GB}}\right)$ and the reddishpink seaweed Galaxaura $\left(\mathrm{H}_{\mathrm{P}}\right)$, while ST individuals, although found in these same habitats, exhibit less background-specific coloration via the use of transparency (Figure 1).

The natural distribution of $H$. obliquimanus individuals between algal habitats is clearly morph-specific (Duarte and Flores 2016). H individuals tend to occupy colour-matching substrates, i.e. greenish-brown shrimp are more abundant in Sargassum, while pink individuals in Galaxaura, and ST shrimp are equally distributed between these macroalgae (Duarte and Flores 2016). While over a period of days and weeks $\mathrm{H}$ shrimp may be able to change colour to different substrate types (see below), at any one time they should be restricted to one matching background type alone, and hence we consider them background specialists (but note that over time they may be considered generalists). Mismatching shrimp, i.e. $H_{G B}$ in Galaxaura or $\mathrm{H}_{\mathrm{p}}$ in Sargassum, are very probably individuals that arrived from a different habitat and had not yet adjusted to local background. In contrast, ST individuals may adopt more generalist background choice behaviour and a camouflage type (transparency) that allows concealment to a range of substrate types. Sex proportions are also different between morphs, with $\mathrm{H}$ shrimp being chiefly females and ST mostly males, suggesting that selection for sex-specific traits may be also important in explaining the maintenance of polymorphism in this species (Duarte and Flores 2016). Morph-specific habitat and sex distribution may indicate the existence of behavioural differences between morphotypes (Merilaita and Jormalainen 1997; Ahnesjö and Forsman 2006), possibly related to contrasting strategies of habitat use. In the case of $\mathrm{H}$. obliquimanus, cryptic behaviour is expected to be selected in $\mathrm{H}$ shrimp, with individuals remaining on colour-matching backgrounds, and a more general life-style is anticipated for transparent ST individuals, which would move more frequently among different substrate types. 


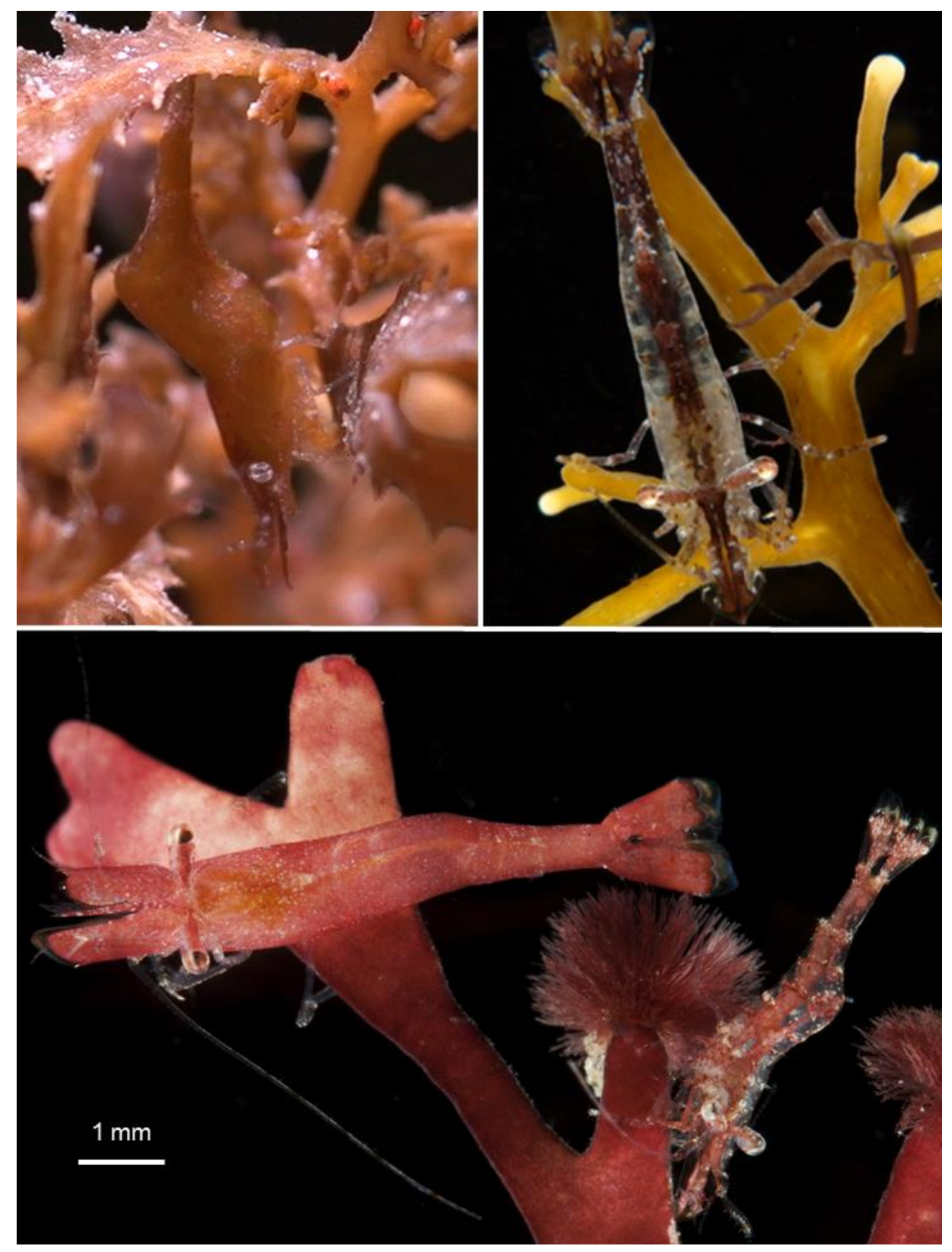

Fig. 1 Hippolyte obliquimanus colour morphs. Homogeneous $(\mathrm{H})$ individuals characterized by a greenish-brown $\left(\mathrm{H}_{\mathrm{GB}}\right.$ : top-left shrimp) or pink ( $H_{p}$ : bottom-left shrimp) coloration attaining a good colour match in the brown algae Sargassum furcatum and the red-pink weed Galaxaura marginata, respectively. Striped translucent (ST) individuals bearing longitudinal colour bands (top-right and bottom-right shrimp), showing a general resemblance to both algae.

In this study, we used a combination of laboratory manipulative experiments, supported by geometric morphometric analyses, to test the hypothesis that colour morphs of $H$. obliquimanus differ in specific behavioural traits and morphology related to strategies of camouflage and habitat use (namely Sargassum and Galaxaura canopy). We first examined two potential mechanisms by which individuals can enhance crypsis: habitat selection and 
colour change. We undertook experiments of behavioural habitat selection to test whether morphs actively select the background-matching macroalgal habitat where concealment is more effective. Then, we performed a colour change experiment to investigate if the capacity of colour change differs between morphs and habitats. Because carapace shape can be a proxy for life-style and habitat use in caridean shrimps, with stout forms being an indicative of benthic life-style and more streamlined shapes of a more pelagic behaviour (Sardà et al. 2005; Aguzzi et al. 2009), we used geometric morphometric analyses and carried out experiments of habitat use to verify whether morphological evidence correlates with behavioural patterns. Together, the results of this study evidenced a link among coloration, morphological, and behavioural traits, illustrating how polymorphism can be advantageous to individuals achieve different camouflage strategies when living in a heterogeneous habitat.

\section{Methods}

\section{General procedures}

Samples of the macroalgae Sargassum and Galaxaura were collected during the summer and autumn of 2011, 2013 and 2015 by skin diving at rocky bottoms in different sites along the São

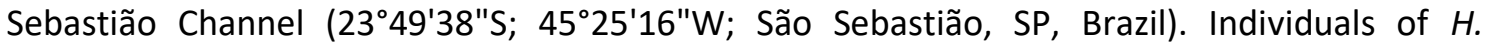
obliquimanus were sorted out from the macroalgae (as in Duarte and Flores 2016), visually classified as $\mathrm{H}_{\mathrm{GB}}, \mathrm{H}_{\mathrm{P}}$ or $\mathrm{ST}$, and used in laboratory experiments to compare morph-specific algal preferences, colour change capacities and behaviour. We validated this visual classification by running a discriminant function analysis (DFA), using the 'Ida' function from the package MASS in $R$ (Venables and Ripley 2002), on random samples of individuals initially classified as $H_{G B}$ and $H_{P}(n=10)$, to which colour reflectance values in image RGB colour channels were measured (as described below in 'Colour change and camouflage'). DFA scores for these morphs were discrete and non-overlapping (DFA scores: $-5.54<\mathrm{H}_{\mathrm{GB}}<-2.46 ; 2.13<\mathrm{H}_{\mathrm{P}}<5.12$ ) indicating that misclassifications were very unlikely. 
Individuals were first acclimated to laboratory conditions for three days and kept in indoor tanks, with their original plant hosts, at ambient temperature and with filtered running seawater and artificial aeration. At the start of the experiments, shrimp were transferred to rectangular plastic aquaria $(30 \times 20 \times 10 \mathrm{~cm})$ and maintained at nearly constant temperature $\left(25^{\circ} \mathrm{C}\right)$. In all experiments, the position of aquaria assigned to different experimental treatments was randomly chosen to avoid potential artefacts due to uncontrolled spatial variation of any physical variables within the laboratory room.

\section{Algal preference}

General procedures followed standard protocols for multiple-choice tests (e.g. Hacker and Steneck 1990; Poore and Steinbenrg 1999). Algae were supplied in equivalent quantities (20 $\mathrm{ml}$ ) as single clumps anchored to opposite corners of the aquaria ( $n=12$ for each morph). Fifteen individuals $\left(\mathrm{H}_{G B}, H_{P}\right.$, or $\left.S T\right)$ were added to the centre of each aquarium and, after 3 days, algae were carefully enclosed in dip nets and the number of living shrimp counted. As a response variable, we used the difference between the shrimp found at Sargassum and Galaxaura, divided by the total number of shrimp remaining alive at the end of the experiment, to account for mortality $(2.8$ shrimps \pm 0.3$)$. These preference indices were compared among morphs using a 1-way ANOVA. The Student-Newman-Keuls (SNK) procedure was used for a posteriori comparisons. Confidence intervals (95\%) were additionally calculated for each morph.

\section{Colour change and camouflage}

Previous observations indicated that the capacity of colour change differs between shrimp morphs, with $\mathrm{H}$ individuals visually changing their body colour in few days when exposed to an unmatched algal habitat, and ST shrimp being unable to change their coloration in the same period (Duarte and Flores 2016). In this study we restricted further and more detailed analyses of colour change to the $\mathrm{H}$ morph. We cannot discard long-term colour shifts in ST shrimp, but 
because transparent individuals are typically characterized by a much reduced number of colour cells and pigments along the body, as observed in the closely related species Hippolyte varians (Gamble and Keeble 1900) and Heptacarpus pictus (Bauer 1981), their eventual reorganization would likely respond to a different physiological process (Stevens 2016), acting over longer time-scales (weeks or months - Umbers et al. 2014; Stevens 2016).

Here, we conducted an experiment to quantify colour change and camouflage in the plastic morph $(\mathrm{H})$, exposing individuals of varying coloration (greenish-brown and pink) to different algal habitats and artificial substrates. By doing this, we aimed to (i) test whether short-term colour changes are possible on these substrates, (ii) examine if the mechanisms controlling colour change in this species depend on visual information or diet by keeping individuals on either artificial or natural substrates, with food resources only available in the latter, and (iii) compare the efficiency of colour alteration to provide camouflage in morphs exposed to colour matched and unmatched backgrounds. Although we acknowledge that it would have been ideal to do so, colour metrics were not quantified before the trials because handling of these small and fragile shrimp could likely alter their behaviour and cause excessive mortality. We therefore used the final colour of shrimp kept against a matching background as their standard in nature. This assumption was tested by comparing hue values (see below) between experimental shrimp on matching backgrounds with shrimp freshly collected in the field $(n=$ 10 for each morph); i.e. experimental $H_{G B}$ on Sargassum vs. natural $H_{G B}$, and experimental $H_{P}$ on Galaxaura vs. natural $\mathrm{H}_{\mathrm{p}}$.

Image analyses - We measured colour for individual algae and shrimp in all experimental treatments using digital image analyses, which provides a powerful and non-invasive approach to quantify animal coloration (Stevens et al. 2007). A Nikon Coolpix P5000 camera, coupled to a stereomicroscope and a constant white light source of 3,200 K colour temperature, was used to obtain all images. Samples were photographed using manual white balancing and exposure settings to avoid colour saturation (Stevens et al. 2007), followed by photographs of one 
standard grey card (Color Checker Passport, X-Rite), reflecting light equally at 35\% between 400 and $750 \mathrm{~nm}$, using the same camera settings, as required by the sequential method of calibration (Stevens et al. 2009). Before obtaining colour data, each image was linearised to control for changes in light intensity using a set of six grey references from the colour checker chart (Color Checker Passport, X-Rite), based on the methods described by Westland and Ripamonti (2004) and Stevens et al. (2007). This procedure was necessary because many digital cameras show non-linear responses of image values to changes in light levels that need to be corrected before obtaining accurate data. The camera responses were also equalised in relation to the $35 \%$ standard grey card to control for changes in the illuminating light conditions. Finally, images were scaled to reflectance values in red (longwave; LW), green (mediumwave; MW), and blue (shortwave; SW) layers (an image value of 255 on an 8-bit scale is equal to $100 \%$ reflectance; Stevens et al. 2007).

For each shrimp or algal image, we measured regions of interest (ROIs) and sampled the values of reflectance in the red, green, and blue channels (RGB) using the program ImageJ (Rasband 1997). For shrimp images, we selected one square $\left(1.5 \mathrm{~mm}^{2}\right)$ on the abdominal region of individuals, between somites 2 and 3, where colour is particularly uniform, and for algal images we selected the entire frond outline (approx. $50 \mathrm{~mm}^{2}$ ). For shrimp data, we obtained values of colour (hue), which was calculated as the red / green ratio, broadly analogous to the general principle of an opponent colour channels, whereby colour types are encoded by antagonistic neural pathways (Osorio et al. 1999; Stevens 2011) and similar to other past studies (Spottiswoode and Stevens 2011; Stevens et al. 2014a). Red, grey, and green tones would provide hue values $>1.0, \approx 1.0$ and $<1.0$, respectively. The use of this metric does not depend of any specific visual system or predator group (Stevens 2011), allowing us to analyse colour in terms of the physical properties of each shrimp in an intuitive way.

Colour change - We prepared two replicate aquaria for each treatment combination of 'morph' $\left(H_{G B}, H_{P}\right)$ and 'background colour' (brown, pink). Parallel trials were run using $20 \mathrm{ml}$ 
substrates of either natural (brown Sargassum and pink Galaxaura) or artificial background (assembled stripes of brown and pink plastic tape), summing up 16 experimental units. Artificial substrates matched algal tones as closely as possible, while providing intermediate habitat architecture between the highly intricate Sargassum matrix and the smoother Galaxaura habitat. Seven to eight shrimp were initially added to each of these aquaria, with individuals maintained in artificial substrates supplied pellet shrimp food daily. Air pumps ensured adequate water circulation and aeration. In all treatments, individuals were recovered after 5 days, immediately frozen (a procedure that did not alter their colour), and later photographed to obtain colour values. A few shrimp were lost (possibly owing to mortality) and we had to reduce sample size to the minimum number of individuals found across aquaria ( $n=5$, for both parallel trials using natural and artificial substrates), ensuring a balanced design. Excess individuals from remaining aquaria were randomly excluded from analyses. To test the ability of individuals to change colour, we compared hue values separately for each experiment (natural or artificial substrates) using a mixed three-factor ANOVA in which factors 'morph' ( $\mathrm{H}_{\mathrm{GB}}$ or $\mathrm{H}_{\mathrm{P}}$ ) and 'substrate colour' (brown or pink) were fixed and orthogonal, and the factor 'aquaria', with two levels, was random and nested in the interaction between main factors. The Student-Newman-Keuls (SNK) procedure was used for a posteriori comparisons.

Camouflage - We also aimed to quantify the efficiency of colour change to provide camouflage against both algae. For that, we compared the final colour of shrimp reared in the different experimental treatments to the actual colour of both Sargassum and Galaxaura. We first standardised the reflectance data in the three colour channels (RGB) of shrimp and algae and then converted these values to $\mathrm{x}$ and $\mathrm{y}$ coordinates in a trichromatic colour space (Kelber et al. 2003). Colour departures were calculated as the Euclidian distances between coordinates of replicate shrimp and algae. Replicate algal coordinates $(n=20)$ were randomly split in two groups, to provide independent and balanced distance estimates between algae and shrimp for each morph. We used $t$-tests, corrected for heteroscedasticity when needed, to compare 
colour coordinates of each shrimp morph against the colour of both algae, predicting that shrimp colour would be closer to the colour of their rearing background than to the colour of the alternative algal background.

\section{Morphological and behavioural differences between morphs}

Intraspecific plasticity of body shape, which substantially affects hydrodynamics, is commonplace in a variety of aquatic invertebrates and fish, and may indicate differential patterns of habitat use and behaviour (Sardà et al. 2005; Aguzzi et al. 2009; Chapman et al. 2015; Kusche et al. 2015). Because H and ST morphs were differently distributed between algal habitats and possibly subjected to distinct selective forces (Duarte and Flores 2016), we predict that $H$. obliquimanus individuals will exhibit morph-specific shape, with possible consequences on shrimp behaviour and life-style. Since homogeneous individuals can change their colour in just a few days (see Results), we pooled the $H_{G B}$ and $H_{P}$ categories together in a single group $(\mathrm{H})$ for follow-up comparisons on morphology and behaviour.

Morph-specific shape - We used geometric morphometric analyses to compare carapace shape differences between morphs. Analyses were restricted to males to eliminate any variability owing to sexual dimorphism. Twenty-one $\mathrm{H}$ and $25 \mathrm{ST}$ individuals were sorted from samples of Sargassum and Galaxaura collected in the São Sebastião Channel (as in Duarte and Flores 2016). Shrimp were fixed in $70 \%$ ethanol, stained with rose bengal, and their left carapace side was photographed using a Nikon Coolpix P5000 camera, coupled to a stereomicroscope set at a magnification power of $10 \mathrm{X}$.

Nine landmarks were defined along the margin of the carapace as follows; 1 : eye orbit, 2 : rostral tip, 3: first dorsal spine, 4: mid-dorsal margin, vertically opposed to landmark 8, 5: posterior dorsal edge, 6: posterior lateral tip, 7: distal ventral margin, vertically opposed to landmark 5, 8: ventral-most point, opposite to landmark 4, 9: ventral insertion point of the antennule. Landmarks were defined using the software tpsDig 2.14 (Rohlf 2009), following 
standardized criteria (Zelditch et al. 2004). Landmark alignment and the acquisition of shape variables, both uniform components (UCs) and relative-warps (RWs), were carried out following the procedures described by Zelditch and co-workers (Zelditch et al. 2004), using the software tpsRelw 1.46 (Rohlf 2008).

The values of UCs and RWs were separately compared between $\mathrm{H}$ and ST individuals, using multivariate analysis of variance (MANOVA). Centroid size (CS), i.e. the square root of the summed squared distances between all landmarks and the carapace centre of gravity (centroid), was used as a size variable and compared between colour morphs with a $t$-test.

Habitat fidelity and mobility - We compared substrate fidelity and individual mobility between morphs in a simple laboratory experiment. Trials were performed in plastic rectangular aquaria $(30 \times 20 \times 10 \mathrm{~cm})$ provided with a longitudinal flow of $2 \mathrm{l} / \mathrm{min}$ containing a single Sargassum clump (40 $\mathrm{ml}$ ) attached to the upstream end, and 20 shrimps, $10 \mathrm{H}_{\mathrm{GB}}$ and $10 \mathrm{ST}$, at the opposite downstream side. We used only Sargassum as habitat in this experiment because this is the algal type supporting the highest shrimp density in the study area (Duarte and Flores 2016), and also because this is the preferred habitat of these colour morphs (see Results). The same experimental setup was replicated five times and, in each trial, all individuals were morph identified (Additional information, Figure S1) and monitored using a video camera (Sony HDRXR250) for 30 minutes. Five three-minute video samples were selected for analyses, starting at time 1.5 min and taken at every other 3 min intervals, thus providing samples centred at times 3, 9, 15, 21 and $27 \mathrm{~min}$. For each video sample we separated 90 frames (one every two seconds) for analyses. Habitat fidelity was estimated as the percentage of shrimp on algae at frame 45 (at the mid of each sample). In order to quantify mobility, we tracked the position of each shrimp remaining out of algae through all the 90 frames for each period and calculated total travelled distances. These analyses were undertaken using the software ImageJ.

The proportion of shrimp settled on algae was used as a proxy of shrimp habitat fidelity. Between-morph comparisons of these proportions, at different times, were examined using 
repeated-measures ANOVA because data from the same aquaria are dependent on time. Raw data were used since the sphericity assumption was met $(W=0.089 ; p=0.078)$. Mobility of individuals was first estimated by comparing individual travelled distances between $\mathrm{H}$ and ST shrimp using Mann-Whitney tests. Comparisons on ranks did not detect differences between morphs (69.5 $<U<396.5, p>0.05$ for all sampled periods) because most individuals (72\%) moved very little around their initial positions, typically less than $2 \mathrm{~cm}$. Therefore, we proceeded by comparing mobility of the fewer remaining shrimp that did swim considerable distances. Since these were outliers within the whole population (based on an outlier coefficient, $k$, of 2.0), we first subtracted swimming distances by baseline movement at their respective sampling period, i.e. the upper fence for non-outlying data. These corrected swimming distances were considered independent records and compared between morphs using a $t$-test.

\section{Results}

\section{Algal preference}

Shrimp colour morphs exhibited different preferences for algal substrates (ANOVA: $F_{(2,33)}=$ $6.84, p=0.003)$. When equal volumes of the two algal types were made simultaneously available to shrimp, both $\mathrm{H}_{\mathrm{GB}}$ and ST morphs showed higher preference towards Sargassum, compared to $H_{p}$ individuals (SNK tests, $p<0.01$ ). Confidence intervals $(95 \%)$ indicate net preference for the brown weed for $\mathrm{H}_{\mathrm{GB}}$ and ST but not for $\mathrm{H}_{\mathrm{p}}$ shrimp (Figure 2). 


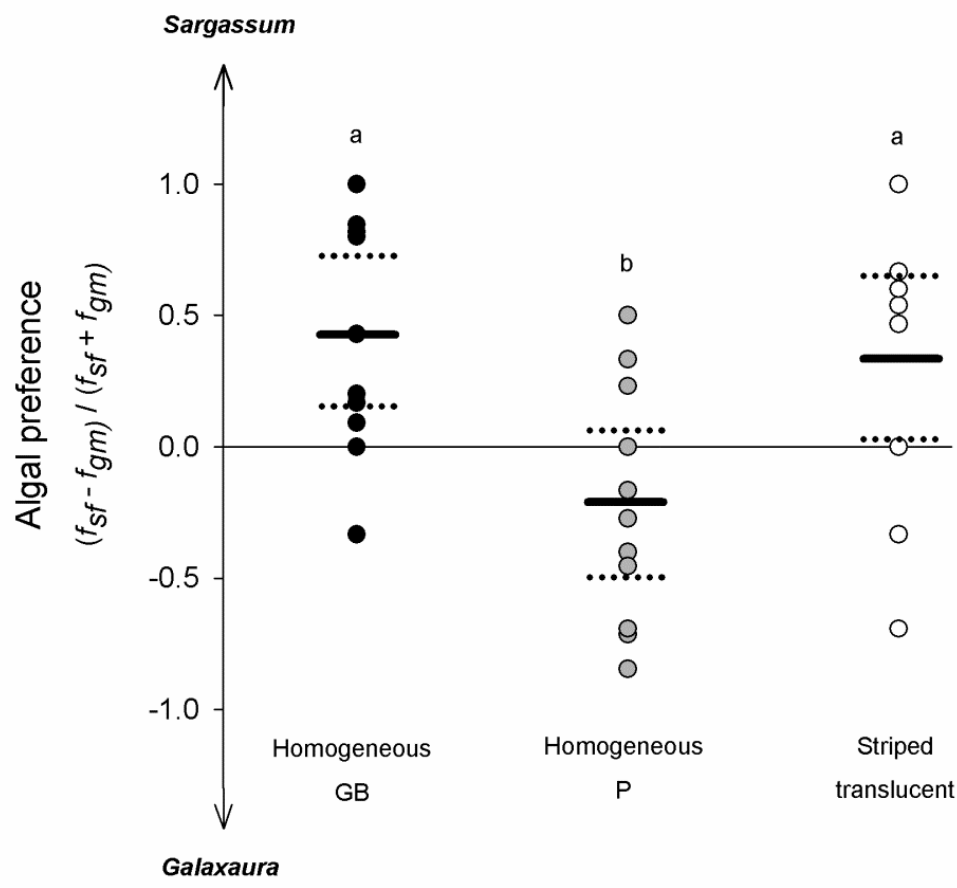

Fig. 2 Algal preference of homogeneous (greenish-brown; GB and pink; P) and striped translucent colour morphs. $\mathrm{f}_{\mathrm{sf}}$ and $\mathrm{f}_{\mathrm{gm}}$ stand for the frequencies of shrimp occupying Sargassum furcatum and Galaxaura marginata fronds at the end of trials. Solid and dashed black lines denote mean values and $\pm 1 \mathrm{Cl}$ (95\%) respectively. Different letters indicate statistical differences among morphs $(p<0.05)$.

\section{Colour change and camouflage}

Hue values of shrimp held on matching backgrounds are regarded as natural standards, since they did not significantly differ from hue values of respective counterparts in the field (experimental $\mathrm{H}_{\mathrm{GB}}$ in Sargassum vs. natural $\mathrm{H}_{\mathrm{GB}}$ : $t_{18}=0.52, p=0.609$; experimental $\mathrm{H}_{\mathrm{P}}$ in Galaxaura vs. natural $\left.\mathrm{H}_{\mathrm{p}}: t_{18}=0.86, p=0.401\right)$. It is thus concluded that homogeneous shrimp $\left(H_{G B}\right.$ and $\left.H_{P}\right)$ exposed to unmatched algal habitats were capable of pronounced colour change over the 5-day periods during which trials were undertaken (Table 1, Figure $3 \mathrm{~A})$.

Colour change was very clear in natural algal substrates but not in artificial ones. $H_{G B}$ individuals increased their hue values after being in contact with the red alga Galaxaura, attaining a reddish coloration, and $\mathrm{H}_{\mathrm{p}}$ shrimp showed the opposite pattern when placed in Sargassum, achieving at the end of the experiment a brownish tone (Figure $3 \mathrm{~A}$ ). As a result, 
hue differences between shrimp morphs, within each algal habitat, disappeared at the end of the trial (Figure 3a; SNK tests, $p>0.05$ ). However, shrimp reared in artificial substrates retained morph-specific hue (thus the significance of 'morph', Table 1), with no changes toward background colour (Table 1; Figure 3B). Hue differences between morphs persisted both in brown (SNK test, $p<0.05$ ) and pink (SNK test, $p<0.01$ ) artificial substrates (Table 1$)$.

Table 1 - Summary results of the mixed three-way analyses of variance testing the effects of morph type (M; greenish-brown or pink), substrate colour ( $S_{c}$; brown or pink) and aquaria (nested in the interaction between main factors) in final hue values measured in Hippolyte obliquimanus individuals after being maintained for five days in artificial or algal substrates.

\begin{tabular}{|c|c|c|c|c|c|c|c|}
\hline \multirow[b]{2}{*}{ Source of variation } & \multirow[b]{2}{*}{$d f$} & \multicolumn{3}{|c|}{ Algae } & \multicolumn{3}{|c|}{ Artificial substrates } \\
\hline & & MS & $F$ & $p$ & MS & $F$ & $p$ \\
\hline Morph (M) & 1 & 0.170 & 0.92 & 0.392 & 3.750 & 44.13 & 0.0027 \\
\hline Substrate Colour $\left(\mathrm{S}_{\mathrm{C}}\right)\left(\mathrm{S}_{\mathrm{C}}\right)$ & 1 & 8.636 & 46.56 & 0.002 & 0.298 & 3.51 & 0.1342 \\
\hline $\mathrm{M} \times \mathrm{S}_{\mathrm{C}}$ & 1 & 0.069 & 0.37 & 0.574 & 0.217 & 2.55 & 0.1854 \\
\hline Aquaria $\left(\mathrm{M} \times \mathrm{S}_{\mathrm{C}}\right)$ & 4 & 0.186 & 1.07 & 0.388 & 0.085 & 0.65 & 0.6322 \\
\hline \multirow[t]{2}{*}{ Error } & 32 & 0.174 & & & 0.131 & & \\
\hline & & \multicolumn{3}{|c|}{$C=0.247 ; n s$} & \multicolumn{3}{|c|}{$C=0.240 ; n s$} \\
\hline
\end{tabular}

C: Cochran statistic; $n s$ : not-significant

Although both shrimp morphs were capable of changing colour when exposed to unmatched natural backgrounds, the effectiveness of this change in promoting camouflage depended on the algal type shrimp were been placed on. Overall results suggest that colour camouflage is more efficient in the pink alga Galaxaura. $\mathrm{H}_{\mathrm{GB}}$ shrimp reared in Sargassum ended up with a coloration equally distant from Sargassum and Galaxaura (Figure 4A; two sample $t$ test: $\left.t_{(18)}=1.85, p=0.080\right)$. However, when $\mathrm{H}_{\mathrm{GB}}$ individuals were placed in the unmatched Galaxaura background they were capable of changing their colour remarkably well, becoming 
quite close to Galaxaura, and very different from the Sargassum background (Figure 4A; two sample $t$-test: $\left.t_{(18)}=7.16, p<0.001\right)$. Very similar outcomes were observed for $\mathrm{H}_{\mathrm{p}}$ shrimp. When individuals were placed on Sargassum, they did change colour but ended with values equidistant from both algal types (Figure 4B; two sample $t$-test: $t_{(18)}=0.91, p=0.114$ ), indicating poor camouflage. When reared on the matching substrate Galaxaura, the final colour of individuals was again very similar to Galaxaura but distant to Sargassum (Figure 4B; two sample $t$-test: $\left.t_{(18)}=4.63, p<0.001\right)$.

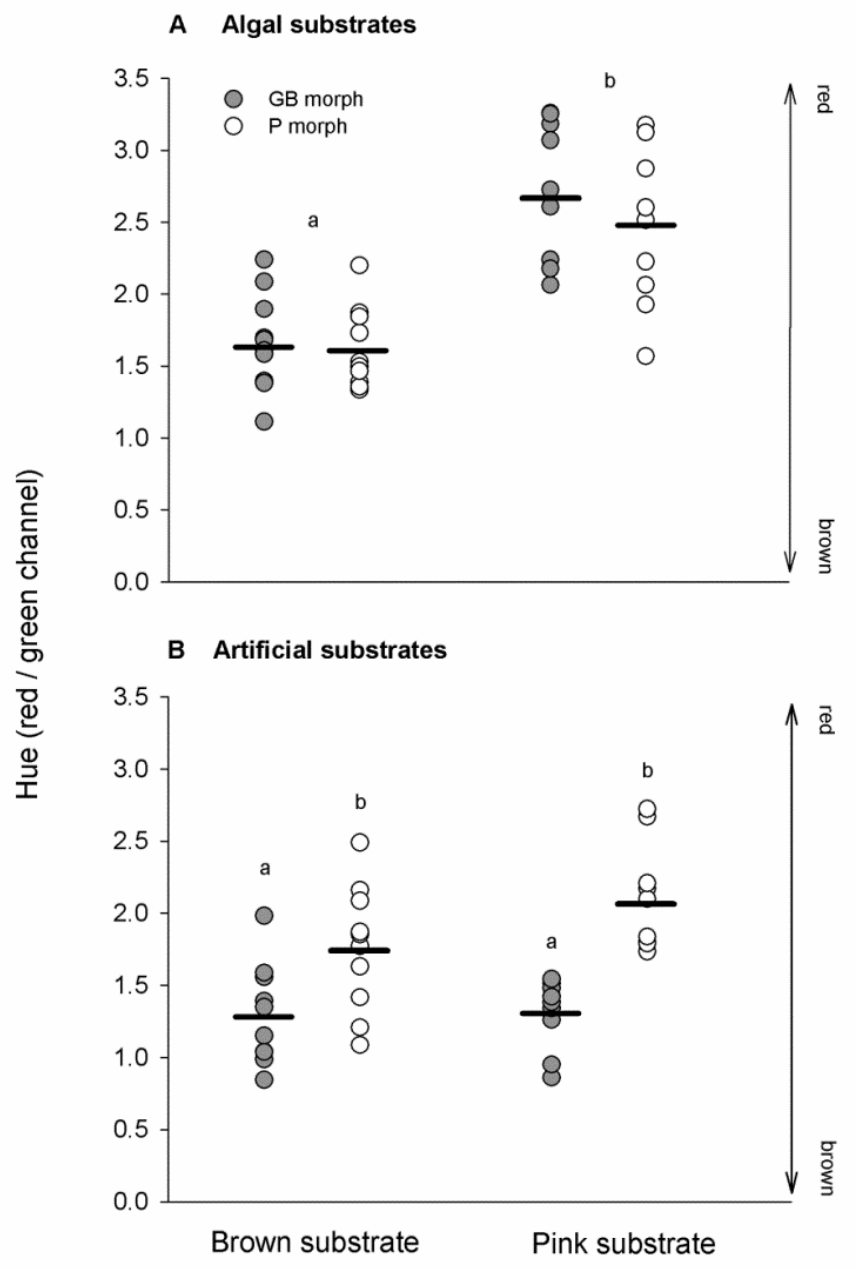

Fig. 3 Colour change in homogeneous greenish-brown (GB) and pink (P) individuals when exposed to (A) algal and (B) artificial substrates of brown and pink-red coloration for five days. Data from different aquaria, in each combination of 'morph' and 'substrate colour', were pooled. Final shrimp colour (hue) was defined as the ratio between reflectance in the red and green colour channels. Higher hue values correspond to reddish tones. Mean values are denoted by solid black lines and different letters indicate significant statistical differences between groups $(p<0.05)$. 

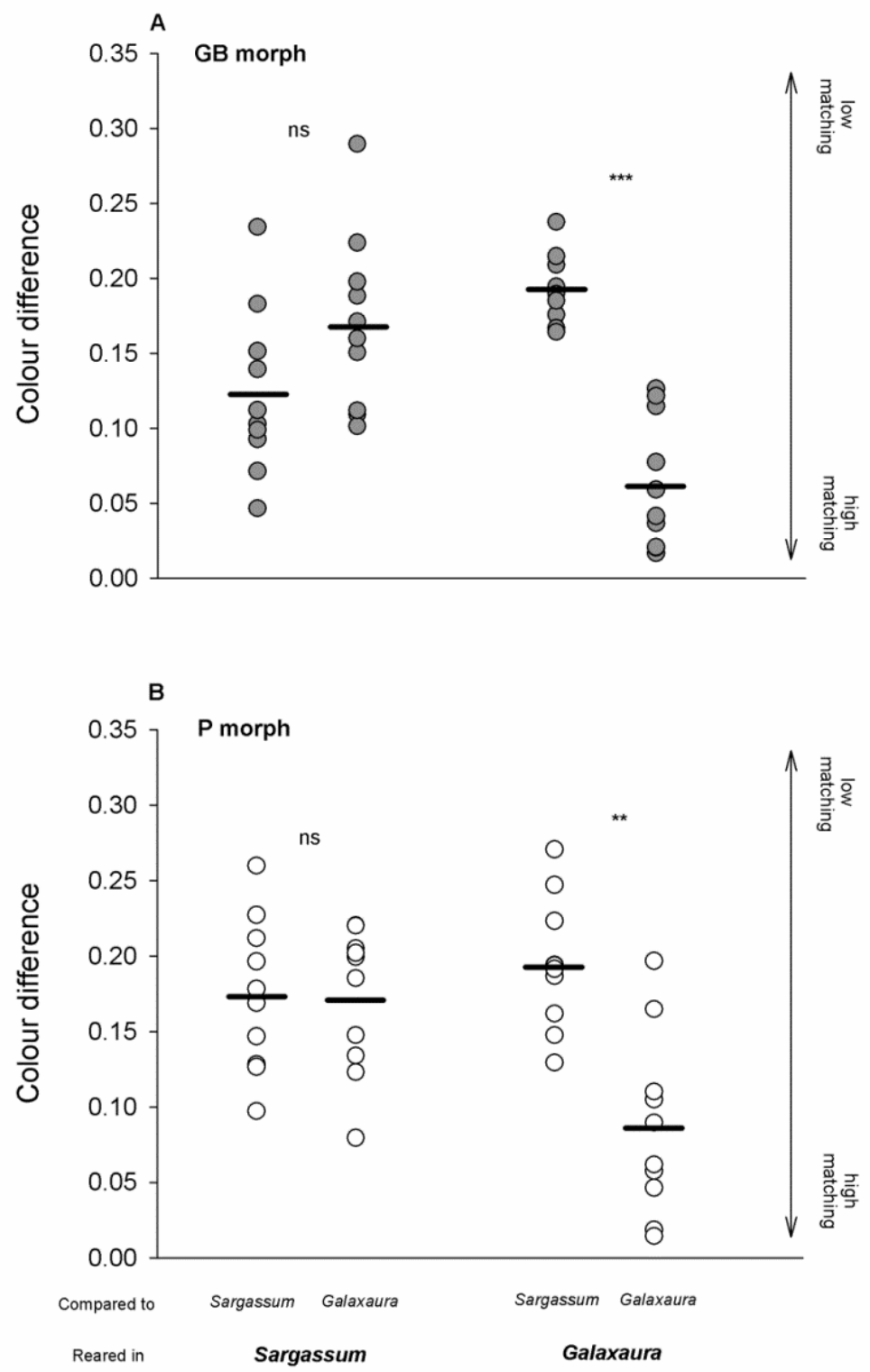

Fig. 4 Colour differences between (A) homogeneous greenish-brown (GB) and (B) homogeneous pink (P) shrimp and the algae Sargassum and Galaxaura, for groups of individuals reared for five days in each of these substrates. Colour differences were defined as the Euclidian distance between standardised colour coordinates in a trichromatic reflectance colour space of shrimp and algae. Solid black lines represent mean group values. ${ }^{* *} p<$ $0.01 ; * * *<0.001 ; n s:$ not-significant.

\section{Morph-specific morphological and behavioural patterns}

Morph-specific shape - Centroid size did not vary between homogeneous and striped translucent males (two sample $t$-test: $t_{(44)}=1.10, p=0.277$ ), i.e. $\mathrm{H}$ and ST shrimp were of similar size. However, shape differences were clear. Fourteen shape variables (relative warps - 
RWs; i.e. axes showing major trends of localised shape variation - Zelditch et al. 2004) were obtained, with the three most important ones explaining $63 \%$ of the whole overall shape variation. MANOVA results, applied to all relative warps axes, indicated shape contrasts between colour morphs (MANOVA Wilks test: $F_{(14,31)}=3.60, p=0.001$ ). Of greatest importance was RW1, accounting for the greatest percentage variance $(30.4 \%)$ and clearly segregating morphs. $\mathrm{H}$ shrimp were mostly distributed along the negative side of RW1, which corresponds to a stouter carapace shape, while ST individuals were mostly distributed along the positive side of the axis, corresponding to a streamlined carapace shape (Figure 5A). A MANOVA analysis applied to the two uniform components (UCS) further suggested a difference between colour morphs (MANOVA Wilks test: $F_{(2,43)}=4.82, p=0.013$ ). As RW1, UC1 explained almost all morphological variation between morphs. Such a component refers to uniform contraction / expansion of the whole body, and segregated $\mathrm{H}$ shrimp at the negative axis half (carapace dorso-ventrally expanded), and ST individuals at the positive one (carapace dorso-ventrally compressed).

Habitat fidelity and mobility - Substrate fidelity was markedly different between $\mathrm{H}$ and ST shrimp over time (repeated-measures ANOVA: $F_{(4,32)}=2.77, p=0.044$; Figure $5 \mathrm{~B}$ ). At the beginning of the experiment ( 3 minutes), the proportion of individuals found on algal clumps was low, but virtually the same for each morph. The number of shrimp using the algal habitat tended to increase through time, but the rate at which they stopped swimming and settled on algae differed between $\mathrm{H}$ and ST shrimp. At 9 minutes, differences were already noticeable, increasing thereafter to statistical significance. At the end of the experiment (27 minutes), $78 \%$ of $\mathrm{H}$ shrimp but only $57 \%$ of ST individuals had settled on algae (Figure 5B).

Mobility above baseline activity was restricted for a small fraction of the population and decreased from $12 \%$ to $6 \%$ over the experiment (Figure $5 \mathrm{C}$ ). Most of these swimming individuals were ST shrimp (61\%). Considering all sampled periods, average mobility was higher in ST (15.2 cm.shrimp $\left.{ }^{-1} \cdot \mathrm{min}^{-1}\right)$ than in $\mathrm{H}$ shrimp $\left(5.20 \mathrm{~cm} \cdot \mathrm{shrimp}^{-1} \cdot \mathrm{min}^{-1}\right.$; two-sample $t$ - 
test: $\left.t_{(17)}=2.20, p=0.043\right)$. It is also important to note that swimming events over distances larger than $25 \mathrm{~cm}$ each minute $(n=5)$ were only recorded for ST shrimp (Figure 5C).

\section{Discussion}

We report contrasting behavioural and morphological patterns in colour morphs of the shrimp Hippolyte obliquimanus, suggesting a diversification of life-styles between morphs which can be linked to alternative camouflage strategies. Our results indicate that $\mathrm{H}$ shrimp are capable of fast colour change, with different colour types concealed in distinct macroalgal habitats. Individuals of this morph are also tightly connected to their benthic habitat, avoiding long-distance swimming away from their host algae, which explains why they concentrate in exceptionally high densities in the brown weed Sargassum (Duarte and Flores 2016). All these features suggest that this morph presents a specialist camouflage strategy, achieved by concealment to a specific background type (at any given point in time, although individuals can change colour over time). In contrast, ST shrimp cannot rapidly adjust their colour to their background environment, and also show low habitat fidelity and substantial swimming activity, indicating a more pelagic life-style. These characteristics are in accordance to their uniform distribution between Sargassum and Galaxaura, the two main vegetated habitats in the study region (Duarte and Flores 2016), suggesting a generalist habitat use linked to a camouflage strategy achieved by transparency. It is noteworthy that the results of experiments on behavioural patterns are consistent with morphological analyses, indicating a more benthic life-style for $\mathrm{H}$ shrimp and a more pelagic habit for ST shrimp, encompassing an important range of the morphological variation found in caridean shrimp (Sardà et al. 2005; Aguzzi et al. 2009). 

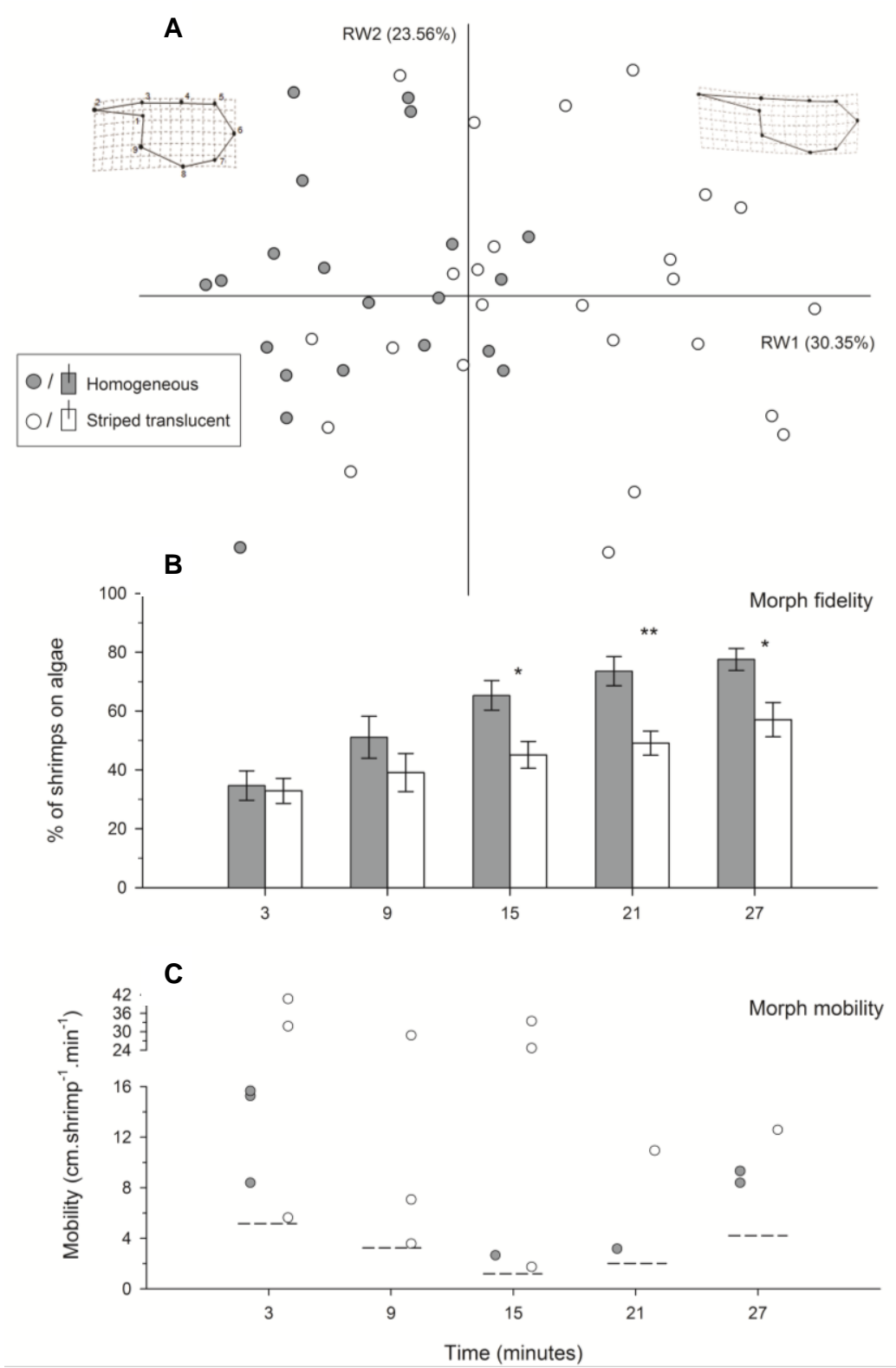

Fig. 5 Proxy variables indicating different life-styles in homogeneous $(\mathrm{H}$; in grey circles or bars) and striped translucent morphs (ST; in white circles or bars). (A) Carapace shape differences based on geometric morphometric results. Morphotypes are clearly segregated along the first relative warp axis, from a stout carapace outline representative of $\mathrm{H}$ individuals, to a more streamlined shape found in ST shrimp. Percentage values represent the relative warps share of the total morphological variation. Dots along carapace margins show the position of landmarks used in the analysis (see Methods). (B) Substrate fidelity of morphs, over 30 minutes experimental trials, expressed as the percentage of individuals settled on algal clumps. Whiskers represent $+1 \mathrm{SE} .{ }^{*} p<0.05 ;{ }^{* *} p<$ 0.01. (C) Morph-specific mobility, expressed as individual average swimming distances (in $\mathrm{cm}$ ) per minute, over 30 minutes experimental trials. Measurements for mobile shrimp are outliers (filled circles) from baseline movement of sedentary individuals. Dashed lines represent the upper fence delimiting the non-outlier range (see Methods for details). 
Colour change in $\mathrm{H}$ shrimp was observed upon contact with living algal habitats, but not artificial substrates, indicating the process of colour change in this species, and possibly in many other algal-dwelling isopods (Hultgren and Mittelstaedt 2015), decapods (Gamble and Keeble 1900; Hultgren and Stachowicz 2010) and fish (Stepien 1986), relies, at least in part, on substrate-individual interactions. In fact, some authors have shown that the ingestion of carotenoid pigments can promote colour change in other crustaceans (Chien and Jeng 1992; Tlusty and Hyland 2005), typically over a longer period (weeks) than observed in this study. Note that this does not discount a role of visual feedback, and future work should independently change diet and visual appearance to tease apart these effects.

Colour change may be a faster process for small crustaceans shedding thin translucent exuviae (own observations) than large ones, because pigment reorganization in hypodermic colour cells may be readily visible, as observed for another hippolytid shrimp species (Gamble and Keeble 1900). Colour change in $\mathrm{H}$ shrimp strongly suggests a camouflage strategy by background matching, whereby individuals' overall body colour, colour pattern, and brightness tend to resemble the general background (Merilaita and Stevens 2011). However, we observed H shrimp concealed better on the pink Galaxaura than on the brown Sargassum. In Sargassum, $\mathrm{H}_{\mathrm{GB}}$ and $\mathrm{H}_{\mathrm{P}}$ ended up with an intermediate body colour pattern, equally distant from the two algal types. In contrast, both shrimp morphs reared in Galaxaura became much better concealed to this substrate than to the alternative Sargassum background. These results were surprising since natural shrimp densities in the brown Sargassum are far higher than in Galaxaura (Duarte and Flores 2016); a difference that could be explained by more efficient camouflage in the former. Our results, however, indicate that this is not the case, and that factors other than colour camouflage alone likely underlie this species distribution in the field. Also, these findings are aligned to ongoing research suggesting better protection against predators in Galaxaura (in prep), highlighting the importance of concealment in the pink weed 
habitat. Further work on longer term changes in colour than those tested here are also needed.

The Sargassum and Galaxaura canopy constitute the most important habitat types to shrimp in our study area, but the relative value of these habitats for $H$. obliquimanus is apparently very different (Duarte and Flores 2016). Experiments in the laboratory testing algal preferences showed that $H_{G B}$ and ST individuals actively select Sargassum fronds while $H_{P}$ shrimp did not show any significant preference, indicating that colour camouflage is not an important selective force setting patterns of habitat choices. Strong preference of individuals for Sargassum may be adaptive for several different reasons not addressed in this study. For instance, as a much more physically complex habitat, especially when associated to epiphytic algae (e.g. Hypnea spp. - Leite and Turra 2003; Tanaka and Leite 2003), Sargassum would probably supply better shelter from predators and more extensive foraging grounds (Orth and Van Montfrans 1984; Martin-Smith 1993) compared to Galaxaura. It is also possible that inconspicuous behaviour coupled to shape resemblance to background details (Main 1987; Hacker and Madin 1991; Maciá and Robinson 2009) in the more complex Sargassum would ultimately render superior predator avoidance. More specific research addressing these issues is pending.

Habitat fidelity and mobility further support morph-specific life-styles. Colour-changing shrimp $(\mathrm{H})$ show higher substrate fidelity and lower mobility rates indicating a more specialized habitat use. Although capable of colour alteration towards background matching, moving from one algal habitat to another would likely come at a cost. Settling on non-matching habitat for even a few days, compatible to the time for colour adjustment, may lead to very high predation rates (Booth 1990; Padilla and Adolph 1996; Hultgren and Stachowicz 2008). Colour change may also carry physiological costs, although these have rarely if ever been quantified (Stuart-Fox and Moussalli 2009). Therefore, at any one time, $\mathrm{H}$ morphs may be able to conceal to a specific background type, being considered background specialists. Conversely, ST shrimp 
may be generally concealed against a wider range of visual backgrounds (Johnsen 2001) while moving from one habitat patch to another. Therefore, the transparency of individuals, linked to a higher mobility and lack of substrate fidelity, may eventually promote camouflage by means of a strategy independent (or partially dependent) of background matching, indicating a more generalist type of concealment and habitat use (Merilaita et al. 1999; Merilaita et al. 2001; Houston et al. 2007). Morph-specific life-styles are supported by natural shrimp distributions (Duarte and Flores 2016) and also by geometric morphometrics analyses of carapace shape. The morphological gradient observed overlaps a great deal of the variation for caridean shrimp in general (Sardà et al. 2005; Aguzzi et al. 2009). While the more hydrodynamic shape found in ST shrimp clearly resembles the shape of pelagic shrimp species, the stouter $\mathrm{H}$ morphology are more akin to benthic species. More streamlined ST shrimp swimming distances within the range of 25 to $45 \mathrm{~cm}$ each minute may easily move across different algal habitats, which is not the case of more sedentary and deep-bodied $\mathrm{H}$ shrimp that were never observed swimming over such distances and tended to settle and remain on algae more frequently. Shrimp morphology, perhaps coupled to behaviour, may also affect camouflage in their algal habitats. Further experimental work is required, however, to examine this issue more closely.

While the different colour types of $\mathrm{H}$ and ST individuals may reflect distinct life-styles, we might ask what drives selection for these different approaches. Low dispersal and optimization of resource use can be particularly advantageous in $\mathrm{H}$ individuals, which concentrate in habitat patches where shelter is abundant and / or camouflage efficient. Even being a habitat where colour camouflage does not appear to be critical, Sargassum supports high densities of $\mathrm{H}$ shrimp, which exhibit high preference and fidelity to this habitat. The less structured Galaxaura substrate would be important as a secondary habitat to this morph, where colour concealment will be a valuable mechanism to reduce prey detection by visual predators. Based on these assumptions, we may expect strong intraspecific competition in Sargassum habitat, 
and hence selection for optimal resource use and territorial behaviour, which would possibly lead to displacement of ST individuals to Galaxaura. Density-dependent processes and loss of preferred habitats could be major mechanisms regulating abundance of $\mathrm{H}$ individuals. On the other hand, high dispersal potential and a generalist habitat use may be useful traits for ST shrimp. Because ST shrimp are mainly males (Duarte and Flores 2016), intense mobility and low substrate fidelity would likely enable males to find more mates in a pure-search strategy, expected for polyginic caridean species such as H. obliquimanus (Wickler and Seibt 1981; Andersson 1994; Baeza and Piantoni 2010).

The coexistence within a population of distinct morphs with alternative strategies of habitat use and camouflage, as observed for $\mathrm{H}$. obliquimanus, facilitates diversification on the use of environmental resources (Duarte and Flores 2016) and can also have ecological and evolutionary consequences, mainly on population stability over time (Forsman et al. 2008). The availability of the presumably higher-quality Sargassum habitat in our study region is markedly seasonal, with very high cover during summer and a much reduced density in winter, sometimes collapsing in that season (Godoy and Coutinho 2002). Temporal variation in Sargassum cover can be a major mechanism controlling $\mathrm{H}$ shrimp densities, once individuals show strong specialization for this habitat. Therefore, the existence of an alternative habitat (Galaxaura) and morphs differing in their degree of habitat specialization may allow temporal changes in individual fitness associated with habitat availability and morphs density and frequency. Ongoing research on trophic niche space would further elucidate morph-specific patterns of resource use.

\section{Conclusions}

Colour camouflage is a common anti-predator strategy in nature, but few studies investigate complex interactions among colour traits and other morphological and behavioural mechanisms, indicative of general morph-specific life-styles. Our findings illustrate that specific 
arrangements among morphology, behaviour, and (micro-) habitat use in colour morphs of the algal-dwelling shrimp $\mathrm{H}$. obliquimanus may result in a diversification of camouflage strategies in a species living in a heterogeneous habitat. Colour change ability and high substrate fidelity, associated to a more robust morphology, suggest a specialist camouflage strategy in $\mathrm{H}$ individuals. On the other hand, high mobility coupled with a more streamlined morphology and lack of substrate fidelity in ST individuals, indicate a general strategy of camouflage in this morph. Higher mobility of the ST morph, in which more than $70 \%$ of individuals are males (Duarte and Flores 2016), may also sustain a pure-search polygynic mating strategy which is predicted for this species. Seasonal changes on macroalgal cover may affect the frequency and fitness of the different colour morphs in the population. Selective mechanisms, such as morphspecific predation by visual consumers through contrasting patterns of habitat use (Jormalainen and Merilaita 1995; Merilaita and Jormalainen 1997), would be important forces maintaining the diversification of life-styles and camouflage strategies in this shrimp species.

\section{Acknowledgements}

We are grateful to Alvaro Migotto for his advice in image acquisition, and two anonymous referees for comments on the paper. We especially thank the technician staff at the Center for Marine Biology for helping in field surveys, and Glauco Machado and Fosca Leite for suggestions on an early manuscript draft. This work was supported by the Fundação de Amparo à Pesquisa do Estado de São Paulo - FAPESP (2009/06675-4 and 2012/17003-0), which granted a master and a PhD fellowship to $\mathrm{RCD}$ and a visiting professor grant to $\mathrm{MS}$ (\#2015/22258-5). This is a contribution of the Research Centre for Marine Biodiversity of the University of São Paulo (NP-Biomar / USP).

\section{References}

Aguzzi J, Costa C, Antonucci F, et al (2009) Influence of diel behaviour in the morphology of decapod natantia. Biol J Linn Soc 96:517-532. 
Ahnesjö J, Forsman A (2006) Differential habitat selection by pygmy grasshopper color morphs; interactive effects of temperature and predator avoidance. Evol Ecol 20:235-257.

Andersson M (1994) Sexual selection. Princeton Universiy Press, Princeton

Baeza JA, Piantoni C (2010) Sexual system, sex ratio, and group living in the shrimp Thor amboinensis (De Man): relevance to resource-monopolization and sex-allocation theories. Biol Bull 219:151-165.

Bauer RT (1981) Color patterns of the shrimps Heptacarpus pictus and H. paludicola (Caridea: Hippolytidae). Mar Biol 64:141-152.

Bolnick DI, Svanbäck R, Fordyce JA, et al (2003) The ecology of individuals: incidence and implications of individual specialization. Am Nat 161:1-28.

Bond $A B$ (2007) The evolution of color polymorphism: crypticity, searching images, and apostatic selection. Annu Rev Ecol Evol Syst 38:489-514.

Bond AB, Kamil AC (2006) Spatial heterogeneity, predator cognition, and the evolution of color polymorphism in virtual prey. Proc Natl Acad Sci U S A 103:3214-3219.

Booth CL (1990) Evolutionary significance of ontogenetic colour change in animals. Biol J Linn Soc 40:125-163.

Bourke P, Magnan P, Rodriguez MA (1997) Individual variations in habitat use and morphology in brook charr. J Fish Biol 51:783-794.

Cain AJ, Sheppard PM (1954) Natural Selection in Cepaea. Genetics 39:89-116.

Chapman BB, Hulthén K, Brönmark C, et al (2015) Shape up or ship out: migratory behaviour predicts morphology across spatial scale in a freshwater fish. J Anim Ecol 84:1187-1193.

Chien Y-H, Jeng S-C (1992) Pigmentation of kuruma prawn, Penaeus japonicus Bate, by various pigment sources and levels and feeding regimes. Aquaculture 102:333-346.

Denno RF, Roderick GK, Olmstead KL, Dobel HG (1991) Density-related migration in planthoppers (Homoptera: Delphacidae): the role of habitat persistence. Am Nat 138:1513-1541.

Diffendorfer JE (1998) Testing models of source-sink dynamics and balanced dispersal. Oikos 81:417433.

Duarte RC, Flores AAV (2016) Morph-specific habitat and sex distribution in the caridean shrimp Hippolyte obliquimanus. J Mar Biol Assoc United Kingdom (online) 1-8. doi: $10.1017 /$ S0025315416000230

Forsman A, Ahnesjö J, Caesar S, Karlsson M (2008) A model of ecological and evolutionary consequences 
of color polymorphism. Ecology 89:34-40.

Forsman A, Appelqvist S (1998) Visual predators impose correlational selection on prey color pattern and behavior. Behav Ecol 9:409-413.

Gamble FW, Keeble FW (1900) Hippolyte varians: a study in colour-change. Q J Micro Sci 43:589-703.

Godoy EAS, Coutinho R (2002) Can artificial beds of plastic mimics compensate for seasonal absence of natural beds of Sargassum furcatum? ICES J Mar Sci 59:111-115.

Gray SM, McKinnon JS (2007) Linking color polymorphism maintenance and speciation. Trends Ecol Evol 22:71-9.

Hacker S, Madin L (1991) Why habitat architecture and color are important to shrimps living in pelagic Sargassum: use of camouflage and plant-part mimicry. Mar Ecol Prog Ser 70:143-155.

Hacker S, Steneck R (1990) Habitat architecture and the abundance and body-size-dependent habitat selection of a phytal amphipod. Ecology 71:2269-2285.

Herder F, Pfaender J, Schliewen UK (2008) Adaptive sympatric speciation of polychromatic "roundfin" sailfin silverside fish in Lake Matano (Sulawesi). Evolution 62:2178-95.

Houston Al, Stevens M, Cuthill IC (2007) Animal camouflage: compromise or specialize in a 2 patch-type environment? Behav Ecol 18:769-775.

Hultgren KM, Mittelstaedt $\mathrm{H}$ (2015) Color change in a marine isopod is adaptive in reducing predation. Curr Zool 61:739-748.

Hultgren KM, Stachowicz JJ (2010) Size-related habitat shifts facilitated by positive preference induction in a marine kelp crab. Behav Ecol 21:329-336.

Hultgren KM, Stachowicz JJ (2008) Alternative camouflage strategies mediate predation risk among closely related co-occurring kelp crabs. Oecologia 155:519-528.

Huyghe K, Vanhooydonck B, Herrel A, et al (2007) Morphology, performance, behavior and ecology of three color morphs in males of the lizard Podarcis melisellensis. Integr Comp Biol 47:211-20.

Johnsen S (2001) Hidden in plain sight: the ecology and physiology of organismal transparency. Biol Bull 201:301-318.

Jormalainen V, Merilaita S (1995) Differential predation on sexes affects colour polymorphism of the isopod Idotea baltica (Pallas). Biol J Linn Soc 55:45-68.

Joron M (2005) Polymorphic mimicry, microhabitat use, and sex-specific behaviour. J Evol Biol 18:54756. 
Kang C, Stevens M, Moon J-Y, et al (2015) Camouflage through behavior in moths: the role of background matching and disruptive coloration. Behav Ecol 26:45-54.

Karpestam E, Merilaita S, Forsman A (2012) Reduced predation risk for melanistic pygmy grasshoppers in post-fire environments. Ecol Evol 2:2204-2212.

Karpestam E, Merilaita S, Forsman A (2013) Detection experiments with humans implicate visual predation as a driver of colour polymorphism dynamics in pygmy grasshoppers. BMC Ecol 13:17.

Kelber A, Vorobyev M, Osorio D (2003) Animal colour vision--behavioural tests and physiological concepts. Biol Rev 78:81-118.

Kettlewell H (1955a) Selection experiments on industrial melanism in the Lepidoptera. Heredity (Edinb) 9:323-342.

Kettlewell HBD (1955b) Recognition of appropriate backgrounds by the pale and black phases of Lepidoptera. Nature 175:943-944.

Kusche H, Elmer KR, Meyer A (2015) Sympatric ecological divergence associated with a color polymorphism. BMC Biol 13:82.

Langellotto GA, Denno RF, Ott JR (2000) A trade-off between flight capability and reproduction in males of a wing-dimorphic insect. Ecology 81:865-875.

Leite F, Turra A (2003) Temporal variation in Sargassum biomass, Hypnea epiphytism and associated fauna. Brazilian Arch Biol Technol 46:665-671.

Lovell PG, Ruxton GD, Langridge K V, Spencer KA (2013) Egg-laying substrate selection for optimal camouflage by quail. Curr Biol 23:260-264.

Maciá S, Robinson MP (2009) Why be cryptic? Choice of host urchin is not based on camouflage in the caridean shrimp Gnathophylloides mineri. Acta Ethol 12:105-113.

Magellan K, Swartz ER (2013) Crypsis in a heterogeneous environment: relationships between changeable polymorphic colour patterns and behaviour in a galaxiid fish. Freshw Biol 58:793-799.

Main K (1987) Predator avoidance in seagrass meadows: prey behavior, microhabitat selection, and cryptic coloration. Ecology 68:170-180.

Marshall KLA, Philpot KE, Stevens M (2016) Microhabitat choice in island lizards enhances camouflage against avian predators. Sci Rep 6:19815.

Martin-Smith KM (1993) Abundance of mobile epifauna: the role of habitat complexity and predation by fishes. J Exp Mar Bio Ecol 174:243-260. 
Martin E, Taborsky M (1997) Alternative male mating tactics in a cichlid, Pelvicachromis pulcher: a comparison of reproductive effort and success. Behav Ecol Sociobiol 41:311-319.

Mclean CA, Stuart-Fox D (2014) Geographic variation in animal colour polymorphisms and its role in speciation. Biol Rev 89:860-873.

Merilaita S, Jormalainen V (1997) Evolution of sex differences in microhabitat choice and colour polymorphism in Idotea baltica. Anim Behav 54:769-78.

Merilaita S, Lyytinen A, Mappes J (2001) Selection for cryptic coloration in a visually heterogeneous habitat. Proc R Soc London Ser B - Biol Sci 268:1925-1929.

Merilaita S, Stevens M (2011) Crypsis through background matching. In: Stevens M, Merilaita S (eds) Animal Camouflage. Cambridge University Press, Cambridge, pp 17-33

Merilaita S, Tuomi J, Jormalainen V (1999) Optimization of cryptic coloration in heterogeneous habitats. Biol J Linn Soc 67:151-161.

Nachman MW, Hoekstra HE, D'Agostino SL (2003) The genetic basis of adaptive melanism in pocket mice. Proc Natl Acad Sci U S A 100:5268-5273.

Novotný V (1994) Relation between temporal persistence of host plants and wing length in leafhoppers (Hemiptera: Auchenorrhyncha). Ecol Entomol 19:168-176.

Orth RJ, Van Montfrans J (1984) Epiphyte-seagrass relationships with an emphasis on the role of micrograzing: a review. Aquat Bot 18:43-69.

Osorio D, Vorobyev M, Jones CD (1999) Colour vision of domestic chicks. J Exp Biol 202:2951-2959.

Padilla DK, Adolph SC (1996) Plastic inducible morphologies are not always adaptive: the importance of time delays in a stochastic environment. Evol Ecol 10:105-117.

Palma AT, Steneck RS (2001) Does variable coloration in juvenile marine crabs reduce risk of visual predation? Ecology 82:2961-2967.

Poore AGB, Steinbenrg PD (1999) Preference-performance relationships and effects of host plant choice in an herbivorous marine amphipod. Ecol Monogr 69:443-464.

Pulliam H (1988) Source, sinks, and population regulation. Am Nat 132:652-661.

Rasband W (1997) ImageJ [online]. http://imagej.nih.gov/ii/

Rohlf F (2009) TpsDig, digitize landmarks and outlines.

Rohlf F (2008) TpsRelw, relative warps analysis. 
Rosenblum EB (2006) Convergent evolution and divergent selection: lizards at the White Sands ecotone. Am Nat 167:1-15.

Sardà F, Company JB, Costa C (2005) A morphological approach for relating decapod crustacean cephalothorax shape with distribution in the water column. Mar Biol 147:611-618.

Sinervo B, Lively CM (1996) The rock-paper-scissors game and the evolution of alternative male strategies. Nature 380:240-243.

Spottiswoode C, Stevens M (2011) How to evade a coevolving brood parasite: egg discrimination versus egg variability as host defences. Proc R Soc B- Biol Sci 278:3566-3573.

Stepien C (1986) Regulation of color morphic patterns in the giant kelpfish, Heterostichus rostratus Girard: genetic versus environmental factors. J Exp Mar Bio Ecol 100:181-208.

Stevens M (2011) Avian vision and egg colouration: concepts and measurements. Avian Biol Res 4:168184.

Stevens M (2016) Color change, phenotypic plasticity, and camouflage. Front Ecol Evol 4:1-10.

Stevens M, Lown AE, Denton AM (2014a) Rockpool gobies change colour for camouflage. PLoS One 9:18.

Stevens M, Lown AE, Wood LE (2014b) Color change and camouflage in juvenile shore crabs Carcinus maenas. Front Ecol Evol 2:1-14.

Stevens M, Lown AE, Wood LE (2014c) Camouflage and individual variation in shore crabs (Carcinus maenas) from different habitats.

Stevens M, Párraga CA, Cuthill IC, Partridge JC, Troscianko TS (2007) Using digital photography to study animal coloration. Biol J Linn Soc 90:211-237.

Stevens M, Stoddard MC, Higham JP (2009) Studying primate color: towards visual system-dependent methods. Int J Primatol 30:893-917.

Stuart-Fox D, Moussalli A (2009) Camouflage, communication and thermoregulation: lessons from colour changing organisms. Philos Trans R Soc Lond B Biol Sci 364:463-70.

Tanaka MO, Leite FPP (2003) Spatial scaling in the distribution of macrofauna associated with Sargassum stenophyllum (Mertens) Martius: analyses of faunal groups, gammarid life habits, and assemblage structure. J Exp Mar Bio Ecol 293:1-22.

Terossi M, López Greco LS, Mantelatto FL (2008) Hippolyte obliquimanus (Decapoda: Caridea: Hippolytidae): a gonochoric or hermaphroditic shrimp species? Mar Biol 154:127-135. 
Terossi M, Mantelatto FL (2010) Sexual ratio, reproductive period and seasonal variation of the gonochoric shrimp Hippolyte obliquimanus (Caridea: Hippolytidae). Mar Biol Res 6:213-219.

Théry M, Casas J (2002) Predator and prey views of spider camouflage. Nature 415:133.

Tlusty M, Hyland C (2005) Astaxanthin deposition in the cuticle of juvenile American lobster (Homarus americanus): implications for phenotypic and genotypic coloration. Mar Biol 147:113-119.

Todd P, Briers R, Ladle R, Middleton F (2006) Phenotype-environment matching in the shore crab (Carcinus maenas). Mar Biol 148:1357-1367.

Umbers KDL, Fabricant SA, Gawryszewski FM, Seago AE, Herberstein ME (2014) Reversible colour change in Arthropoda. Biol Rev 89:820-848.

Van Valen L (1965) Morphological variation and width of ecological niche. Am Nat 99:377-390.

Venables W, Ripley B (2002) Modern Applied Statistics with S, Fourth Edi. Springer, New York

Westland S, Ripamonti C (2004) Computational Color Science. John Wiley \& Sons Ltd., Chichester

Wickler W, Seibt U (1981) Monogamy in Crustacea and man. Z Tierpsychol 57:215-234.

Zelditch M, Swiderski D, Sheets H, Fink W (2004) Geometric morphometrics for biologists: a primer. Elsevier Academic Press, New York 


\section{Additional Information}
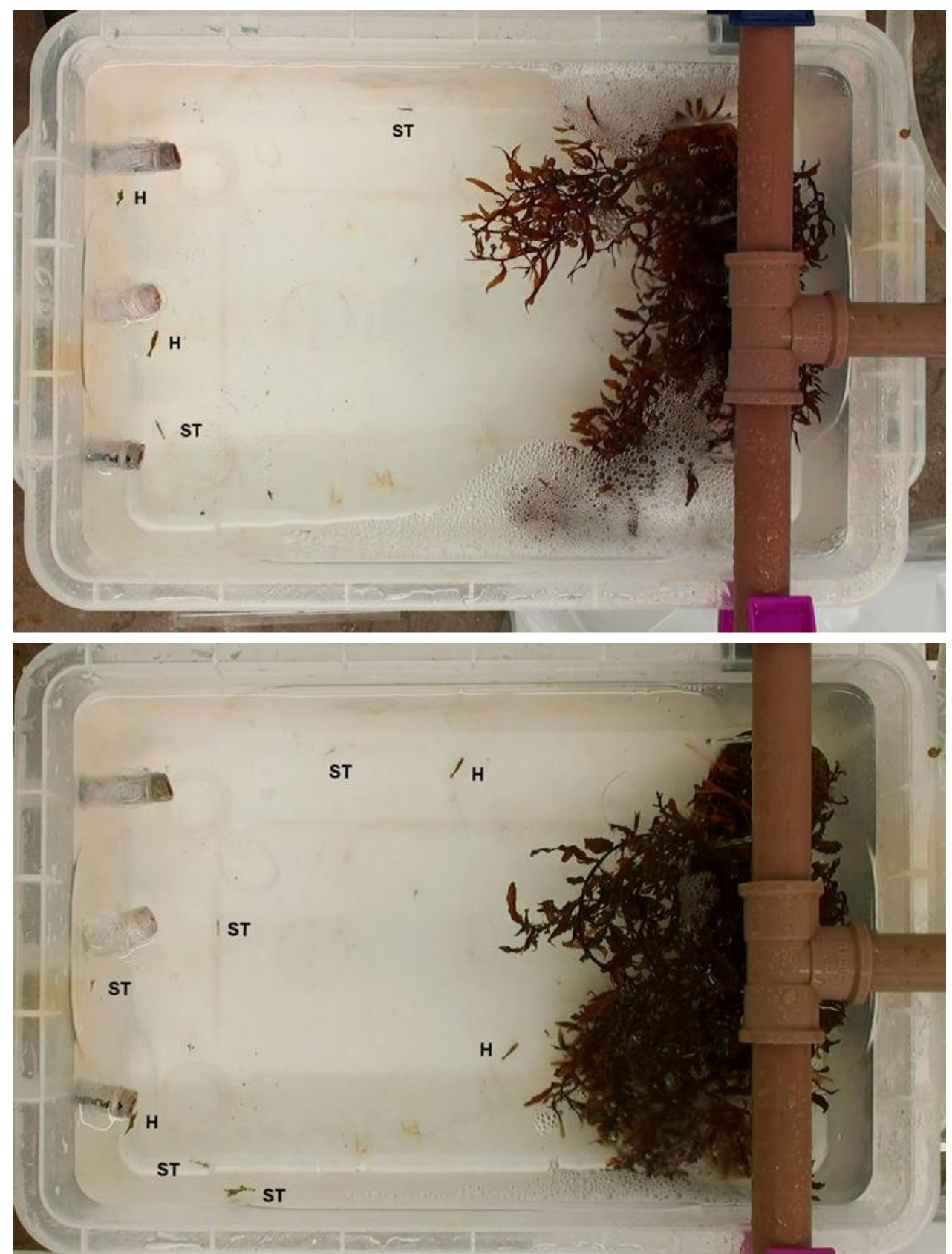

Fig. S1 Images extracted from video footage showing the experimental set up used in habitat fidelity and mobility trials (see details in the main text). Homogeneous $(\mathrm{H})$ and striped translucent (ST) morphs of the shrimp Hippolyte obliquimanus were more easily identified in dorsal view, when thin longitudinal stripes of ST shrimps stood clearly out from the bottom of aquaria, contrasting to the solid coloration typical of $\mathrm{H}$ shrimp. A lateral view of an ST individual (as the lowermost shrimp in the lower image), showing translucent areas over the abdomen and carapace, could however suffice for morph identification. 


\section{CHAPTER 3}

The adaptive value of camouflage and colour change in a polymorphic shrimp

Manuscript submitted as a "Correspondence" to the journal "Current Biology" 


\section{The adaptive value of camouflage and colour change in a polymorphic}

\section{shrimp}

Rafael Campos Duarte ${ }^{1,2^{*}}$, Martin Stevens ${ }^{3}$, and Augusto Alberto Valero Flores ${ }^{1}$

1 - Centro de Biologia Marinha, Universidade de São Paulo, São Sebastião, SP, Brazil.

2 - Programa de Pós-Graduação em Biologia Comparada, Faculdade de Filosofia, Ciências e Letras de Ribeirão Preto, Universidade de São Paulo, Ribeirão Preto, Brazil.

3 - Centre for Ecology and Conservation, University of Exeter, Penryn Campus, Penryn. TR10 9FE, UK.

\section{Main text}

Camouflage is an iconic outcome of natural selection, and an example of adaptation used since Wallace and others (Wallace 1867). However, remarkably despite 150 years of research, experimental evidence directly showing that better camouflage of prey to predator vision results in reduced risk of predation is lacking. Previous classic work has shown differences in recapture rates of apparently differentially concealed morphs in different habitats (Kettlewell 1955), that camouflage of individual wild animals correlates with survival (Troscianko et al. 2016), and has used artificial dummy prey in 'survival' experiments (Cuthill et al. 2005). No study, however, has directly and experimentally shown that the level of camouflage of real animals to predator vision affects predation risk. This includes animals that change colour for concealment, where as yet, no study has directly quantified the adaptive value provided. Here, we tested the camouflage value and corresponding predation rates on a polymorphic colourchanging shrimp (Hippolyte obliquimanus), which is characterized by brown (B) and pink (P) individuals concealed in brown (Sargassum furcatum) and pink-red alga (Galaxaura marginata) respectively (Duarte and Flores 2016) (Figure 1A). Shrimp change colour between these morphs depending on which seaweed they occur (Duarte et al. 2016). Image analyses and visual modelling of predator (seahorse) vision predicted that brown shrimp would be imperfectly concealed against both algal habitats, whereas the pink shrimp should be well 
camouflaged in red Galaxaura but easily detectable in Sargassum. Predation trials with seahorses (Hippocampus reidi), coupled with high-speed video analyses, exactly matched model predictions: predation rates were similar for brown morphs among seaweed types, but pink shrimp were attacked significantly less on red than brown weed. Our study is the first to quantitatively demonstrate that predation risk in a real animal is directly related to predatorperceived levels of camouflage, and that colour change for camouflage provides a direct survival benefit. It also supports widely used but seldom behaviourally validated models of visual discrimination.

Our results, based on a seahorse vision model, indicate that functional camouflage was effectively attained by shrimp living in the red Galaxaura background, where they can adjust their colour over a few days to resemble this habitat (Duarte et al. 2016). However, in the more heterogeneous Sargassum habitat, where individuals adopt brown coloration, both shrimp camouflage and colour change abilities are less effective in reducing detection. To quantify shrimp camouflage, we used standardised and linearised digital images, mapped to seahorse cone response data (Stevens et al. 2007) of both morphs ( $\mathrm{B}$ and $\mathrm{P}$ ) and backgrounds (Sargassum and Galaxaura), and analysed them using a visual model of a trichromatic Hippocampus seahorse predator, which likely detects colour based on the presence of three cone types (Mosk et al. 2007) (sensitive to relatively short, medium, and long wavelengths of light). We used a widely implemented log-linear form of a colour discrimination model (Vorobyev and Osorio 1998), which assumes that discrimination is limited by receptor noise, predicting colour discriminability as "just noticeable differences" (JNDs). JND comparisons across levels of 'shrimp morph' and 'algal habitat' indicated contrasting morph detection rates by seahorses in distinct backgrounds (2-way ANOVA: $d f=1,116 ; F_{\text {morph }}$ alga $=175.97 ; p<$ 0.001). Specifically, $\mathrm{P}$ shrimp showed lower colour contrasts (median \pm interquartile range) against Galaxaura (1.72 \pm 0.69) compared to Sargassum (7.46 \pm 1.55 ; Figure 1B). Discrimination thresholds for B shrimp were similar between backgrounds and, on average, 
higher than three JNDs (Figure 1B), indicating that seahorses should detect this morph in both algal types. Morph-algal-specific background matching was further confirmed by a Principal Component Analysis (PCA) based on standardised seahorse photon catch values of shrimp. P shrimp cohesively clustered with Galaxaura algae along the main PCA axis (Additional information, Figure S1) and away from B individuals, which were more spread out in space (Supplemental information, Figure S1). Overall, modelling results predicted that B shrimp will be readily and equally detected by predators in both algal habitats, whereas $\mathrm{P}$ individuals will be effectively camouflaged in red Galaxaura but not brown Sargassum.

We tested modelling predictions in a laboratory experiment that measured the attack rate of captive seahorses (Hippocampus reidi) on shrimp morphs placed in both Sargassum and Galaxaura. We coupled this in several trials with high-speed video camera recordings (480 fps) of seahorse attack behaviour. This showed that seahorses primarily use visual cues for prey detection, taking on average $4.28 \pm 0.82 \mathrm{~s}$ (mean \pm standard deviation) to attack shrimp after their first visual contact. Once detected, attack success rate was $90 \%$ and always occurred in less than $0.063 \mathrm{~s}$ (Figure 1C). Attack results very closely matched the JND analyses. Attack differences between colour morphs depended on the algal habitat (2-way ANOVA: $d f=1,32 ; F$ morph $\times$ alga $=4.24 ; p=0.048$ ). Brown shrimp were equally attacked (mean $\pm \mathrm{SE}$ ) in both algal types (Sargassum $=46.1 \pm 3.7 \%$; Galaxaura $=50.6 \pm 5.2 \%$ ), while pink individuals in Galaxaura were attacked almost 30\% less than in Sargassum (Sargassum $=49.4 \pm 4.8 \%$; Galaxaura $=35.6$ $\pm 3.6 \%$ ), indicating efficient camouflage in the red background (Figure 1D).

Here, we found experimental evidence that the level of camouflage, assessed to a vision model of an ecologically relevant predator, directly influences individuals' survival chances. Our data also provides rare validation of the use of vision models. Given that the shrimp species studied here also uses colour change over a few days against each background type, without any apparent accompanying changes in behaviour (Duarte et al. 2016), our study also demonstrates the adaptive value of colour change. The effectiveness of camouflage, however, 
was asymmetric, appearing to be a valuable mechanism to reduce predation for shrimp living in Galaxaura but less so in Sargassum. Adequate shelter and extensive foraging grounds provided by the more intricate architecture and higher amount of epiphytic algae in natural Sargassum canopy may overcome some lack of camouflage. Overall, our study shows that the level of camouflage, here in a colour-changing animal, directly translates into its risk of attack, providing key validation for the adaptive value of this widely used strategy.

\section{Methods}

Samples of the macroalgae Sargassum furcatum and Galaxaura marginata were collected during the spring of 2015 (image analysis) and summer of 2016 (predation experiment) by skin diving at rocky bottoms in sites close to the Centre for Marine Biology (CEBIMAR - USP), São Sebastião, SP, Brazil ( $\left.23^{\circ} 49^{\prime} 40^{\prime \prime} \mathrm{S} ; 4^{\circ} 25^{\prime} 22^{\prime \prime} \mathrm{W}\right)$. Shrimp were sorted from macroalgae (as in Duarte and Flores 2016) and visually classified in brown (B) or pink (P) colour morphs, which proved to be a simple method for morph assignment, as well as one that is objectively robust (Duarte et al. 2016; Figure S1). After collection, shrimp and macroalgae were kept in indoor tanks $(30 \times 20 \times 10 \mathrm{~cm})$ at ambient temperature $\left(\sim 27^{\circ} \mathrm{C}\right)$, with filtered running seawater and artificial aeration. A set of shrimp and algal samples was separated for image analyses used for modelling the camouflage of the two morphs, in each of the two algal habitats, using a model of a seahorse predator vision. Another set of samples was used for predation experiments to test predictions of the modelling results. 
A

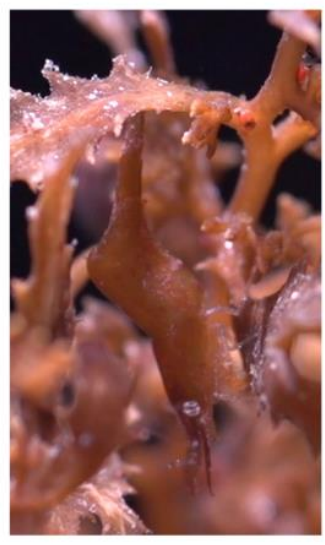

C

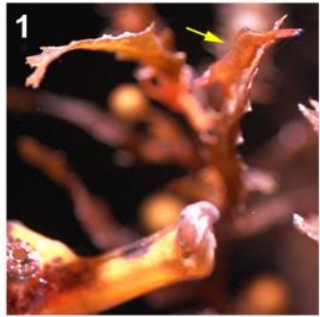

3

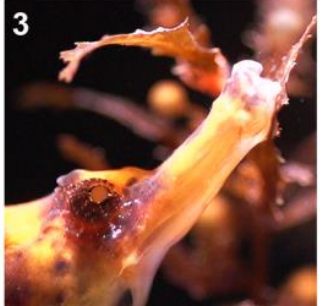

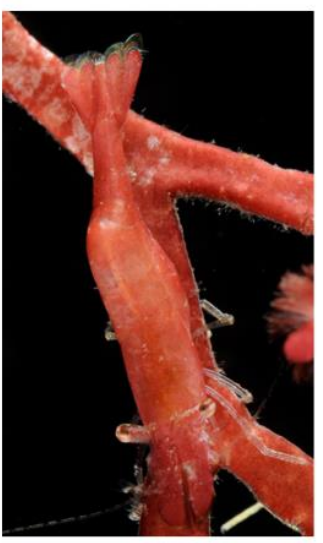
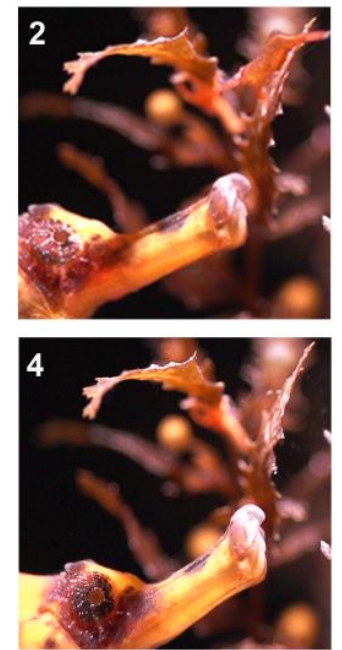

B
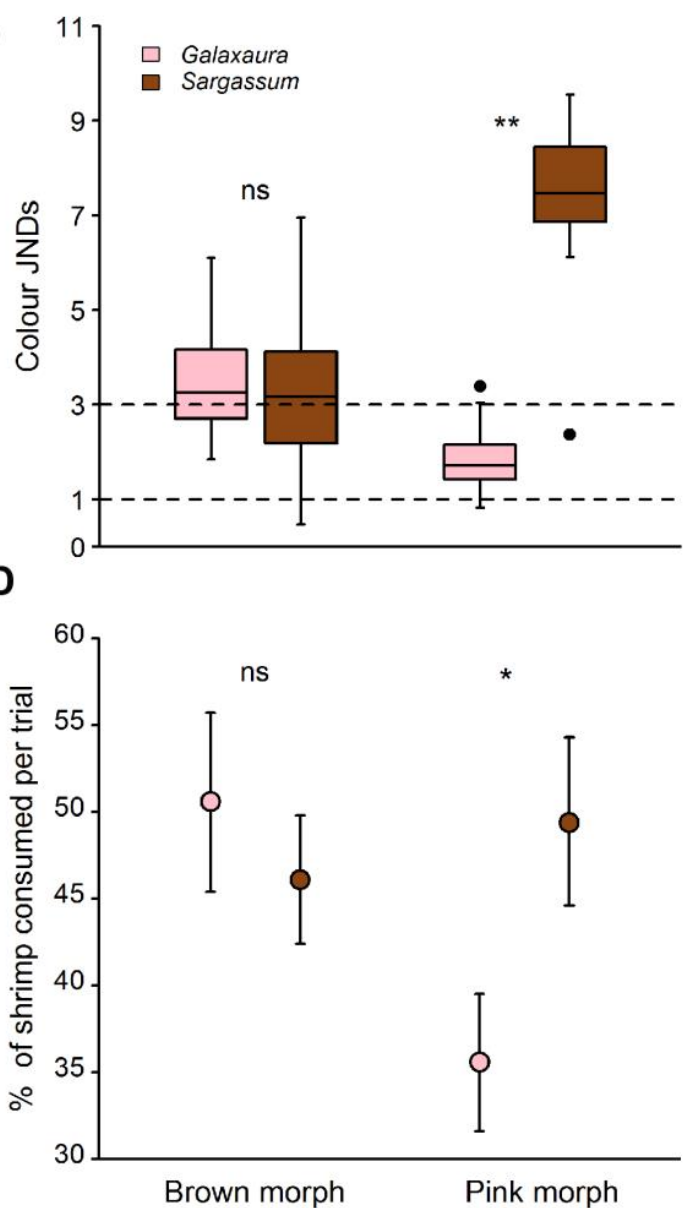

Figure 1 - The adaptive value of camouflage in Hippolyte obliquimanus shrimp. A) Brown (left) and pink (right) individuals attaining a good colour match in the brown algae Sargassum furcatum and the red-pink weed Galaxaura marginata, respectively. B) Seahorse vision discrimination values, expressed as "just noticeable differences" (JNDs) between morphs and algae. Boxes show medians plus inter-quartile range (IQR), whiskers are lowest and highest values that are within $1.5 *$ IQR from the upper and lower quartiles, and black filled circles represent outliers. Values between 1 and 3 (dashed lines) predict low probability of prey detection by predators. ns: not significant; ${ }^{* *} p<$ 0.01. C) Sequence of still images from high speed video recordings (480 fps), over less than $1.5 \mathrm{~s}$, showing a seahorse predator (Hippocampus reidi) hunting a camouflaged brown shrimp on the weed Sargassum. The yellow arrow indicates the shrimp position in the first frame. D) Seahorse attack rates on individuals of each morph, as a percentage of individuals consumed in $2 \mathrm{~h}$ trials (mean \pm standard error), when placed in Galaxaura and Sargassum habitats. ns: not significant; $* p<0.05$. 


\section{Shrimp camouflage}

Image analysis - Pieces of macroalgae ( $n=30$; Sargassum and Galaxaura) and living B and P shrimp ( $n=30$ for each morph) were photographed in one acrylic chamber $(5 \times 5 \mathrm{~cm})$ using a Nikon D80 digital camera, coupled with a Nikkor $60 \mathrm{~mm}$ lens and a UV-blocker filter $(62 \mathrm{~mm}$, Tiffen, USA), allowing light capture along the visible spectra (400 to $700 \mathrm{~nm}$ ). The camera was set up to capture only visible light since both shrimp and algae exhibited low overall UV reflection, as we preliminary observed using an UV-sensible camera, and also because some fish, including likely predators of the shrimp, are less sensitive to this waveband of light (UtnePalm and Bowmaker 2006; Mosk et al. 2007). Images were taken in RAW format, with manual white balancing and fixed aperture settings, to avoid overexposed areas (Stevens et al. 2007). Each photograph included black (7.5\%) and white (91\%) Spectralon reflectance standards (Labsphere, Congleton, UK) following recently developed approaches (Troscianko and Stevens 2015). Illumination was provided by one human visible Arc Lamp (70W, 6500K Iwasaki Colour Arc Lamp) and, to ensure even lightning conditions, a PTFE (polytetrafluoroethylene) diffuser cylinder was placed around the photography chamber. After capture, images were linearised to correct for camera non-linear image pixel responses to light intensity (Stevens et al. 2007; Troscianko and Stevens 2015), using curves modelled from eight Spectralon reflectance standards from 2 to $99 \%$ reflectance (Labsphere). Linearisation was successful for all camera channels showing $R^{2}$ values $\geq 0.997$. Each photograph was equalised for any changes in light conditions using the two Spectralon standards and saved as 32-bit multispectral images. All these routines were performed by a series of customized functions implemented in the ImageJ software (Troscianko and Stevens 2015).

Predator vision modelling - Shrimp and algal colour were analysed according to a predator vision model, which often provides a more accurate way to measure camouflage than using only light reflectance (Stevens et al. 2009). Seahorses are commonly associated with algal beds 
(Foster and Vincent 2004) and are known predators of caridean shrimps (Kendrick and Hyndes 2005). Along the Brazilian coast, the seahorse Hippocampus reidi exhibits high preference for H. obliquimanus shrimp (Felício et al. 2006), being a valuable candidate for visual modelling. Because there was no available information on the specific visual system of $H$. reidi, we used the spectral sensitivities of the related Australian seahorse Hippocampus subelongatus (Mosk et al. 2007) for the modelling. We assumed that the visual capabilities of the two species would be similar, since they both live in similar green water vegetated habitats (Mosk et al. 2007; Rosa et al. 2007).

H. subelongatus has spectral peaks for single cones at $467 \mathrm{~nm}$ (shortwave sensitivity - SWS), and for double cones (paired cells with a similar morphology) at $522 \mathrm{~nm}$ (mediumwave sensitivity - MWS), $537 \mathrm{~nm}$ (medium-longwave sensitivity - M-LWS), and $560 \mathrm{~nm}$ (longwave sensitivity - LWS) (Mosk et al. 2007). We also incorporated 50\% light transmission cut-off at $425 \mathrm{~nm}$ (Mosk et al. 2007) and used a D65 standard irradiance spectrum as a measure of incident illumination (Wyszecki and Stiles 2000). Although this is not the precise light conditions under which natural predation would occur, water clarity is normally high at our study site and the depth of shrimp habitat is shallow (maximum $1.5 \mathrm{~m}$ deep), minimising attenuation. In addition, our experiments were conducted in shallow water tanks (see below). Double cones (DC) are often the most common cone types in diurnal fish and may have different functions (Marshall and Vorobyev 2003), including in determining colour vision for some species (Hughes et al. 1998; Pignatelli et al. 2010). However, whether cone members in DCs work synergistically or independently to provide colour discrimination is still an open question, although a recent study of the reef fish Rhinecanthus aculeatus showed that colour vision is encoded by independent spectral channels in the DCs (Pignatelli et al. 2010). Compared to other coastal and tropical reef fish, which possess only one or two different pigments in their DCs (Pignatelli et al. 2010; Cortesi et al. 2015), the seahorse H. subelongatus exhibit an unusual DC configuration, with three different cone types accounting for the 
medium-long wave sensitivity (Mosk et al. 2007). In our study, we considered H. subelongatus as having a trichromatic visual system. However, we modelled the use of DCs accounting for colour vision differently under two scenarios, to control for possible alternative visual coding. We chose this option over assuming that seahorses are tetrachromatic because two similar cone types absorbing medium-wave light (MWS and M-LWS) were present in the DCs, strongly suggesting one of them as being used for luminance (achromatic) contrast (Mosk et al. 2007). 'Model 1 ' considered the SWS single cone, and the MWS and LWS members of DCs as responsible for colour vision, while 'Model 2', replaced the MWS member by the M-LWS cones in the DCs. Results from both models were very similar (Table S1) and we report in the main text only those derived from 'Model 1'.

A polynomial mapping technique was used to convert shrimp and macroalgae images from the camera colour space to fish vision (Westland and Ripamonti 2004; Stevens et al. 2007), generating values of seahorse cone catches. This procedure is a widely used method for visual modelling in several animal species, yielding cone catch values that are in close accordance with data derived from spectrometry approaches (Pike 2011; Stevens et al. 2014a; Stevens et al. 2014b; Troscianko and Stevens 2015; Kang et al. 2016; Troscianko et al. 2016). Before building the model, we calculated the spectral sensitivity curves of our photographic equipment using a quadratic programming procedure (Pike 2011) and a new recent method (described in Stevens et al. 2014b). The sensitivity range and peaks of the camera set up in our current study are as follows for each sensor: SW; $400-550 \mathrm{~nm}$ (peak $472 \mathrm{~nm}$ ), MW; $420-620$ nm (peak 534 nm), LW; $550-700$ nm (peak 596 nm).

Visual modelling resulted in multispectral images, where we measured regions of interest (ROIs) in shrimp carapace and abdomen (from the region behind the eyes to the end of the abdominal somite 3 , avoiding the stomach region), and in algal fronds, to obtain photon catches values for each colour channel. We performed a principal component analysis (PCA) on the covariance matrix of the standardized cone data to visualise colour differences between 
morphs and backgrounds and to verify what colour channels are responsible for such differentiation. We then assessed whether morphs were visually discriminated by seahorses when compared to the different algal backgrounds. We used a widely implemented log-linear form of the colour discrimination model (Vorobyev and Osorio 1998), which assumes that visual discrimination is limited by receptor noise. This model predicts chromatic signal discriminability as a unit of "just noticeable difference" (JND). Because we do not have behavioural data concerning signal discrimination in $H$. subelongatus, we used a relatively conservative and frequently adopted Weber fraction value $(0.05)$ for the most abundant cone type (Wyszecki and Stiles 2000), and set the cone proportions as LWS $=0.44, \mathrm{MWS}=1.00, \mathrm{M}-$ LWS $=0.89$ and SWS $=0.56$ (Mosk et al. 2007). Results are expressed as JNDs, whereby values lower than 1 indicate that two colours cannot be discriminated, values between 1 and 3 indicate that colours are only likely to be discriminable under adequate viewing conditions, and values higher than 3 correspond to probable colour discrimination by predators (Siddiqi et al. 2004).

Statistical analyses - We used a Discriminant Function Analysis (DFA) to first determine how effectively shrimps and algae were classified into visually discrete morph categories and algal types, based in photon catches derived from modelling. We also classified colour morphs according to a discriminant function obtained from a DFA applied to algal photon catches. We predicted that morphs classified as B and P would be more similar to Sargassum and Galaxaura respectively. In all cases, we ran the 'Ida' function from the MASS library in R (Venables and Ripley 2002) to the principal components scores obtained from the PCA applied to the photon catches data (see above) for both shrimp morphs and algal types.

In order to test for shrimp camouflage, we calculated colour differences (expressed as JNDs) between replicate individuals of each morph and a single randomly selected image from a pool of 60 samples of both Sargassum and Galaxaura, resulting in 30 JND values for each comparison. Data were analysed using a 2-way ANOVA, in which the factors 'morph' (B or P) 
and 'algal type' (Sargassum or Galaxaura) were fixed and orthogonal. Variances were heterogeneous for colour JNDs even after log transformation. However, we proceed with the analyses using raw data because this was a balanced design with a large sample size $(n=30)$, which makes the test robust to variance heterogeneity (Underwood 1997). The StudentNewman-Keuls (SNK) procedure was used for a posteriori comparisons. JND results were also analysed with one sample $t$-tests to determine whether values were significantly lower or higher than the discrimination thresholds of 1.00 and 3.00 , respectively.

\section{Predation experiment}

Experimental setup - We performed a laboratory experiment to test whether predation on colour morphs differed when individuals were placed in algal backgrounds providing distinct levels of camouflage. The seahorse Hippocampus reidi is commonly found in our study region (Freret-Meurer and Andreata 2008) and was used as predator in trials because there are several lines of evidence suggesting that this species might be one of the most important predators of algal dwelling caridean shrimps. First, seahorses are one of the few fish predators that actually remain amongst algal fronds, curling their tail around the algal holdfast and ambushing prey upon visual detection (Foster and Vincent 2004); second, they are specialised consumers of algal-dwelling invertebrates, of which caridean shrimp have been ranked first or second in their diet (Woods 2002; Yip et al. 2015); and, finally, H. reidi commonly feeds on $H$. obliquimanus, with this shrimp species being a preferred prey when compared to amphipods and brine shrimp (Felício et al. 2006). In addition to being a key component of our study in their own right, results of the predation experiment allowed validation of predictions based on seahorse visual modelling.

We prepared a set of ten cubic aquaria $(25 \times 25 \times 25 \mathrm{~cm})$, supplied a thin layer of natural sand covering the bottom and constant flow of seawater filtered through a $5 \mu \mathrm{m}$ pore size filter, which was maintained in ambient temperature $\left(26.45^{\circ} \mathrm{C} \pm 1.07\right)$ and salinity $(31.07 \pm$ 
0.66) conditions. This environmental setting would correspond to natural conditions at shallow waters, when water clarity is particularly high. Five of these aquaria were used to maintain stocks of freshly collected shrimp and seahorses, and the other five to perform the experimental trials. Shrimp stocks were kept with their original plant hosts (one tank provided Sargassum fronds and accompanying B shrimp; and one tank with Galaxaura and P individuals). Three non-reproductive $H$. reidi individuals (P1: female, height $11.42 \mathrm{~cm}$; P2: female, height $10.56 \mathrm{~cm}$; P3: male, height $11.44 \mathrm{~cm}$ ) were collected by snorkelling in algal meadows close to the Centre for Marine Biology (São Sebastião, Brazil) and kept in individual tanks, where they were fed ad libitum with a variety of algal-dwelling invertebrates. Predation trials were carried out under natural daylight in the five remaining tanks, to which a clump of either Sargassum or Galaxaura was added and 20 individuals of either B or P morph were included. Shrimp were left to acclimatize for 10 minutes, and then one $H$. reidi individual, caged in a $5 \mathrm{~mm}$ mesh-bag, was added to the tank. After 20 minutes, when all shrimp had settled on algae, the predator was released and left in tanks for 2 hours. The attack rate was calculated as the difference between initial and final numbers of shrimp per aquarium. A maximum of two experimental aquaria were run at the same time and combinations among levels of the factors shrimp morph, algal habitat and seahorse ID were randomly replicated in time, three times, summing up 36 trials over 1.5 months. The tank used in each trial was also randomly chosen to avoid potential artefacts due to uncontrolled spatial variation of any physical variables within the laboratory room. We also certified that seahorses were left without food for at least 20 hours before their use in trials, ensuring complete gastric evacuation has occurred (Ryer and Boehlert 1983; Felício et al. 2006). In some trials ( $n=10)$ we used a high-speed camera (Sony NX-FS700R, coupled with a Nikkor $60 \mathrm{~mm}$ lens, capturing images at $480 \mathrm{fps}$ ) in order to record seahorse behaviour when capturing shrimp. These recordings were also used to estimate the time seahorses took to attack shrimp after visual detection and to assess the successful rate of these attacks. 
Statistical analyses - Predation effects were first analysed using a fully orthogonal three-way ANOVA, in which the factors 'morph' (B and P) and 'algal habitat' (Sargassum and Galaxaura) were fixed and the factor 'seahorse ID' (P1, P2 and P3) was random. Initial results of the full model showed that predator identity had no effect on consumption rates $\left(F_{(2,24)}<0.001 ; p>\right.$ 0.95), indicating that possible behavioural difference among individuals did not influence their attack success. Therefore, we pooled the data from different seahorses for each combination of remaining factors, and thus increased sample size from three to nine in a reduced 2-way model. The SNK procedure was used for a posteriori comparisons.

\section{Acknowledgements}

This study was funded by the Fundação de Amparo à Pesquisa do Estado de São Paulo (FAPESP) which granted a PhD fellowship to R.C.D. (\#2012/17003-0, \#2015/04484-8), and a visiting professor grant to MS (\#2015/22258-5), and is a contribution of the Research Centre for Marine Biodiversity of the University of São Paulo (NP-Biomar / USP). We are grateful to Devi Stuart-Fox for her valuable comments on an earlier draft of this manuscript, to Jolyon Troscianko for his advice in image analysis and visual modelling and to Alvaro Migotto for his help in recording the high-speed videos.

\section{References}

Cortesi F, Feeney WE, Ferrari MCO, et al (2015) Phenotypic plasticity confers multiple fitness benefits to a mimic. Curr Biol 25:949-954.

Cuthill IC, Stevens M, Sheppard J, et al (2005) Disruptive coloration and background pattern matching. Nature 434:72-74.

Duarte RC, Flores AAV (2016) Morph-specific habitat and sex distribution in the caridean shrimp Hippolyte obliquimanus. J Mar Biol Assoc United Kingdom (online) 1-8. doi: $10.1017 /$ S0025315416000230

Duarte RC, Stevens M, Flores AA V. (2016) Shape, colour plasticity, and habitat use indicate morphspecific camouflage strategies in a marine shrimp. BMC Evol Biol 16:218.

Felício AKC, Rosa IL, Souto A, Freitas RHA (2006) Feeding behavior of the longsnout seahorse 
Hippocampus reidi Ginsburg, 1933. J Ethol 24:219-225.

Foster S, Vincent A (2004) Life history and ecology of seahorses: implications for conservation and management. J Fish Biol 65:1-61.

Freret-Meurer NV, Andreata JV (2008) Field studies of a Brazilian seahorse population, Hippocampus reidi Ginsburg, 1933. Brazilian Arch Biol Technol 51:743-751.

Hughes A, Saszik S, Bilotta J, et al (1998) Cone contributions to the photopic spectral sensitivity of the zebrafish ERG. Vis Neurosci 15:1029-1037.

Kang C, Kim YE, Jang Y (2016) Colour and pattern change against visually heterogeneous backgrounds in the tree frog Hyla japonica. Sci Rep 6:22601.

Kendrick AJ, Hyndes GA (2005) Variations in the dietary compositions of morphologically diverse syngnathid fishes. Environ Biol Fishes 72:415-427.

Kettlewell H (1955) Selection experiments on industrial melanism in the Lepidoptera. Heredity (Edinb) 9:323-342.

Marshall N, Vorobyev M (2003) The design of color signals and color vision in fishes. In: Collin S, Marshall N (eds) Sensory Processing of the Aquatic Environment. Springer-Verlag, New York, pp 194-222

Mosk V, Thomas N, Hart NS, et al (2007) Spectral sensitivities of the seahorses Hippocampus subelongatus and Hippocampus barbouri and the pipefish Stigmatopora argus. Vis Neurosci 24:345-354.

Pignatelli V, Champ C, Marshall J, Vorobyev M (2010) Double cones are used for colour discrimination in the reef fish, Rhinecanthus aculeatus. Biol Lett 6:537-539.

Pike TW (2011) Using digital cameras to investigate animal colouration: estimating sensor sensitivity functions. Behav Ecol Sociobiol 65:849-858.

Rosa IL, Oliveira TPR, Castro ALC, et al (2007) Population characteristics, space use and habitat associations of the seahorse Hippocampus reidi (Teleostei: Syngnathidae). Neotrop Ichthyol 5:405-414.

Ryer CH, Boehlert GW (1983) Feeding chronology, daily ration, and the effects of temperature upon gastric evacuation in the pipefish, Syngnathus fuscus. Environ Biol Fishes 9:301-306.

Siddiqi A, Cronin TW, Loew ER, et al (2004) Interspecific and intraspecific views of color signals in the strawberry poison frog Dendrobates pumilio. J Exp Biol 207:2471-2485.

Stevens M, Lown AE, Denton AM (2014a) Rockpool gobies change colour for camouflage. PLoS One 9:18. 
Stevens M, Lown AE, Wood LE (2014b) Color change and camouflage in juvenile shore crabs Carcinus maenas. Front Ecol Evol 2:1-14.

Stevens M, Párraga CA, Cuthill IC, et al (2007) Using digital photography to study animal coloration. Biol J Linn Soc 90:211-237.

Stevens M, Stoddard MC, Higham JP (2009) Studying primate color: towards visual system-dependent methods. Int J Primatol 30:893-917.

Troscianko J, Stevens M (2015) Image Calibration and Analysis Toolbox - a free software suite for objectively measuring reflectance, colour and pattern. Methods Ecol Evol 6:1-32.

Troscianko J, Wilson-Aggarwal J, Stevens M, Spottiswoode CN (2016) Camouflage predicts survival in ground-nesting birds. Sci Rep 6:1-8.

Underwood A (1997) Experiments in ecology: their logical design and interpretation using analysis of variance. Cambridge University Press, Cambridge

Utne-Palm AC, Bowmaker JK (2006) Spectral sensitivity of the two-spotted goby Gobiusculus flavescens (Fabricius): a physiological and behavioural study. J Exp Bol 209:2034-41.

Venables W, Ripley B (2002) Modern Applied Statistics with S, Fourth Edi. Springer, New York

Vorobyev M, Osorio D (1998) Receptor noise as a determinant of colour thresholds. Proc R Soc London Ser B - Biol Sci 265:351-358.

Wallace A (1867) Mimicry and other protective resemblances among animals. Westminster Rev (London Ed 1 July:1-43.

Westland S, Ripamonti C (2004) Computational Color Science. John Wiley \& Sons Ltd., Chichester

Woods CMC (2002) Natural diet of the seahorse Hippocampus abdominalis. New Zeal J Mar Freshw Res $36: 655-660$.

Wyszecki G, Stiles W (2000) Colour science: concepts and methods, quantitative data and formulae, 2nd editio. Wiley-Interscience

Yip MY, Lim ACO, Chong VC, et al (2015) Food and feeding habits of the seahorses Hippocampus spinosissimus and Hippocampus trimaculatus (Malaysia). J Mar Biol Assoc United Kingdom 95:1033-1040. 


\section{Additional Information}

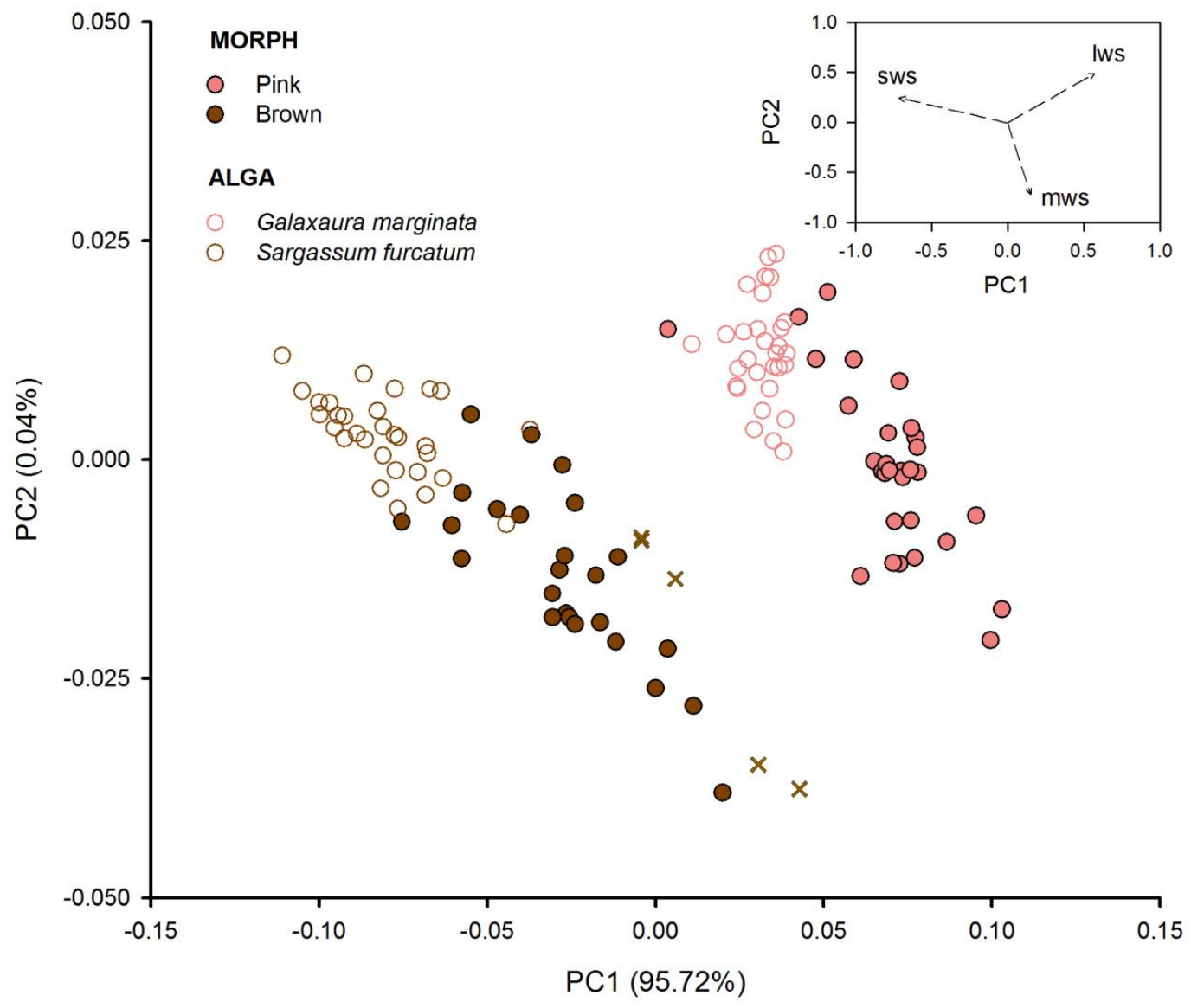

Figure S1 - Principal component analysis (PCA) applied to photon catches data obtained from visual modelling of the seahorse Hippocampus subelongatus, showing colour variation between Hippolyte obliquimanus colour morphs (pink and brown) and algal habitats (Galaxaura marginata and Sargassum furcatum). Pink shrimp and G. marginata algae are clustered while brown individuals, even clumped with S. furcatum weed, are more widespread along the PC1 axis. Percentage values represent total variation explained by each principal component. The upper-right panel shows that the shortwave colour channel (sws) is the main responsible for the segregation between morph and algal groups. Brown individuals $(n=5)$ classified by a discriminant function analysis closer to the red algae $G$. marginata than to the presumed 'colour matching' S. furcatum canopy are represented by crosses. sws: shortwave sensitivity channel; mws: mediumwave sensitivity channel, and lws: longwave sensitivity channel. 
Table S1 - Summary results of seahorse visual modelling. Results of the two-way analyses of variance testing differences in "just-noticeable differences (JND), derived from two visual modelling scenarios (see Supplemental Experimental Procedures), according to combinations of shrimp morphs (brown or pink) and algal backgrounds (Galaxaura and Sargassum) (upper table). Mean JND values and respective 95\% confidence intervals (lower and upper bounds) for the different combinations between factors. Note that both models resulted in overlapping JND 95\% confidence intervals for three factor combinations, with exception for "Pink Sargassum", in which Model 2 estimated higher mean JND than Model 1 (lower table). JND differences for the pink morph between algal habitats reported in the main text may be therefore conservative, although the overall results are in very close correspondence.

\begin{tabular}{|c|c|c|c|c|c|c|c|}
\hline \multirow[b]{2}{*}{$\begin{array}{l}\text { Source of } \\
\text { variation }\end{array}$} & \multirow[b]{2}{*}{$d f$} & \multicolumn{3}{|c|}{ Model 1} & \multicolumn{3}{|c|}{ Model 2} \\
\hline & & MS & $F$ & $p$ & MS & $F$ & $p$ \\
\hline Morph & 1 & 55.466 & 36.42 & $* * *$ & 81.057 & 48.45 & $* * *$ \\
\hline Alga & 1 & 218.042 & 143.16 & $* * *$ & 325.183 & 194.39 & $* * *$ \\
\hline Morph x Alga & 1 & 268.018 & 175.97 & $* * *$ & 321.229 & 192.02 & $* * *$ \\
\hline \multirow[t]{3}{*}{ Residual } & 116 & 1.523 & & & 1.673 & & \\
\hline & & \multicolumn{3}{|c|}{ Model 1} & \multicolumn{3}{|c|}{ Model 2} \\
\hline & & & \multicolumn{2}{|c|}{$95 \% \mathrm{Cl}$} & & \multicolumn{2}{|c|}{$95 \% \mathrm{Cl}$} \\
\hline \multicolumn{2}{|l|}{$\begin{array}{l}\text { Factor } \\
\text { combinations }\end{array}$} & mean & $\begin{array}{l}\text { lower } \\
\text { bound }\end{array}$ & $\begin{array}{l}\text { upper } \\
\text { bound }\end{array}$ & mean & $\begin{array}{l}\text { lower } \\
\text { bound }\end{array}$ & $\begin{array}{l}\text { upper } \\
\text { bound }\end{array}$ \\
\hline Brown Galaxaura & & 3.468 & 3.072 & 3.864 & 3.557 & 3.052 & 4.061 \\
\hline Brown Sargassum & & 3.175 & 2.555 & 3.795 & 3.577 & 2.986 & 4.168 \\
\hline Pink Galaxaura & & 1.838 & 1.607 & 2.070 & 1.928 & 1.692 & 2.165 \\
\hline Pink Sargassum & & 7.523 & 7.018 & 8.028 & 8.493 & 7.970 & 9.016 \\
\hline
\end{tabular}




\section{CHAPTER 4}

Habitat-dependent niche partitioning between colour morphs of the algal-dwelling shrimp Hippolyte obliquimanus

Manuscript submitted to the journal "Ecological Indicators" 


\title{
Habitat-dependent niche partitioning between colour morphs of the algal-dwelling shrimp Hippolyte obliquimanus
}

\author{
Rafael C. Duarte ${ }^{1,2}$, Augusto A. V. Flores ${ }^{1}$, Catarina Vinagre ${ }^{3}$ and Miguel C. Leal ${ }^{4}$ \\ 1 - Centro de Biologia Marinha, Universidade de São Paulo, São Sebastião, Brazil. \\ 2 - Programa de Pós-Graduação em Biologia Comparada, Faculdade de Filosofia, Ciências e Letras de Ribeirão Preto, \\ Universidade de São Paulo, Ribeirão Preto, Brazil. \\ 3 - MARE - Marine and Environmental Sciences Centre, Faculdade de Ciências da Universidade de Lisboa, Lisboa, \\ Portugal \\ 4 - Department of Fish Ecology \& Evolution, Center for Ecology, Evolution and Biogeochemistry, Eawag: Swiss \\ Federal Institute of Aquatic Science and Technology, Kastanienbaum, Switzerland
}

\section{Abstract}

Trait-based differences among individuals are common and particularly important for polymorphic species in which alternative morphs exploit the same habitat types but occupy different trophic niches to reduce competition. The shrimp Hippolyte obliquimanus inhabits shallow-water vegetated habitats, particularly the seasonal and physically-complex brown alga Sargassum furcatum and the less-structured but temporally stable red weed Galaxaura. Two main colour morphs can be found in these habitats: homogeneous colour-changing shrimp that conceal to their background and show little mobility, and transparent shrimp with coloured stripes, which cannot match their background, show lower habitat fidelity and are more evenly distributed between algal habitats. We used carbon and nitrogen stable isotopes and Bayesian mixing models to test whether morph-specific patterns of habitat use observed for $\mathrm{H}$. obliquimanus living in Sargassum and Galaxaura meadows also imply on diet and trophic niche segregation. We observed habitat-dependent isotopic differences between shrimp morphs, with narrower niche space and lower niche overlap in Galaxaura, and broader niche areas and higher niche overlap in Sargassum. Niche segregation between morphs occurred only in Galaxaura, where available resources are presumably less abundant than in Sargassum. Trophic differences probably result from morph-specific feeding preferences, associated to 
ecological and behavioural traits, combined to spatial variation of the supply of food sources. Particularly, specialized feeding in transparent shrimp may provide this morph an advantage in the marginal Galaxaura habitat.

Keywords: stable isotopes, niche partition, niche overlap, mixing model, colour polymorphism 


\section{Introduction}

Individual phenotypic variation in behavioural and morphological traits is commonly observed across species (Bolnick et al. 2003) and is frequently associated to habitat-specific requirements (Booth 1990; Nylin and Gotthard 1998). Such phenotypic variation may involve differential use of (micro)habitats and food resources leading to trophic niche segregation among groups of individuals within a single species (Svanbäck and Eklöv 2002; Power et al. 2005; Kusche et al. 2015). Polymorphic species are ideal models to assess dietary diversification because different morphs are expected to use a subset of available resources and occupy different niches, ultimately reducing competition (Svanbäck and Bolnick 2007; Forsman et al. 2008). Morph-specific dietary patterns related to differential habitat use have been documented for a variety of polymorphic species, with morphs varying either in body coloration, as observed for isopods (Jormalainen and Tuomi 1989; Merilaita and Jormalainen 1997), grasshoppers (Karpestam and Forsman 2011) and lizards (Lattanzio and Miles 2016), and / or body shape, as observed for fish (Bourke et al. 1997; Svanbäck and Bolnick 2007) and salamanders (Maerz et al. 2006).

Colour polymorphic species have been frequently used as models to test theories and hypothesis about the evolution and ecological significance of warning signals, crypsis and social displays (Caro et al. 2016). Differences in habitat use between colour morphs, for example, are commonly interpreted as a consequence of phenotype-environment matching in order to obtain camouflage and avoid predation (Todd et al. 2006; Stevens et al. 2014), or a consequence of thermoregulatory requirements, as often observed for terrestrial ectotherms animals (Ahnesjö and Forsman 2006; Stuart-Fox and Moussalli 2009). However, while using variable habitats, different colour morphs are exposed to specific subsets of resources, which can result in morph-specific realized niches (Herder et al. 2008; Karpestam and Forsman 2011; Lattanzio and Miles 2014). Diet variation among morphs is, therefore, not only defined by individual variation in feeding preferences but also by qualitative and quantitative resource 
availability and specific ecological constraints and demands occurring in each habitat (Svanbäck and Eklöv 2002; Power et al. 2005; Karpestam and Forsman 2011). Different colour morphs of tree lizards (Urosaurus ornatus), for example, vary in microhabitat use, diet and aggressiveness between control and frequently burned sites, where the reduced availability of resources leads to a variation in the spatial network structure of these habitats (Lattanzio and Miles 2014).

Resource competition is widely assumed to be the main driver for both inter- and intraspecific trophic diversification, whereby niche overlap is reduced by diet segregation thus promoting coexistence of competing species or populations (MacArthur and Levins 1967; Pianka 1981). However, the effects of competition on niche partitioning between alternative morphs may have different outcomes according to individual feeding preferences and habitatspecific demands, including the availability, diversity and stability of potential food resources (Araújo et al. 2011). In a scenario where two phenotypically distinct morphs do not compete for resources and have similar food preferences, coexistence is possible even with high niche overlap (May 1973; Pianka 1981). Conversely, when the preferred resource has limited availability and the competition between morphs is keen, niche segregation can favour coexistence due to morph-specific use of secondary resources (Araújo et al. 2011). Coexistence patterns may also be influenced by temporal changes in the availability of resources, in which large niche overlap among individuals is expected to occur during periods of high resource availability. On the other hand, more stable habitats may favour niche segregation by allowing individual specialization under conditions of resource limitation (Sebastiano et al. 2012; Correa and Winemiller 2014).

Stable isotope analysis (SIA) has been increasingly used over the last 15 years to study the trophic ecology of organisms (Post 2002; Phillips 2012; e.g. Parnell et al. 2013). SIA is based on the principle that elements present in food sources, mainly carbon and nitrogen, are transferred to consumers and incorporated in their tissues (Phillips et al. 2014). More recently, 
SIA benefited from Bayesian mixing models to better estimate the contribution of different food sources consumed by an individual (Parnell et al. 2013). Additionally, isotopic variation can also be used to estimate ecological niche variation (Bearhop et al. 2004; Jackson et al. 2011). Ultimately, SIA is an important tool to assess resource and habitat use from the individual to the community level (Gannes et al. 1997; Newsome et al. 2007; Newsome et al. 2012).

The shrimp Hippolye obliquimanus is a polymorphic algal-dwelling species, very abundant in algal meadows at shallow rocky substrates along the Western Atlantic coast, including the northern coast of São Paulo State, Brazil. Shrimp populations comprise two distinct colour morphs: homogeneous individuals $(\mathrm{H})$ with the body totally covered by a brown or pink coloration, and striped translucent individuals (ST) with a transparent body, and either longitudinal or transversal colour bands (Duarte and Flores 2016). Both morphs are found in association with the physically-complex brown alga Sargassum furcatum (from now on Sargassum) and with the less-structured red weed Galaxaura marginata (hereafter Galaxaura). Sargarssum is a seasonal habitat (Godoy and Coutinho 2002; Leite and Turra 2003) hosting very dense shrimp populations in summer. In contrast, Galaxaura is likely a marginal and secondary habitat holding low shrimp densities (Duarte and Flores 2016) but maintaining a more stable cover year-round (Duarte, personal observation). Although there is no available information on the trophic ecology of $H$. obliquimanus, its diet is expected to be mostly composed by algal sources associated to Sargassum and Galaxaura, similarly to other algaldwelling hippolytid species that are important mesograzers and consume large proportions of macroalgae, algal epiphytes and vascular plants (Howard 1984; Zupo and Nelson 1999). The distribution of $\mathrm{H}$. obliquimanus in Sargassum and Galaxaura meadows is clearly morphdependent, with $\mathrm{H}$ shrimp occupying colour-matching substrates and concentrating in very high densities in Sargassum (where they show a brown coloration), whereas ST individuals are evenly distributed in both habitats (Duarte and Flores 2016). Also, morph-specific 
morphological and behavioural traits are observed, suggesting different strategies of habitat use. While $\mathrm{H}$ shrimp have a stout carapace shape, are more sedentary, and show a specialist strategy to exploit colour-matching backgrounds, ST individuals have a more streamlined shape, are more mobile, and make a more generalist use of algal habitats (Duarte et al. 2016). Differences in habitat use may drive dietary divergence between morphs, as individuals may encounter distinct subsets of food resources while foraging, or even may have different feeding preferences.

In this study, we used SIA coupled to Bayesian mixing models and niche parameters estimation to test whether differential patterns of habitat use also imply on trophic niche segregation between $H$. obliquimanus colour morphs. Given the observed differences in overall shrimp abundance and habitat complexity, we predicted (i) a broader niche space in Sargassum compared to Galaxaura, and thus a clearer niche segregation between morphs, allowing morph coexistence and explaining the unusual observations of very high shrimp densities in Sargassum (Duarte and Flores, 2016). Alternatively, and taking into account that ST and H shrimp generally prefer Sargassum to Galaxaura (Duarte et al., 2016), between-morph competition with ST shrimp spill-over to the marginal Galaxaura canopy may be also a probable scenario. In this case, (ii) niche segregation in Galaxaura, not in Sargassum, would indicate ST foraging specialization in a secondary but more stable habitat.

\section{Material and methods}

\section{Sampling Design and Stable Isotope Analysis}

Hippolyte obliquimanus shrimp were sampled from the canopy-forming macroalgae Sargassum and Galaxaura using a hand-net while snorkelling during the summer of 2016. Sampling was performed at shallow rocky bottoms (maximum depth of $2 \mathrm{~m}$ ) in two sites $5 \mathrm{~km}$ apart within

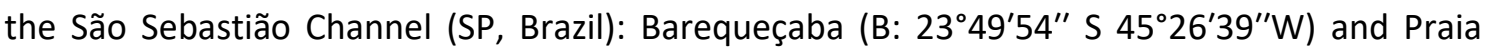
Grande (PG: $23^{\circ} 49^{\prime} 28^{\prime \prime} \mathrm{S} 45^{\circ} 24^{\prime} 50^{\prime \prime} \mathrm{W}$ ). In each site, sampling was limited to an area of 
approximately $1,000 \mathrm{~m}^{2}$ to avoid collecting shrimp from different populations. In the laboratory, shrimp were classified according to colour morph (homogeneous $-\mathrm{H}$, and striped translucent - ST, as in Duarte \& Flores, 2016). A total of 32 individuals from each site, algal habitat and colour morph (summing up 256 shrimps) were obtained and stored at $-20^{\circ} \mathrm{C}$.

In order to estimate the contribution of potential food sources to $\mathrm{H}$. obliquimanus diet, we collected three samples (ca. $150 \mathrm{~g}$ wet weight) of the host algae (Sargassum and Galaxaura) and the two most common macroepiphytes that grow associated to both host algae (Hypnea musciformis, from now on Hypnea; and Asparagopsis taxiformis, in its sporophytic form, hereafter Asparagopsis). In the laboratory, macroepiphytes were separated from their algal hosts and all material was washed with distilled water and carefully cleaned from sediments, detritus, and fauna under a dissecting microscope. Shrimp, host algae and epiphytes from each sample were dried at $60^{\circ} \mathrm{C}$ for $24 \mathrm{~h}$ and grounded to a fine powder using a porcelain mortar and pestle. Shrimp and Galaxaura samples were acidified owing to the presence of carbonates. Galaxaura samples were directly washed with $\mathrm{HCl}(10 \%)$ until bubbling ceased. Shrimp samples, because of their small biomass, were fumigated with $10 \mathrm{~mL}$ of $\mathrm{HCl}(10 \%)$ inside a desiccator for $12 \mathrm{~h}$ (Komada et al. 2008). All samples were then dried at $60^{\circ} \mathrm{C}$ for $24 \mathrm{~h}$. Results confirmed that acid-washing efficiently removed carbonates by reducing $\delta^{13} \mathrm{C}$ values in acidified samples (paired $t$-test: $n=40 ; t=4.921 ; p<0.001$ ) with no effects on $\delta^{15} \mathrm{~N}$ (paired $t$ test: $n=40 ; t=1.452 ; p=0.154)$.

Samples of $\sim 0.5 \mathrm{mg}$ were loaded into tin cups for stable isotope analysis using an Elementar Isoprime continuous-flow mass spectrometer (GV Instruments) coupled to a vario PYRO cube elemental analyser (Elementar, Hanau, Germany). Reference materials (acetanilide; Stable Isotope Research Facility, Indiana University, USA) were assayed at the beginning of each run and after every 10 samples, with an average measurement precision of $0.04 \%$ and $0.12 \%$ for $\delta^{13} \mathrm{C}$ and $\delta^{15} \mathrm{~N}$, respectively. 


\section{Statistical analyses}

Isotopic signatures - We compared shrimp isotopic signatures $\left(\delta^{13} \mathrm{C}\right.$ and $\left.\delta^{15} \mathrm{~N}\right)$, both individually and simultaneously, across the levels of the factors "site" (B and PG), "algal habitat" (Sargassum and Galaxaura) and "morph" (H and ST) and their interactions using PERMANOVA analysis (permutational multivariate ANOVA; Anderson 2001). Isotope values $\left(\delta^{13} \mathrm{C}\right.$ or $\delta^{15} \mathrm{~N}$ ) were normalised (mean-subtraction and division by the standard deviation) and a resemblance matrix was obtained based on Euclidian distances. Tests were carried out using Type III sum of squares and 9,999 permutations of the residuals under a reduced model. Post-hoc pairwise ttests were run to further examine significant sources of variation. Analyses were conducted using Primer 6 and PERMANOVA (Primer-E Ltd., Plymouth, UK).

Isotopic niche - Biplot ellipses are frequently used to delineate isotopic niche space of a species or group of individuals (Jackson et al. 2011), thereby revealing their core niche area as each ellipse contains approximately $40 \%$ of the data (Ricklefs and Nealen 1998). To test if niche space differed between shrimp morphs in each algal habitat, we adjusted ellipses to the isotopic data and obtained the standard ellipse area (SEA) and the overlap area (OA) using the package SIAR (Jackson et al. 2011), implemented in the statistical computing environment $R$ ( $R$ Development Core Team 2016). We incorporated uncertainty in both SEA and OA estimates with an iterative Bayesian approach that uses Monte Carlo Markov-Chain simulations. SEA (expressed as $\%^{2}$ ) was used as a proxy for niche space, and OA (expressed as $\%$ of area) was used as a quantitative measure of dietary similarity. Both parameters were estimated based on 10,000 draws, from which the ellipse parameters were calculated. We applied a standard step size $(=5)$ to define ellipses with smooth roundness for overlap calculations. Simulations were run separately for each sampling location (B or PG) and posterior probabilities were estimated through pairwise comparisons of niche parameters (SEA and OA) between morphs and algal habitats (Jackson et al. 2011). 
Mixing model - The relative contribution of potential food sources (Sargassum, Galaxaura, Hypnea and Asparagopsis) to the diet of shrimp was estimated using a Bayesian mixing model within the statistical package 'simmr' (Stable Isotope Mixing Model in R, version 0.2), which is based on the model SIAR (Parnell et al. 2013) implemented in R (Parnell 2016). Parameters included in the model were $\delta^{13} \mathrm{C}$ and $\delta^{15} \mathrm{~N}$ isotopic ratios of shrimp (raw data) and food sources (mean $\pm S D$ ), concentration dependence means, i.e. the estimated value for the proportion of $\mathrm{C}$ and $\mathrm{N}$ in each food source, and a fractionation factor (trophic enrichment factor; TEF) between resources and consumers. No significant differences in isotopic signatures of both algae and epiphytes were observed between $B$ and PG $\left(p>0.05\right.$; for both $\delta^{13} C$ and $\left.\delta^{15} N\right)$, which allowed us pooling the data from both sites and increase test power (Supplementary Table 1). Because we do not have information on TEFs for $H$. obliquimanus, standard values were implemented in the model (i.e. $1.63 \pm 0.63 \%$ ofor $\delta^{13} \mathrm{C}$ and $3.54 \pm 1.50 \%$ ofor $\delta^{15} \mathrm{~N}$ - Minagawa and Wada 1984; Post 2002), as frequently applied for amphipods (Bessa et al. 2014) and other algal dwelling invertebrates, including species living in Sargassum meadows (Rossi et al. 2010). However, we used a higher SD for $\delta^{15} \mathrm{~N}(1.50)$ compared to standard (0.74), as in Hata et al. (2015), because herbivorous species normally display larger TEFs than carnivores or detritivores (Mill et al. 2007). We ran separate models for each sampling site and algal habitat and set Markov Chain Monte Carlo (MCMC) parameters as follows: number of iterations = 10,000 , burn $=1,000$, thin $=10$, number of chains $=4$. Gelman-Rubin diagnostic tests were used to verify the convergence of the models (Parnell et al. 2013).

\section{Results}

\section{Isotopic signatures}

The combined analysis of the isotopic signatures of $H$. obliquimanus showed significant differences between colour morphs, algal habitats and sites, but the significant interactions observed among some factors suggest that the direction and magnitude of such differences 
are habitat and site specific (Table 1). For instance, $\mathrm{H}$ and ST shrimp showed different isotopic niches in Galaxaura (PERMANOVA, $t_{1,124}=4.42, p<0.001$ ) but not in Sargassum (PERMANOVA, $\left.t_{1,124}=1.71, p=0.055\right)$, which explains the significant interaction between algal habitat and morphs (Table 1). Similarly, different isotopic signatures were observed between shrimp occupying distinct algal habitats in both sampling sites (PERMANOVA; Barequeçaba: $t_{1,124}=$ 3.07, $p<0.001 /$ Praia Grande: $t_{1,124}=5.74, p<0.001$ ), but the magnitude of this difference was higher in PG than in $B$, as observed by the significant interaction between site and algal habitat (Table 1).

The univariate analysis of isotopic ratios showed differences between morphs for both $\delta^{15} \mathrm{~N}$ and $\delta^{13} \mathrm{C}$ (Table 1, Fig. 1). Nevertheless, $\delta^{15} \mathrm{~N}$ differences between morphs depended on algal habitat: $\delta^{15} \mathrm{~N}$ values were similar between $\mathrm{H}$ (mean $\pm \mathrm{SE}=6.57 \%$ o \pm 0.10 ) and ST shrimp $(6.57 \% \circ \pm 0.13)$ in Sargassum $\left(t_{1,124}=0.02 ; p=0.977\right)$, whereas in Galaxaura ST individuals presented lower isotopic values than $\mathrm{H}$ shrimp $\left(\mathrm{ST}=5.58 \% \circ \pm 0.12 ; \mathrm{H}=6.20 \% \circ \pm 0.11 ; t_{1,124}=\right.$ 3.63; $p<0.001$; Fig. 1a, for both B and PG sites). On the other hand, the $\delta^{13} \mathrm{C}$ signature of ST shrimp was significantly more enriched than that of $\mathrm{H}$ individuals, regardless of site or algal habitat $\left(\mathrm{ST}=-16.10 \%\right.$ o $\pm 0.08 ; \mathrm{H}=-16.54 \% \pm \pm 0.07 ; t_{1,124}=5.24 ; p<0.001 ;$ Fig. $\left.1 \mathrm{~b}\right)$. Carbon isotope values were also different between shrimp from each algal habitat in both sites (Barequeçaba: $t_{1,124}=3.12, p=0.002$ / Praia Grande: $t_{1,124}=6.51, p<0.001$ ). Individuals from Galaxaura were more enriched than those from Sargassum, and shrimp from B were more enriched than those from PG (Fig. 1b). The significant interaction between site and algal habitat was associated with the magnitude of the $\delta^{13} \mathrm{C}$ difference between algal habitats, which was higher in PG than in B (Table 1). 
Table 1 - Results of the three-way PERMANOVA testing simultaneous and individual differences of $\delta^{15} \mathrm{~N}$ and $\delta^{13} \mathrm{C}$ isotopes measured in Hippolyte obliquimanus shrimp between sampling sites (Barequeçaba and Praia Grande), algal habitats (Sargassum and Galaxaura) and colour morphs (homogeneous and striped translucent).

\begin{tabular}{|c|c|c|c|c|c|c|c|c|c|c|}
\hline \multirow[b]{2}{*}{ Source of variation } & \multirow[b]{2}{*}{$d f$} & \multicolumn{3}{|c|}{$\delta^{15} N+\delta^{13} C$} & \multicolumn{3}{|c|}{$\delta^{15} N$} & \multicolumn{3}{|c|}{$\delta^{13} \mathrm{C}$} \\
\hline & & $M S$ & $F$ & $p$ (perm) & $M S$ & $F$ & $p$ (perm) & $M S$ & $F$ & $p$ (perm) \\
\hline Site (S) & 1 & 55.036 & 38.16 & 0.000 & 0.744 & 0.88 & 0.351 & 54.291 & 90.45 & 0.000 \\
\hline Algal habitat (A) & 1 & 57.221 & 39.68 & 0.000 & 28.345 & 33.66 & 0.000 & 28.875 & 48.11 & 0.000 \\
\hline Morph (M) & 1 & 22.267 & 15.44 & 0.000 & 5.772 & 6.85 & 0.009 & 16.496 & 27.48 & 0.000 \\
\hline$S \times A$ & 1 & 6.930 & 4.80 & 0.009 & 2.317 & 2.75 & 0.100 & 4.613 & 7.69 & 0.006 \\
\hline$S \times M$ & 1 & 3.153 & 2.19 & 0.113 & 2.468 & 2.93 & 0.089 & 0.686 & 1.14 & 0.297 \\
\hline$A \times M$ & 1 & 6.842 & 4.74 & 0.008 & 5.922 & 7.03 & 0.008 & 0.921 & 1.53 & 0.221 \\
\hline$S \times A \times M$ & 1 & 0.873 & 0.61 & 0.551 & 0.618 & 0.73 & 0.388 & 0.255 & 0.43 & 0.512 \\
\hline Residual & 248 & 1.442 & & & 0.842 & & & 0.600 & & \\
\hline
\end{tabular}



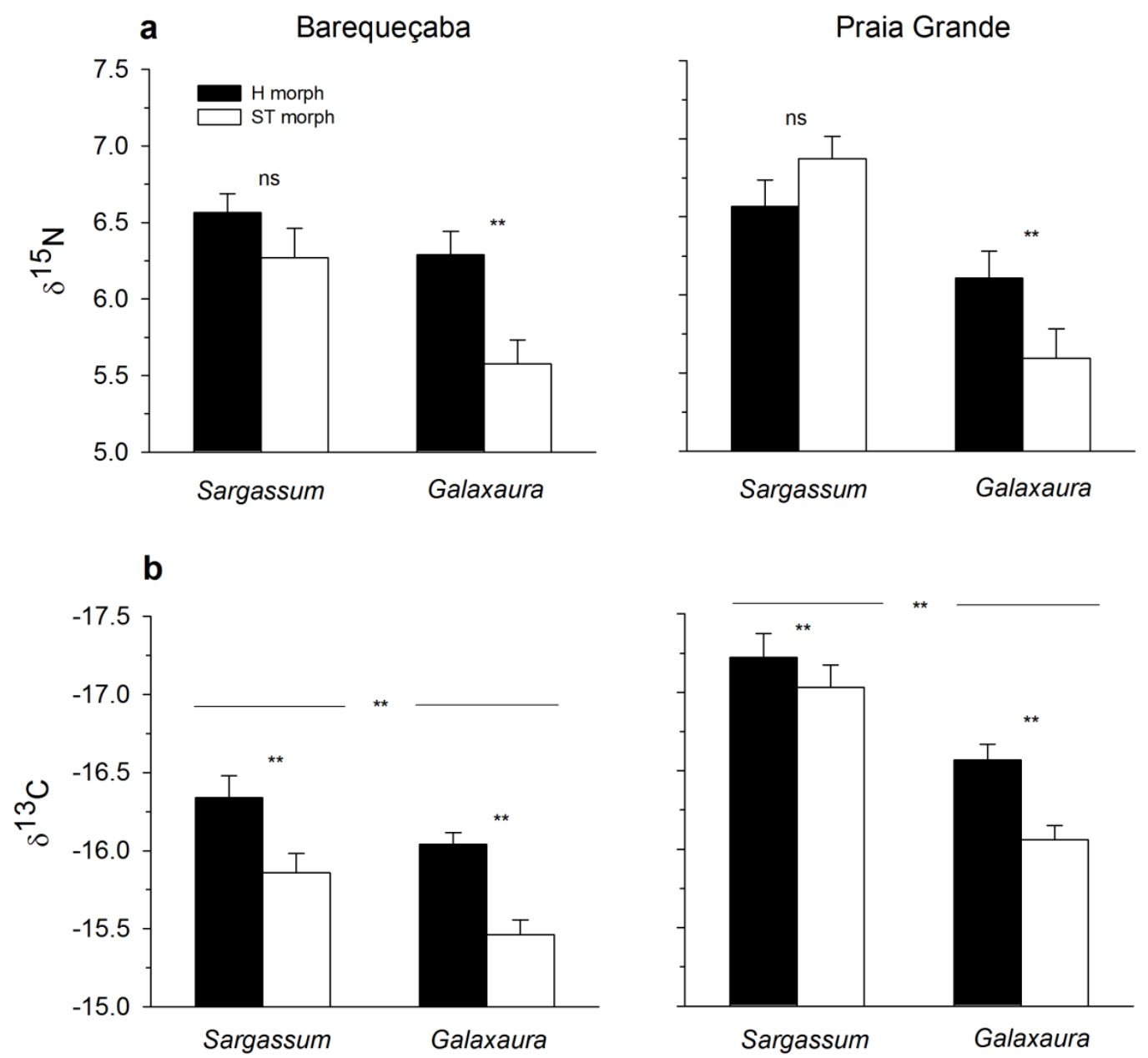

Figure 1 - Mean (+1SE) isotopic signatures of $\delta^{15} \mathrm{~N}(\mathbf{a})$ and $\delta^{13} \mathrm{C}(\mathbf{b})$ for Hippolyte obliquimanus individuals from different colour morphs (Homogeneous - H; Striped Translucent - ST) and algal habitats (Sargassum and Galaxaura), collected at Barequeçaba and Praia Grande. ns: not significant; ${ }^{* *} p<0.01$.

\section{Isotopic niche}

The isotopic niche modelling revealed significant differences in both ellipse area and overlap between morphs and algal habitats (Fig. 2). At B, the niche area (SEA) occupied by shrimp in Galaxaura was smaller than in Sargassum regardless of morph, with an associated probability of $92.34 \%$ (Fig. 2a). Additionally, ST shrimp from B exhibited a larger isotopic area compared to $\mathrm{H}$ individuals (Fig. 2a), with an associated probability of $81.45 \%$. Niche overlap between $\mathrm{H}$ and ST morphs varied with algal habitats, being significantly lower in Galaxaura (median and $\mathrm{Cl}_{95 \%}: 0.20,0.02$ to 0.47 ) than in Sargassum (0.57, $\mathrm{Cl}_{95 \%} 0.31$ to 0.85 ; Fig. $2 \mathrm{~b}$ ). The 
probability of lower niche overlap between morphs in Galaxaura than in Sargassum was $94.99 \%$.

In PG, SEA values were relatively similar between morphs and algal habitats (Fig. 2c). Based on SEA simulations, the probability for shrimp showing smaller niche areas in Galaxaura than in Sargassum was $74.29 \%$. For morph differences, the posterior probability for ST shrimp occupying larger niche area than $\mathrm{H}$ individuals was only $32.62 \%$. Niche overlap between $\mathrm{H}$ and ST morphs was lower in Galaxaura (0.42, $\mathrm{Cl}_{95 \%} 0.20$ to 0.67 ) than in Sargassum ( $0.53, \mathrm{Cl}_{95 \%} 0.35$ to 0.74 ; Figure $2 \mathrm{~d}$ ), but the associated probability was $73.25 \%$. This value was lower than in $B$, suggesting that shrimp morphs in PG exhibit more similar niche spaces between algal habitats.
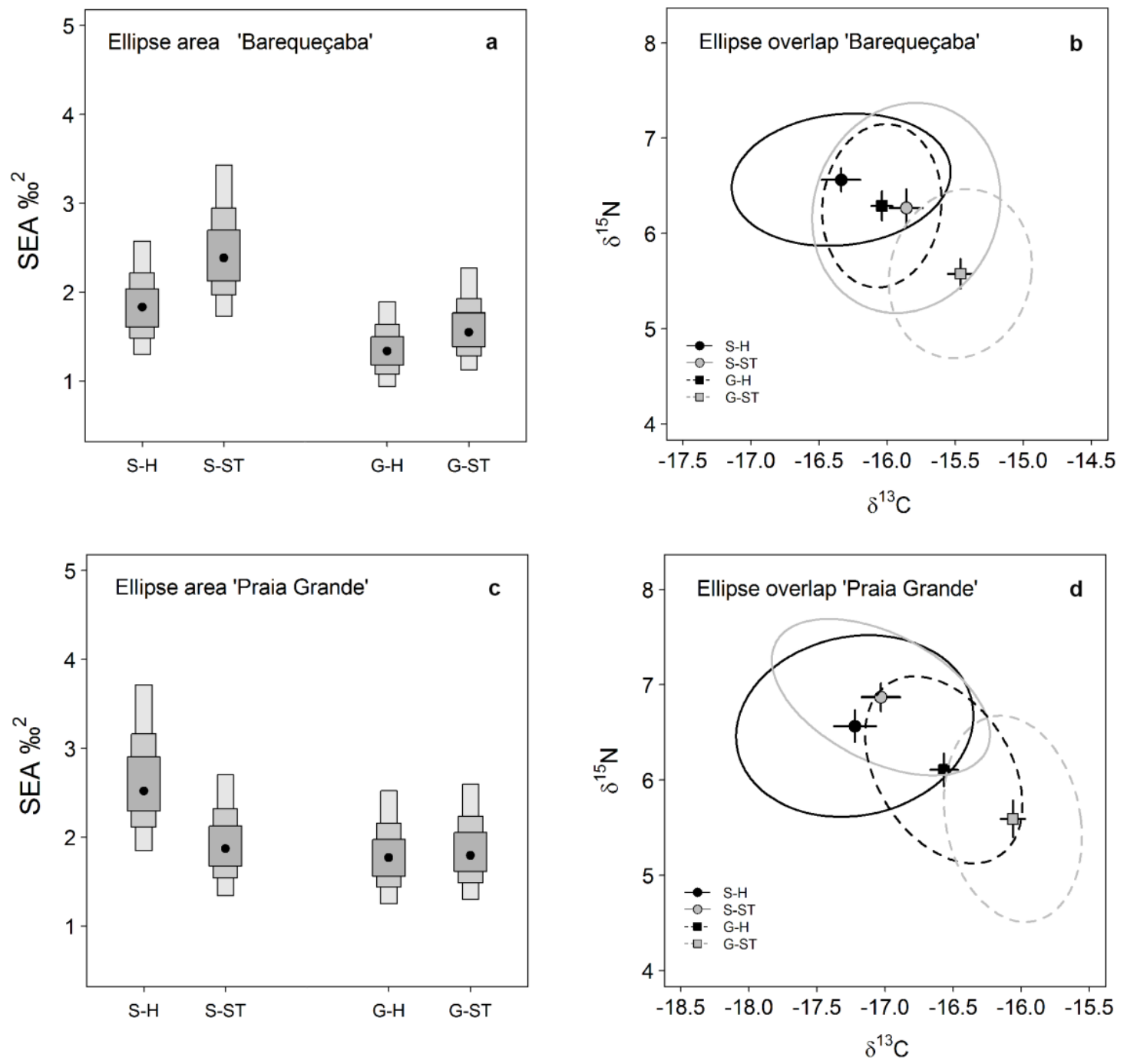
Figure 2 - Niche area and overlap estimates for the shrimp Hippolyte obliquimanus collected at Barequeçaba (a, b) and Praia Grande (c, d). a, c Measures of uncertainty and central tendency (black symbols = mean) of Bayesian standard ellipse areas (SEA) fitted to isotopic data of shrimp colour morphs sampled in Sargassum or Galaxaura algal habitats. SEA estimates were based on 10,000 posterior draws of parameters, and the stacked bars show 95 , 75 and $50 \%$ credibility intervals from light to dark grey, respectively. b, d Mean isotopic signatures ( \pm 1 SE) and isotopic niche breadth (proportional to ellipse size), showing niche overlap between shrimp morphs at the two algal habitats. S-H and S-ST: Homogeneous and Striped Translucent morphs in Sargassum; G-H and G-ST: Homogeneous and Striped Translucent morphs in Galaxaura.

\section{Mixing model}

The contribution of potential food sources to the diet of $H$. obliquimanus was analysed separately for each algal habitat and sampling site. Mixing models properly converged in all cases (Gelman diagnostics, all estimates < 1.01). The outputs for fitted models are detailed in Supplementary Table 2. Independently of morph, algal habitat or site, the epiphytic alga Hypnea, which grows over both Sargassum and Galaxaura, was estimated as the main food source (Fig. 3). In the Sargassum habitat, Hypnea contributed similarly to the diet of both morphs at both sampling sites (ca. 60\%, Fig. 3a). Sargassum had the second largest contribution for shrimp in $\mathrm{B}$, with similar proportions for both morphs $(17.5 \%$ for $\mathrm{H}$ and $20.4 \%$ for ST). On the contrary, Asparagopsis represented the second largest proportion of shrimp's diet in PG, with a contribution of $22.5 \%$ and $20.1 \%$ for $\mathrm{H}$ and ST shrimp respectively. Galaxaura had a minor contribution to the diet of both morphs living in Sargassum (Fig. 3a). In the Galaxaura habitat, Hypnea was also estimated as the main food source to shrimp, but its importance was consistently higher in $\mathrm{H}$ compared to ST shrimp across sampling sites (Fig. 3b). The probability of dietary proportion of Hypnea being greater in $\mathrm{H}$ shrimp than in ST individuals was $86.6 \%$ in B and $79.2 \%$ in PG. However, the main dietary difference between morphs in the Galaxaura habitat was the relative contribution of Galaxaura itself. The probability of the contribution of the red alga to the diet of ST shrimp was almost the double than that observed for $\mathrm{H}$ individuals, regardless of sampling site (Fig. $3 \mathrm{~b}$ ). Posterior probability 
for Galaxaura contribution was higher in ST than H shrimp in both sites $(90.4 \%$ in B and $87.6 \%$ in PG). Sargassum and Asparagopsis had both minor contributions to the diet of shrimp in Galaxaura meadows (Fig. 3b).

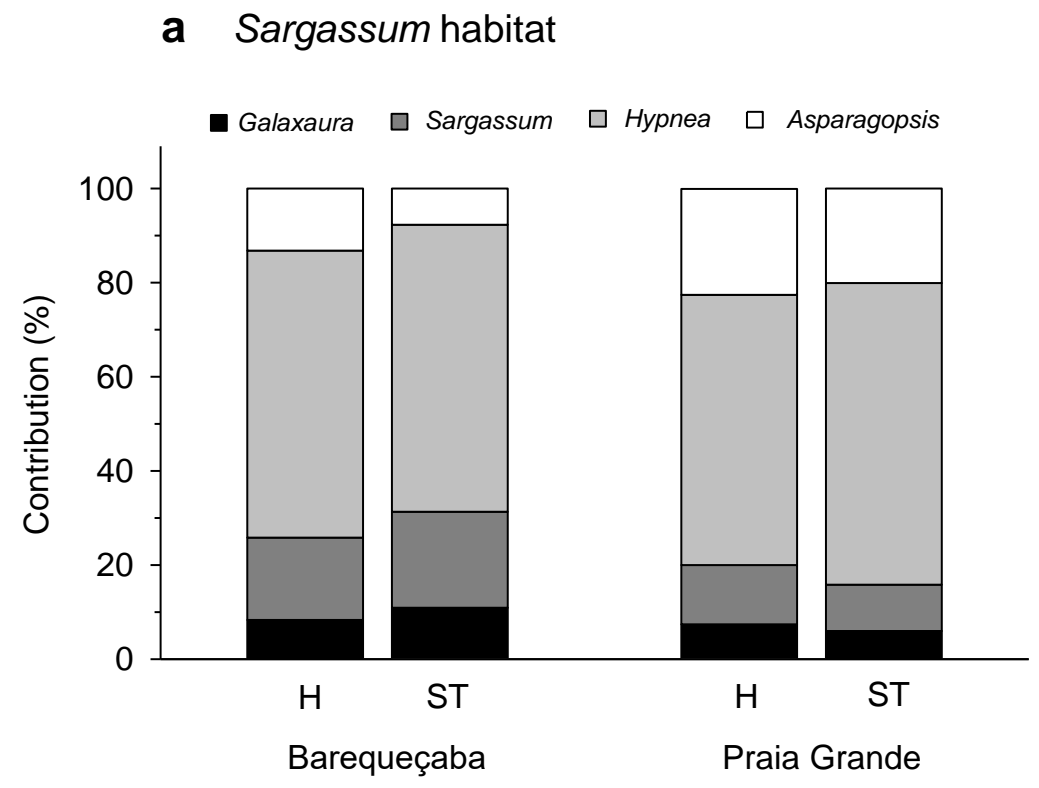

b Galaxaura habitat

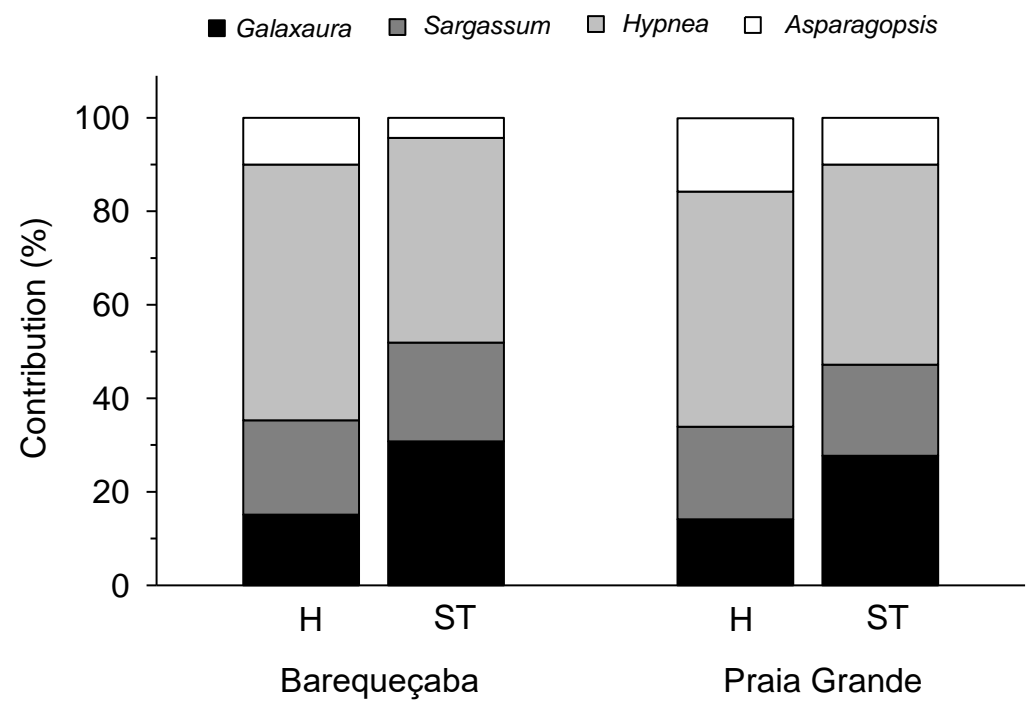

Figure 3 - Results of Bayesian mixing models for the contributions (mean \%) of algal sources Galaxaura, Sargassum, Hypnea and Asparagopsis to the diet of Hippolyte obliquimanus colour morphs (Homogeneous - H and Striped Translucent - ST) sampled in Sargassum (a) and Galaxaura (b) habitats in Barequeçaba and Praia Grande. Detailed results of the fitted models are shown in Supplementary Table 2. 


\section{Discussion}

We report dietary segregation between colour morphs of the algal-dwelling shrimp Hippolyte obliquimanus in different habitats and sampling sites. Shrimp morphs living in the more complex and, presumably, higher-quality Sargassum habitat exhibited broad niches and similar isotopic ratios, indicating the use of similar resources and a large dietary overlap. In contrast, shrimp colour morphs sampled in the physically less structured Galaxaura habitat showed different isotopic signatures, narrow niches and more restricted niche overlap. The morphand habitat-specific niche segregations here observed are likely associated with morph-specific feeding preferences, together with ecological and behavioural differences between morphs (Duarte et al. 2016), and spatial variation in the availability and accessibility of food sources.

\section{Habitat and site effects}

The stable isotopic signatures of $H$. obliquimanus were different between sites and habitats, with habitat effects being similar between sites. These isotopic differences can be primarily associated with contrasting supply of resources to shrimp morphs in each habitat and site. Site differences may also reflect spatial variation in baseline conditions regulating primary production, which affect the isotopic signature of carbon transferred throughout the food web (Post 2002). Differently from Galaxaura, Sargassum meadows host very large densities of epiphytic algae, especially during the summer (Leite and Turra 2003; Jacobucci et al. 2009), which may explain the larger contribution of Hypnea and Asparagopsis to the diet of shrimp sampled in Sargassum. The low values of $\delta^{13} \mathrm{C}$ in shrimp from the Sargassum habitat can be also explained by such large density of epiphytes, since these algae showed more depleted $\delta^{13} \mathrm{C}$ values than the other food sources here examined.

The sites sampled in this study, although relatively close (approx. $5 \mathrm{~km}$ ), are exposed to different inputs of organic matter and coastal runoff, likely affecting the availability of resources. Praia Grande is close to Araçá Bay and the São Sebastião Harbour, two areas 
receiving freshwater drainage from small creeks and sewage discharge. The prevailing circulation within the São Sebastião Channel favours southwestward transport (Silva et al. 2005) and the deposition of those organic materials in Praia Grande, but not in Barequeçaba which is located at the south end of the channel where the influence of oceanic waters prevails. The more depleted carbon isotopic signatures at Praia Grande are consistent with such an increased nutrient concentration and riverine input (Fry 1999). High nutrient loads at Praia Grande may also lead to increased algal growth, and therefore more extensive foraging grounds at this site. The higher niche overlap between morphs at Praia Grande, compared to Barequeçaba, is consistent to an intense use of those additional resources mediated by weaker between-morph competitive interactions (Pianka 1981; Strong 1982; González-Solís et al. 1997).

\section{Habitat-dependent trophic segregation between morphs}

Niche and dietary divergence between $H$. obliquimanus colour morphs were habitat dependent. In Sargassum, morphs exhibited similar isotopic signatures and high niche width and overlap, suggesting they use a wide range of similar food sources in this habitat. This result does not support one of our initial predictions, namely that trophic differentiation in Sargassum, where shrimp density can be exceptionally high (Duarte and Flores 2016), could reduce competition between colour morphs (MacArthur and Levins 1967; Bolnick 2001; Araújo et al. 2011). The surplus of food resources in the Sargassum habitat (Jacobucci and Leite 2014) may relax competition between morphs, even when coexisting in very large densities. The role of epiphytic algae in the brown weed canopy is apparently very important, as mixing models estimated Hypnea as the main food source for both morphs, suggesting trophic generalization, with diets based on resources likely preferred by these shrimp (Araújo et al. 2011). Results suggest that high abundance of food sources (i.e. epiphytes), especially in summer when sampling was performed (Leite and Turra 2003; Jacobucci et al. 2009), allows extensive morph 
coexistence in Sargassum (Duarte and Flores 2016) in spite of a broad trophic niche overlap (May 1973; Pianka 1981). Similar evidence was observed for different species of hispine beetles living in Heliconia plants, where both habitat and food availability are abundant and promote coexistence among species without niche segregation (Strong 1982).

Although Sargassum is considered a high-quality habitat for $H$. obliquimanus shrimp (Duarte and Flores 2016), it constitutes seasonal habitat with very high cover and biomass during summer followed by a drastic reduction in winter (Godoy and Coutinho 2002). Because of this seasonality, there might be simply no sufficient time for longer-term niche differentiation to build up, as dietary specialization is expected to take place in more stable habitats. Resource partitioning between morphs may otherwise occur during periods of low Sargassum cover (i.e. winter), when more limited availability of resources may force individuals of both morphs to exploit alternative food sources, as observed in the more stable Galaxaura habitat. Our findings are consistent to results obtained for other seasonal systems, such as the sympatric salamander species (Speleomantes strinatii and Salamandrina perspicillata) in a temperate forest, which exhibited similar trophic diversity and large niche overlap during spring, when prey availability was very high, but not in autumn, when prey biomass decreased and resource partitioning between species emerged (Sebastiano et al. 2012).

Although the Galaxaura habitat supplies a relatively reduced range of resources, as indicated by the narrow isotopic space, the lower $\delta^{15} \mathrm{~N}$ of ST shrimp compared to $\mathrm{H}$ individuals provides evidence for between-morph niche segregation in this habitat. Epiphytic Hypnea was still the main food source for both morphs, but its share on the diet of ST shrimp was smaller, owing to an increased consumption of Galaxaura. Compared to Sargassum, Galaxaura meadows show lower structural complexity and support lower epiphytism (Russo 1990; Duarte and Flores 2016), which likely affect shrimp foraging probabilities (Hall and Bell 1988; MartinSmith 1993) and intensify competition among individuals. The shorter supply of the most 
consumed food source (Hypnea) in this habitat may force the use of a secondary resource (Galaxaura) by the more generalist ST morph, ultimately reducing competition and promoting morph coexistence (Svanbäck and Bolnick 2007; Tinker et al. 2008; Araújo et al. 2011). Differently from Sargassum, Galaxaura habitats are temporally stable, with similar biomass and substrate cover year-round (Duarte, personal observation), favouring long-term dietary diversification, with ST individuals specializing on alternative resources when the supply of preferred resources is short (Araújo et al. 2011; Sebastiano et al. 2012; Correa and Winemiller 2014).

The two $\mathrm{H}$. obliquimanus colour morphs differ in a suite of morphological, behavioural and life-history traits (Duarte et al. 2016), which can have direct consequences on the trophic ecology of individuals (Forsman et al. 2008). ST shrimp are active swimmers and make a generalist use of habitats, while $\mathrm{H}$ shrimp are sedentary and show higher habitat fidelity (Duarte et al. 2016; Duarte and Flores 2016). High mobility and the generalist behaviour of the ST morph may favour individuals to find different food sources when exploring alternative microhabitats, which may result in a broader and more diversified trophic niche (Zalewski et al. 2015). Indeed, we found a larger niche space for ST shrimp compared to $H$ individuals in Barequeçaba, but not in Praia Grande, where nutrient contents and food abundance are presumably higher (see discussion above). Additionally, as a probable consequence of shrimp mobility, a more diversified diet with lower dominance of Hypnea and more similar contributions of other food sources was observed in ST shrimp, but only in Galaxaura, where the apparent limitation of resources may induce individuals to explore additional resources in order to reduce competition (Araújo et al. 2011). We do not discard, however, that shrimp morphs may vary in their innate preferences, metabolism, and physiological demands for food. Experimental trials measuring individual preference for food sources of shrimp sampled in different algal habitats are necessary to answer these pending questions. 
Conceptual and theoretical models have been developed to explain how species polymorphism contribute to population stability through diet segregation and decreased intraspecific competition (Bolnick et al. 2003; Forsman et al. 2008). Our findings consistently illustrate these concepts, supporting niche partitioning between $\mathrm{H}$ and ST colour morphs of the shrimp $H$. obliquimanus when living in the secondary, less-structured Galaxaura habitat (Duarte and Flores 2016). In spite of a broad niche overlap between morphs, coexistence is possible in Sargassum since resources (i.e. food and shelter) are likely not critically limited in this algal habitat (Jacobucci et al. 2009; Jacobucci and Leite 2014). Morph diversification on resource use can also be important to maintain shrimp populations stable during temporal fluctuations of the high-quality habitat Sargassum. Upon habitat transitions, the plasticity of ST individuals may allow the use of alternative food sources and thus efficient colonization of new habitat patches. Combined with their overall generalist behaviour and high dispersal potential (Duarte et al. 2016), ST shrimp dynamics are apparently of pivotal importance for population persistence over time.

\section{Acknowledgements}

We are grateful to Maria Fernanda Morrison for her help on sample processing and to Inês Carvalho for preparation of stable isotope analyses. This work was supported by the Fundação de Amparo à Pesquisa do Estado de São Paulo - FAPESP (2012/17003-0), which granted a PhD fellowship to RCD. This is a contribution of the Research Centre for Marine Biodiversity of the University of São Paulo (NP-Biomar / USP).

\section{References}

Ahnesjö J, Forsman A (2006) Differential habitat selection by pygmy grasshopper color morphs; interactive effects of temperature and predator avoidance. Evol Ecol 20:235-257.

Anderson MJ (2001) A new method for non-parametric multivariate analysis of variance. Austral Ecol 26:32-46. 
Araújo MS, Bolnick DI, Layman CA (2011) The ecological causes of individual specialisation. Ecol Lett 14:948-958.

Bearhop S, Adams CE, Waldron S, et al (2004) Determining trophic niche width: a novel approach using stable isotope analysis. J Anim Ecol 73:1007-1012.

Bessa F, Baeta A, Marques JC (2014) Niche segregation amongst sympatric species at exposed sandy shores with contrasting wrack availabilities illustrated by stable isotopic analysis. Ecol Indic $36: 694-702$.

Bolnick DI (2001) Intraspecific competition favours niche width expansion in Drosophila melanogaster. Nature 410:463-466.

Bolnick DI, Svanbäck R, Fordyce JA, et al (2003) The ecology of individuals: incidence and implications of individual specialization. Am Nat 161:1-28.

Booth CL (1990) Evolutionary significance of ontogenetic colour change in animals. Biol J Linn Soc 40:125-163.

Bourke P, Magnan P, Rodríguez M, Rodriguez MA (1997) Individual variations in habitat use and morphology in brook charr. J Fish Biol 51:783-794.

Caro T, Sherratt TN, Stevens M (2016) The ecology of multiple colour defences. Evol Ecol 30:797809.

Correa SB, Winemiller KO (2014) Niche partitioning among frugivorous fishes in response to fluctuating resources in the Amazonian floodplain forest. Ecology 95:210-224.

Duarte RC, Flores AAV (2016) Morph-specific habitat and sex distribution in the caridean shrimp Hippolyte obliquimanus. J Mar Biol Assoc United Kingdom (online) 1-8. doi: $10.1017 / \mathrm{S} 0025315416000230$

Duarte RC, Stevens M, Flores AA V. (2016) Shape, colour plasticity, and habitat use indicate morphspecific camouflage strategies in a marine shrimp. BMC Evol Biol 16:218.

Forsman A, Ahnesjö J, Caesar S, Karlsson M (2008) A model of ecological and evolutionary consequences of color polymorphism. Ecology 89:34-40.

Fry B (1999) Using stable isotopes to monitor watershed influences on aquatic trophodynamics. Can J Fish Aquat Sci 56:2167-2171.

Gannes LZ, O’Brien DM, Del Rio CM (1997) Stable isotopes in animal ecology: assumptions, caveats, and a call for more laboratory experiments. Ecology 78:1271-1276. 
Godoy EAS, Coutinho R (2002) Can artificial beds of plastic mimics compensate for seasonal absence of natural beds of Sargassum furcatum? ICES J Mar Sci 59:111-115.

González-Solís J, Oro D, Jover L, et al (1997) Trophic niche width and overlap of two sympatric gulls in the southwestern Mediterranean. Oecologia 112:75-80.

Hall M, Bell S (1988) Response of small motile epifauna to complexity of epiphytic algae on seagrass blades. J Mar Res 46:613-630.

Hata H, Shibata J, Omori K, et al (2015) Depth segregation and diet disparity revealed by stable isotope analyses in sympatric herbivorous cichlids in Lake Tanganyika. Zool Lett 1:1-11.

Herder F, Pfaender J, Schliewen UK (2008) Adaptive sympatric speciation of polychromatic "roundfin" sailfin silverside fish in Lake Matano (Sulawesi). Evolution (N Y) 62:2178-95.

Howard R (1984) The trophic ecology of caridean shrimps in an eelgrass community. Aquat Bot 18:155174.

Jackson AL, Inger R, Parnell AC, Bearhop S (2011) Comparing isotopic niche widths among and within communities: SIBER - Stable Isotope Bayesian Ellipses in R. J Anim Ecol 80:595-602.

Jacobucci GB, Leite FPP (2014) The role of epiphytic algae and different species of Sargassum in the distribution and feeding of herbivorous amphipods. Lat Am J Aquat Res 42:353-363.

Jacobucci GB, Tanaka MO, Leite FPP (2009) Factors influencing temporal variation of a Sargassum filipendula (Phaeophyta: Fucales) bed in a subtropical shore. J Mar Biol Assoc United Kingdom 89:315.

Jormalainen V, Tuomi J (1989) Sexual differences in habitat selection and activity of the colour polymorphic isopod Idotea baltica. Anim Behav 38:576-585.

Karpestam E, Forsman A (2011) Dietary differences among colour morphs of pygmy grasshoppers revealed by behavioural experiments and stable isotopes. Evol Ecol Res 13:461-477.

Komada T, Anderson MR, Dorfmeier CL (2008) Carbonate removal from coastal sediments for the determination of organic carbon and its isotopic signatures, $\delta^{13} \mathrm{C}$ and $\Delta^{14} \mathrm{C}$ : comparison of fumigation and direct acidification by hydrochloric acid. Limnol Oceanogr Methods 6:254-262.

Kusche H, Elmer KR, Meyer A (2015) Sympatric ecological divergence associated with a color polymorphism. BMC Biol 13:82.

Lattanzio MS, Miles DB (2014) Ecological divergence among colour morphs mediated by changes in spatial network structure associated with disturbance. J Anim Ecol 83:1490-1500. 
Lattanzio MS, Miles DB (2016) Trophic niche divergence among colour morphs that exhibit alternative mating tactics. R Soc Open Sci 3:150531.

Leite F, Turra A (2003) Temporal variation in Sargassum biomass, Hypnea epiphytism and associated fauna. Brazilian Arch Biol Technol 46:665-671.

MacArthur R, Levins R (1967) The limiting similarity, convergence, and divergence of coexisting species. Am Nat 101:377-385.

Maerz JC, Myers EM, Adams DC (2006) Trophic polymorphism in a terrestrial salamander. Evol Ecol Res 8:23-35.

Martin-Smith KM (1993) Abundance of mobile epifauna: the role of habitat complexity and predation by fishes. J Exp Mar Bio Ecol 174:243-260.

May RM (1973) On relationships among various types of population models. Am Nat 107:46-57.

Merilaita S, Jormalainen V (1997) Evolution of sex differences in microhabitat choice and colour polymorphism in Idotea baltica. Anim Behav 54:769-78.

Mill AC, Pinnegar JK, Polunin NVC (2007) Explaining isotope trophic-step fractionation: why herbivorous fish are different. Funct Ecol 21:1137-1145.

Minagawa M, Wada E (1984) Stepwise enrichment of ${ }^{15} \mathrm{~N}$ along food chains: Further evidence and the relation between $\delta^{15} \mathrm{~N}$ and animal age. Geochim Cosmochim Acta 48:1135-1140.

Newsome SD, Rio, Martinez del C, Bearhop S, Phillips DL (2007) A Niche for Isotope Ecology. Front Ecol Environ 5:429-436.

Newsome SD, Yeakel JD, Wheatley P V., Tinker MT (2012) Tools for quantifying isotopic niche space and dietary variation at the individual and population level. J Mammal 93:329-341.

Nylin S, Gotthard K (1998) Plasticity in life-history traits. Annu Rev Entomol 43:63-83.

Parnell A (2016) simmr: A Stable Isotope Mixing Model. https://cran.r-project.org/package=simmr.

Parnell AC, Phillips DL, Bearhop S, et al (2013) Bayesian stable isotope mixing models. Environmetrics 24:387-399.

Phillips DL (2012) Converting isotope values to diet composition: the use of mixing models. J Mammal 93:342-352.

Phillips DL, Inger R, Bearhop S, et al (2014) Best practices for use of stable isotope mixing models in food-web studies. Can J Zool 835:823-835. 
Pianka ER (1981) Competition and niche theory. Theor Ecol 8:167-196.

Post DM (2002) Using stable isotopes to estimate trophic position: models, methods, and assumptions. Ecology 83:703-718.

Power M, O'Connell MF, Dempson JB (2005) Ecological segregation within and among Arctic char morphotypes in Gander Lake, Newfoundland. Environ Biol Fishes 73:263-274.

R Development Core Team (2016) R: A Language and Environment for Statistical Computing. https://cran.r-project.org/.

Ricklefs RE, Nealen P (1998) Lineage-dependent rates of evolutionary diversification: analysis of bivariate ellipses. Funct Ecol 12:871-885.

Rossi F, Olabarria C, Incera M, Garrido J (2010) The trophic significance of the invasive seaweed Sargassum muticum in sandy beaches. J Sea Res 63:52-61.

Russo AR (1990) The role of seaweed complexity in structuring Hawaiian epiphytal amphipod communities. Hydrobiologia 194:1-12.

Ruxton G, Sherratt T, Speed M (2004) Avoiding attack. Oxford University Press, Oxford

Sebastiano S, Antonio R, Fabrizio O, et al (2012) Different season, different strategies: feeding ecology of two syntopic forest-dwelling salamanders. Acta Oecologica 43:42-50.

Silva L dos S, Miranda LB, Castro Filho BM (2005) Numerical study of circulation and thermohaline structure in the São Sebastião channel. Rev Bras Geofis 23:407-425.

Stevens M, Lown AE, Wood LE (2014) Camouflage and individual variation in shore crabs (Carcinus maenas) from different habitats. PLoS One 9:1-31.

Strong DR (1982) Harmonious coexistence of hispine beetles on Heliconia in experimental and natural communities. Ecology 63:1039-1049.

Stuart-Fox D, Moussalli A (2009) Camouflage, communication and thermoregulation: lessons from colour changing organisms. Philos Trans R Soc Lond B Biol Sci 364:463-70.

Svanbäck R, Bolnick DI (2007) Intraspecific competition drives increased resource use diversity within a natural population. Proc R Soc B Biol Sci 274:839-844.

Svanbäck R, Eklöv P (2002) Effects of habitat and food resources on morphology and ontogenetic growth trajectories in perch. Oecologia 131:61-70.

Tinker MT, Bentall G, Estes JA (2008) Food limitation leads to behavioral diversification and dietary specialization in sea otters. Proc Natl Acad Sci U S A 105:560-565. 
Todd P, Briers R, Ladle R, Middleton F (2006) Phenotype-environment matching in the shore crab (Carcinus maenas). Mar Biol 148:1357-1367.

Zalewski M, Dudek-Godeau D, Tiunov A V, et al (2015) Wing morphology is linked to stable isotope composition of nitrogen and carbon in ground beetles (Coleoptera : Carabidae). Eur J Entomol 112:810-817.

Zupo V, Nelson W (1999) Factors influencing the association patterns of Hippolyte zostericola and Palaemonetes intermedius (Decapoda: Natantia) with seagrasses of the Indian River Lagoon, Florida. Mar Biol 134:181-190. 


\section{Additional Information}

Table S1 - Mean \pm standard deviation of $\delta^{13} \mathrm{C}$ and $\delta^{15} \mathrm{~N}$ isotopes of algal sources sampled in Barequeçaba and Praia Grande sites. Algal isotopic values were pooled from different sites and included in the Bayesian mixing models in order to estimate their contribution to Hippolyte obliquimanus diet.

\begin{tabular}{lccccc}
\hline & \multicolumn{2}{c}{ Barequeçaba } & & \multicolumn{2}{c}{ Praia Grande } \\
\cline { 2 - 3 } \cline { 5 - 6 } Algal sources & $\delta^{13} \mathrm{C}$ & $\delta^{15} \mathrm{~N}$ & & $\delta^{13} \mathrm{C}$ & $\delta^{15} \mathrm{~N}$ \\
\hline Sargassum & $-16.97 \pm 1.50$ & $2.55 \pm 2.51$ & & $-16.22 \pm 0.33$ & $0.02 \pm 1.91$ \\
Galaxaura & $-15.91 \pm 0.49$ & $-2.23 \pm 0.50$ & & $-16.59 \pm 0.25$ & $-2.35 \pm 0.36$ \\
Hypnea & $-16.93 \pm 0.68$ & $2.17 \pm 1.09$ & & $-16.68 \pm 0.17$ & $3.50 \pm 1.00$ \\
Asparagopsis & $-27.02 \pm 2.00$ & $2.60 \pm 1.13$ & & $-27.12 \pm 0.61$ & $2.61 \pm 0.70$ \\
\hline
\end{tabular}


Table S2 - Results of mean, standard deviation (SD) and different credibility intervals (expressed as proportions) from mixing models performed on Hippolyte obliquimanus shrimp of different colour morphs (Homogeneous - H, Striped Translucent - ST), algal habitats and sampling sites to analyse the contribution of potential algal sources (Sargassum, Galaxaura, Hypnea and Asparagopsis) to the diet of individuals.

\begin{tabular}{|c|c|c|c|c|c|c|c|c|c|c|c|c|c|}
\hline \multicolumn{14}{|c|}{ Barequeçaba } \\
\hline \multirow[b]{2}{*}{ Alga } & \multirow[b]{2}{*}{ Source } & \multicolumn{2}{|c|}{ Mean (SD) } & \multicolumn{2}{|c|}{$2.5 \%$} & \multicolumn{2}{|c|}{$25 \%$} & \multicolumn{2}{|c|}{$50 \%$} & \multicolumn{2}{|c|}{$75 \%$} & \multicolumn{2}{|c|}{$97.5 \%$} \\
\hline & & $\mathrm{H}$ & ST & $\mathrm{H}$ & ST & $\mathrm{H}$ & ST & $\mathrm{H}$ & ST & $\mathrm{H}$ & ST & $\mathrm{H}$ & ST \\
\hline & Sargassum & $0.17(0.09)$ & $0.21(0.10)$ & 0.03 & 0.10 & 0.11 & 0.23 & 0.17 & 0.29 & 0.23 & 0.36 & 0.36 & 0.49 \\
\hline \multirow{4}{*}{ Sargassum } & Galaxaura & $0.08(0.05)$ & $0.11(0.06)$ & 0.01 & 0.02 & 0.04 & 0.06 & 0.07 & 0.10 & 0.11 & 0.15 & 0.20 & 0.26 \\
\hline & Hypnea & $0.61(0.09)$ & $0.61(0.10)$ & 0.42 & 0.41 & 0.55 & 0.54 & 0.61 & 0.61 & 0.67 & 0.68 & 0.78 & 0.79 \\
\hline & Asparagopsis & $0.13(0.02)$ & $0.08(0.02)$ & 0.10 & 0.04 & 0.12 & 0.07 & 0.13 & 0.08 & 0.14 & 0.09 & 0.17 & 0.11 \\
\hline & Sargassum & $0.20(0.07)$ & $0.21(0.08)$ & 0.07 & 0.06 & 0.15 & 0.15 & 0.20 & 0.21 & 0.25 & 0.26 & 0.35 & 0.38 \\
\hline \multirow[t]{3}{*}{ Galaxaura } & Galaxaura & $0.15(0.07)$ & $0.31(0.08)$ & 0.03 & 0.13 & 0.10 & 0.26 & 0.14 & 0.32 & 0.20 & 0.37 & 0.30 & 0.46 \\
\hline & Hypnea & $0.55(0.07)$ & $0.44(0.07)$ & 0.41 & 0.31 & 0.50 & 0.39 & 0.55 & 0.44 & 0.60 & 0.48 & 0.70 & 0.58 \\
\hline & Asparagopsis & $0.10(0.01)$ & $0.04(0.01)$ & 0.07 & 0.02 & 0.09 & 0.03 & 0.10 & 0.04 & 0.11 & 0.05 & 0.13 & 0.07 \\
\hline \multicolumn{14}{|c|}{ Praia Grande } \\
\hline \multirow{4}{*}{ Sargassum } & Sargassum & $0.13(0.08)$ & $0.10(0.06)$ & 0.02 & 0.01 & 0.07 & 0.05 & 0.11 & 0.08 & 0.18 & 0.13 & 0.32 & 0.24 \\
\hline & Galaxaura & $0.07(0.04)$ & $0.06(0.04)$ & 0.01 & 0.01 & 0.04 & 0.03 & 0.06 & 0.05 & 0.10 & 0.08 & 0.18 & 0.15 \\
\hline & Hypnea & $0.57(0.09)$ & $0.64(0.07)$ & 0.37 & 0.47 & 0.52 & 0.59 & 0.58 & 0.65 & 0.64 & 0.69 & 0.72 & 0.76 \\
\hline & Asparagopsis & $0.23(0.02)$ & $0.20(0.02)$ & 0.19 & 0.17 & 0.21 & 0.19 & 0.22 & 0.20 & 0.24 & 0.21 & 0.27 & 0.24 \\
\hline \multirow{4}{*}{ Galaxaura } & Sargassum & $0.20(0.08)$ & $0.19(0.08)$ & 0.05 & 0.05 & 0.14 & 0.13 & 0.19 & 0.19 & 0.25 & 0.25 & 0.36 & 0.36 \\
\hline & Galaxaura & $0.14(0.07)$ & $0.28(0.09)$ & 0.03 & 0.10 & 0.08 & 0.22 & 0.13 & 0.28 & 0.18 & 0.34 & 0.29 & 0.44 \\
\hline & Hypnea & $0.51(0.08)$ & $0.43(0.07)$ & 0.34 & 0.29 & 0.45 & 0.38 & 0.51 & 0.43 & 0.56 & 0.47 & 0.67 & 0.58 \\
\hline & Asparagopsis & $0.16(0.02)$ & $0.10(0.01)$ & 0.13 & 0.07 & 0.15 & 0.09 & 0.16 & 0.10 & 0.17 & 0.11 & 0.19 & 0.13 \\
\hline
\end{tabular}




\section{GENERAL CONCLUSIONS}

The results obtained along the four chapters of this thesis independently indicated that the colour polymorphism observed in populations of the shrimp Hippolyte obliquimanus has significant consequences to the ecology and behaviour of individuals, in terms of camouflage properties and use of algal habitats, which vary in quality and temporal stability.

The capacity of changing colour is common to many animal species and may involve multiple and interconnected mechanisms and processes which are far from being properly understood (Chapter 1). Such processes are under influence of a suite of selective pressures, which are probably driving the ultimate appearance and adaptive value of different colour forms in several species. Some of these mechanisms and selective forces behind camouflage and colour change were further investigated in the polymorphic shrimp Hippolyte obliquimanus (Chapter 2). In this species, morph-specific combinations among morphological and behavioural traits probably leads to a diversification in camouflage strategies between homogeneous $(\mathrm{H})$ and striped translucent (ST) colour morphs, promoting a more efficient use of Sargassum and Galaxaura habitats by individuals. While a specialist camouflage strategy is predicted for the $\mathrm{H}$ morph, with shrimp being capable of change colour when placed against colour mismatching backgrounds, and exhibiting high substrate fidelity associated to a more robust morphology, ST individuals show fixed coloration, high mobility linked to a more streamlined shape and lack of substrate fidelity, suggesting a more generalist camouflage strategy and life-style. The colour change ability and the capacity of $\mathrm{H}$ shrimp to conceal against their main algal habitats, especially to the red weed Galaxaura, are adaptive in reducing shrimp predation (Chapter 3). Low colour discrimination between homogeneous pink shrimp and Galaxaura, as predicted by visual modelling, directly translates in reduced predation rates by a seahorse predator. Conversely, poor camouflage of brown shrimp in both Sargassum and Galaxaura habitats leads to increased shrimp mortality. Morph-specific 
differences in habitat use also imply on diet and trophic niche segregation between $\mathrm{H}$ and ST shrimp (Chapter 4). Morphs use different food sources when living in the secondary and lessstructured Galaxaura habitat in order to reduce intra-specific competition for limiting resources. Conversely, broad niche overlap and stable morphs coexistence is possible in the resource-abundant Sargassum habitat. Niche segregation between H and ST shrimp probably results from ecological and behavioural differences between morphs combined to spatial variation of the supply of food sources.

Altogether the results of this thesis cover important topics of current research on the mechanisms and functions promoting animal diversity and adaptation. Topics such as species polymorphism, camouflage and animal coloration are frequently investigated within a rather descriptive framework. Contributions that integrate these topics within an ecological and evolutionary approach are extremely rare. The diversification on camouflage strategies and resource use in $\mathrm{H}$. obliquimanus can be particularly important for the maintenance of shrimp populations along time. The markedly seasonal variation of the high-quality Sargassum habitat, which is very important for shrimp in terms of shelter and food, may promote alternative scenarios of resources availability. Upon habitat transitions, the generalist behaviour and capacity of ST individuals to use alternative food sources may be extremely important for an efficient colonization of new habitat patches. Also, the efficient camouflage of $\mathrm{H}$ shrimp in Galaxaura may be crucial to reduce predation in this less-complex but more stable habitat. On the other hand, during periods of high Sargassum cover, when shelter and food are abundant, the specialist strategy of $\mathrm{H}$ shrimp may reflect intensive habitat utilization, allowing the maintenance of very dense shrimp stocks in algal meadows. 